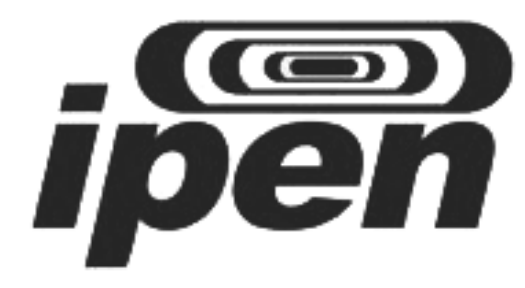

\title{
"Preparo e Caracterização de um Candidato a Material de Referência de Siliceto de Urânio - $\mathrm{U}_{3} \mathrm{Si}_{2}{ }^{3}$
}

\section{LUCIANA VIEIRA DE SANTANA}

Tese apresentada como parte dos Requisitos para obtenção do Grau de Doutor em Ciências na Área de Tecnologia Nuclear - Materiais

Orientadora:

Profa. Dra. Maria Aparecida Faustino

Pires

Coorientadora:

Profa. Dra. Marycel Elena Barboza Cotrim

São Paulo

2019 


\section{INSTITUTO DE PESQUISAS ENERGÉTICAS E NUCLEARES \\ Autarquia Associada à Universidade de São Paulo}

\section{Preparo e caracterização de um candidato a material de referência de}

siliceto de urânio $-\mathrm{U}_{3} \mathrm{Si}_{2}$

\section{Versão corrigida}

Versão original disponível no IPEN

\section{LUCIANA VIEIRA DE SANTANA}

Tese apresentada como parte dos requisitos para obtenção do grau de Doutor em Ciências na área de Tecnologia Nuclear - Materiais

Orientadora:

Prof. Dra. Maria Aparecida Faustino Pires

Coorientadora:

Prof. Dra. Marycel Elena Barboza Cotrim 
Fonte de Financiamento: Conselho Nacional de Pesquisa e Desenvolvimento Tecnológico

Autorizo a reprodução e divulgação total ou parcial deste trabalho, para fins de estudo e pesquisa, desde que citada a fonte

Como citar:

VIEIRA DE SANTANA, L. Preparo e caracterização de um candidato a material e referência de siliceto de urânio - U3Si2. 2019. 137 p. Tese (Doutorado em Tecnologia Nuclear), Instituto de Pesquisas Energéticas e Nucleares, IPEN-CNEN/SP, São Paulo.

Disponível em: <www.teses.usp.br> (data de consulta no formato: dd/mm/aaaa)

Ficha catalográfica elaborada pelo Sistema de geração automática da Biblioteca IPEN/USP, com os dados fornecidos pelo(a) autor(a)

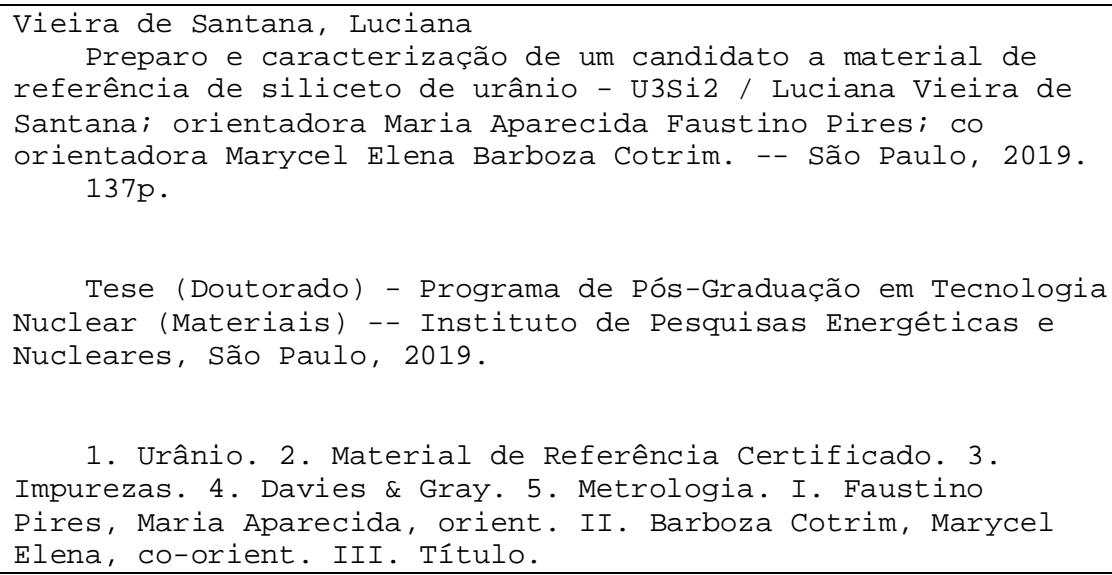




\section{FOLHA DE APROVAÇÃO}

Autor: Luciana Vieira de Santana

Título: Preparo e caracterização de um candidato a material de referência de siliceto de urânio $-\mathrm{U}_{3} \mathrm{Si}_{2}$

Tese apresentada como parte dos requisitos para obtenção do grau de Doutor em Ciências.

Data: 29/07/2019

\section{Banca Examinadora}

Prof. Dr.: Maria Aparecida Faustino Pires

Instituição:IPEN Julgamento: Aprovado

Prof. Dr.: Sergio Luis Graciano Petroni

Instituição: Instituto de Aeronáutica e Espaço Julgamento: Aprovado

Prof. Dr.: Walter dos Reis Pedreira Filho

Instituição: FUNDACENTRO Julgamento: Aprovado

Prof. Dr: Olívio Pereira de Oliveira Junior

Instituição: SRC-IPEN Julgamento: Aprovado 


\section{DEDICATÓRIA}

Dedico este trabalho a todos os que colaboraram de forma direta ou indireta para sua execução em especial à minha família, ao meu marido, as $\operatorname{Dr}(\mathrm{a}) \mathrm{s}$. Maria Aparecida Faustino Pires e Marycel Elena Barboza Cotrim pela paciência e orientação, as técnicas Cleide Moreira da Silva, Cristina Sisti, aos colegas do CQMA e as amigas Daphne Said e Sabine Guilhen pelo apoio. 


\section{AGRADECIMENTOS}

Gostaria de agradecer a todos que deram sua valiosa contribuição para execução deste trabalho. Em especial, ao Conselho Nacional de Desenvolvimento Científico e Tecnológico, ao Instituto de Pesquisas Energéticas e Nucleares, ao Conselho Nacional de Desenvolvimento Científico e Tecnológico e à Pró-reitoria de Pós graduação da Universidade de São Paulo pelo auxílio financeiro ao projeto;

A parceria com o CCN - Centro Combustível Nuclear, em especial a Dra. Elita Fontenele Urano De Carvalho e os responsáveis pelo processo de produção do material de siliceto de urânio;

As Dras. Maria Aparecida Faustino Pires e Marycel Elena Barboza, pelo apoio, sugestões e confiança em meu trabalho; aos colegas e amigos do Centro de Química e Meio Ambiente, Laboratório de Análises Química e Ambiental, em especial àqueles que doaram horas valiosas de seu tempo na colaboração deste estudo, Dr. João Cristiano Ulrich, Dra. Elâine Arantes Jardim Martins, Dr. Hélio Akira Furusawa, Dra. Sabine Neusatz Guilhen, MSc.Cristina Sisti, Química Cleide Moreira da Silva e aos Técnicos Sr. Elias Santana Da Silveira e Sra. Neuza Costa Da Silva. 


\section{EPIGRAFE}

"A imprensa pode causar mais danos que a bomba atômica. E deixar cicatrizes no cérebro".

Noam Chomsky 


\section{RESUMO}

SANTANA, Luciana V. Preparo e caracterização de um candidato a material de referência de siliceto de urânio - $\boldsymbol{U}_{3} \boldsymbol{S i}_{2}$. 2019. 137 p. Tese (Doutorado em Tecnologia Nuclear) - Instituto de Pesquisas Energéticas e Nucleares - IPENCNEN/SP. São Paulo.

De acordo com a Norma CNEN-NN-2.02,1999, as instalações nucleares brasileiras devem usar sistemas de medição que permitem a determinação de seus inventários de materiais nucleares e também avaliar e verificar a qualidade de seus sistemas de medição por meio da participação dos laboratórios envolvidos em programas de intercomparação, além do uso de materiais de referência e materiais de referências certificado.

Neste contexto, este estudo relata os esforços para assegurar o preparo e caracterização do primeiro material de referência para matriz de siliceto de urânio que visa garantir a qualidade do combustível nuclear produzido no Brasil. Foram investigados os teores de urânio, silício e impurezas em 8 amostras analisadas em triplicata para o estudo de homogeneidade e 12 amostras para o estudo de estabilidade. Foi utilizada a análise de variância para fornecer informações sobre a variabilidade em massa e o grau de não homogeneidade. A caracterização do material se deu por meio de um estudo comparativo entre 3 laboratórios independentes. A caracterização do material nuclear foi realizada aplicando a titulação potenciométrica por "Davies \& Gray/NBL" para a determinação das concentrações de urânio, e a determinação gravimétrica para as concentrações de silício, métodos recomendados pela Agencia Internacional de Energia Atômica. O teor de impurezas foi determinado por espectrometria de emissão com fonte de plasma induzido (ICPOES), após separação previa da matriz. Comparativamente, foi aplicada a técnica de fluorescência de raios $X$ com energia dispersiva (WDXRF). Foram considerados como valores certificados aqueles cujos resultados de concentração foram obtidos com incertezas expandidas relativas inferiores a $20 \%$. Esse limite foi escolhido como o adequado para o uso pretendido para o material de referência e para a determinação dos elementos na matriz nas condições desse estudo. 
Palavras chave: urânio; silício; material de referência; homogeneidade;

Davies \& Gray. 


\begin{abstract}
SANTANA, Luciana V. Preparation and characterization of a candidate for uranium silicide reference material - $\mathbf{U}_{3} \mathbf{S i}_{2}$. 2019. $137 \mathrm{p}$. Thesis (Doctorate in Nuclear Technology) - Institute of Energy and Nuclear Research - IPEN-CNEN / SP. Sao Paulo.
\end{abstract}

According to CNEN-NN-2.02.1999, Brazilian nuclear facilities must use measurement systems that allow the determination of their nuclear material inventories and also evaluate and verify the quality of their measurement systems through the participation of laboratories. Involved in intercomparison programs, in addition to the use of reference materials and certified reference materials.

In this context, this study reports the efforts to ensure the preparation and characterization of the first reference material for uranium silicate matrix that aims to guarantee the quality of nuclear fuel produced in Brazil. Uranium, silicon and impurities contents were investigated in 8 samples analyzed in triplicate for the homogeneity study and 12 samples for the stability study. Variance analysis was used to provide information on mass variability and degree of inhomogeneity. The characterization of the material was made through a comparative study between 3 independent laboratories. The characterization of nuclear material was performed by applying potentiometric titration by "Davies \& Gray / NBL" for determination of uranium concentrations and gravimetric determination for silicon concentrations, methods recommended by the International Atomic Energy Agency. The impurity content was determined by induced plasma source emission spectrometry (ICPOES) after prior matrix separation. By comparison, the energy dispersive X-ray fluorescence (WDXRF) technique was applied. Certified values were those whose concentration results were obtained with relative expanded uncertainties of less than $20 \%$. This limit was chosen as appropriate for the intended use of the reference material and for the determination of elements in the matrix under the conditions of this study.

Keywords: uranium; silicon; reference material; homogeneity; Davies \& Gray. 


\section{LISTA DE TABELAS}

Página

Tabela 1 - Limite de impurezas para controle de pó de $\mathrm{U}_{3} \mathrm{Si}_{2} \quad 21$

Tabela 2 - Principais propriedades físicas do urânio 21

Tabela 3 - $\quad$ Propriedades dos isótopos de urânio 26

Tabela 4 - Especificações padrão da ASTM, ASTM C1334-1993 27 para $\mathrm{U}_{3} \mathrm{O}_{8}$ e $\mathrm{UO}_{2}$, ASTM C1334-2000, ASTM C13342016 (grau nuclear)

Tabela 5 - Condições de operação do equipamento 30

Tabela 6 - $\quad$ Análise da variância para regressão linear 49

Tabela 7 - Concentrações dos elementos, considerados como 54 impurezas, utilizadas para a preparação das Curvas analíticas, meio $\mathrm{HNO}_{3} 10 \%$

Tabela 8 - Concentração para preparação da curva analítica para o elemento $\mathrm{Sn}$ em meio $\mathrm{HCl} 10 \%$

Tabela 9 - Condições de medição do espectrômetro WDXRF 64 (Rigaku Co., Modelo RIX 3000)

Tabela 10 - Caracterização Química do lote de pó de $\mathrm{U}_{3} \mathrm{Si}_{2}$ EULAB, Identificação: UNSI05

Tabela 11 - Composição Isotópica de Urânio do lote utilizado

Resultados do estudo de homogeneidade referente à concentração média, variância, desvio padrão, DPR e resultados da ANOVA, calculados na determinação de

Tabela 12 - urânio total por Davies \& Gray e silício total por gravimetria nas amostras preservadas a temperatura de $23 \pm 1{ }^{\circ} \mathrm{C}$

Resultados do estudo de estabilidade, referente à

Tabela 13 - concentração média, desvio padrão, resultados do estudo de regressão, calculados na determinação de 
urânio total e silício total, em \%, nas amostras

Resultados do estudo de homogeneidade referente à concentração, média, variância, desvio padrão, DPR e

Tabela 14 - resultados da ANOVA, calculados na determinação de urânio e silício totais, em \%, nas amostras a temperatura de $23 \pm 1{ }^{\circ} \mathrm{C}$ analisadas por WDXRF

Resultados do estudo de estabilidade, referente à

Tabela 15 média, desvio padrão, resultados do estudo de regressão, calculados na determinação de urânio total e silício total, em \%, nas amostras analisadas por WDXRF

Tabela 16 - Estimativa das incertezas padrão combinadas para os elementos $U$ total por Davies \& Gray e Si total por gravimetria

Tabela 17 - Estimativa das incertezas padrão combinadas para os elementos U total e Si total por WDXRF

Estimativa da incerteza expandida associada $U(\%)$ ao 78

Tabela 18 - valor de propriedade das amostras de $U$ total por Davies \& Gray e Si total por gravimetria em \% para um nível de confiança de $95 \%(k=2)$

Estimativa da incerteza expandida associada $U(\%)$ ao 79

Tabela 19 valor de propriedade das amostras de U total e Si total em \% por WDXRF para um nível de confiança de $95 \%$ $(k=2)$

Valor de referência e incerteza expandida associada $U$

Tabela 20 (\%) para o candidato a material de referência para um nível de confiança de $95 \%$ (k=2)

Tabela 21 - Resultados do estudo de massa mínima para impurezas de $\mathrm{U}_{3} \mathrm{Si}_{2}$

Tabela 22 - $\begin{aligned} & \text { Concentração, média, desvio padrão, DPR e } \\ & \text { resultados da ANOVA, calculados na determinação de }\end{aligned}$ impurezas, em $\mu \mathrm{g} \mathrm{g}{ }^{-1}$ em massa de $\mathrm{U}_{3} \mathrm{Si}_{2}$, nas amostras, a temperatura de $23 \pm 1^{\circ} \mathrm{C}$ 
Concentração média, desvio padrão, DPR e resultados da regressão linear, calculados na determinação de Tabela 23 - impurezas, em $\mu \mathrm{g} \mathrm{g}{ }^{-1}$ em massa de $U_{3} \mathrm{Si}_{2}$, nas amostras, nas temperaturas de $5 \pm 2{ }^{\circ} \mathrm{C}, 23 \pm 1{ }^{\circ} \mathrm{C}$ e $50 \pm 2^{\circ} \mathrm{C}$.

Informações para a decisão sobre a atribuição de

Tabela 24 - valores certificados ao candidato a material de referência de siliceto de urânio

Tabela 25 - Estimativa das incertezas padrão combinadas para as impurezas

Estimativa da incerteza expandida associada $U(\%)$ ao 95 valor de referência das amostras de impurezas para um nível de confiança de $95 \%$ (k=2)

Tabela 27 - Critério adotado para aceitação da recuperação

Resultados obtidos com os testes estatísticos para 107

Tabela 28 validação da análise de impurezas em $\mathrm{U}_{3} \mathrm{Si}_{2}$ por ICPOES 


\section{LISTA DE FIGURAS}

Página

Figura 1 - $\quad$ Processo de fabricação de combustíveis tipos MTR 35

Figura 2 - $\quad$ Processo de fabricação do $\mathrm{UF}_{4}$

Figura 3 - $\quad$ Processo de fabricação de urânio metálico 36

Figura 4 - $\quad$ Processo de fabricação de siliceto de urânio 37

Figura 5 - Hierarquia dos padrões metrológicos $\quad 40$

Figura 6 - Modelo esquemático demonstrando o efeito fotoelétrico e a ocorrência de raios $X \quad 51$

Fluxograma de Preparo do Material

Figura 7 -

Gráficos do desvio padrão relativo obtido na

Figura 8determinação de U e Si no intervalo de massa estudado

Gráfico dos resultados da análise de regressão para

Figura 9 o estudo de estabilidade para silício em diferentes temperaturas e períodos de tempo por gravimetria

Gráfico dos resultados da análise de regressão para

Figura 10 o estudo de estabilidade para urânio em diferentes temperaturas e períodos de tempo por Davies \& Gray

Gráfico dos resultados da análise de regressão para

Figura 11 o estudo de estabilidade para urânio em diferentes temperaturas e períodos de tempo por WDXRF

Gráfico dos resultados da análise de regressão para

Figura 12 o estudo de estabilidade para silício em diferentes temperaturas e períodos de tempo WDXRF

Gráfico dos resultados da análise de regressão para

Figura 13(a) - o estudo de estabilidade para Al, B e Ba em diferentes temperaturas e períodos de tempo

Figura 13(b) - Gráfico dos resultados da analise de regressão para 
o estudo de estabilidade para V, Ca e Cd em

diferentes temperaturas e períodos de tempo

Gráfico dos resultados da analise de regressão para

Figura 13(c) - o estudo de estabilidade para $\mathrm{Cu}, \mathrm{Fe}$ e Li em

88 diferentes temperaturas e períodos de tempo

Gráfico dos resultados da analise de regressão para o estudo de estabilidade para Zn, Co e $\mathrm{Cr}$ em

Figura 13(d) - diferentes temperaturas e períodos de tempo

Gráfico dos resultados da análise de regressão para

Figura 13(e) - o estudo de estabilidade para Sn, Mg e Mn em diferentes temperaturas e períodos de tempo

Gráfico dos resultados da analise de regressão para

Figura 13 (f) - o estudo de estabilidade para Mo, Ni e Pb em diferentes temperaturas e períodos de tempo 
Sumário

1 INTRODUÇÃO

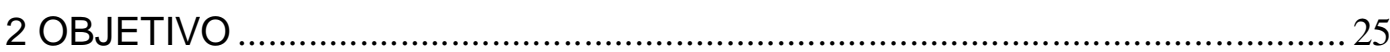

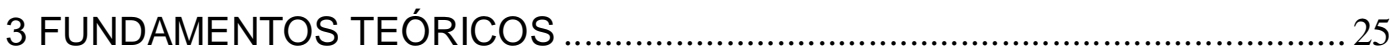

3.1 Contexto histórico do Combustível Nuclear no IPEN ............................... 25

3.2 Compostos de urânio utilizados como combustível nuclear e quantidade e tipo de impurezas que afetam sua qualidade......................... 26

3.3 Produção do elemento combustível de dispersão de pó de $\mathrm{U}_{3} \mathrm{Si}_{2} \ldots \ldots . . .34$

3.3.1 Confiabilidade de resultados analíticos para controle do pó de $\mathrm{U}_{3} \mathrm{Si}_{2}$ 38

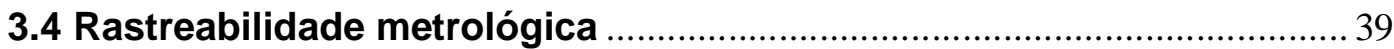

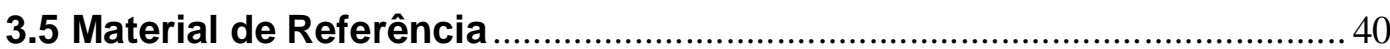

4 PRODUÇÃO DE MATERIAIS DE REFERENCIA ….......................................... 42

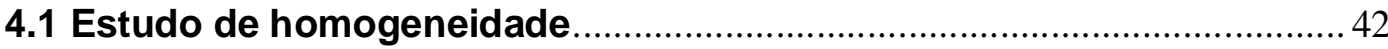

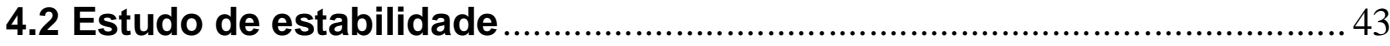

4.3 Métodos Analíticos Empregados para Caracterização dos Elementos

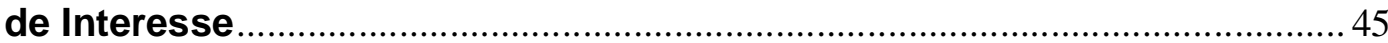

4.3.1 Método de Titulação Potenciométrica - Davies \& Gray ……………...... 46

4.3.2 Determinação do Silício por Gravimetria .................................................... 47

4.3.3 Espectrometria de Emissão Óptica com Plasma Indutivamente

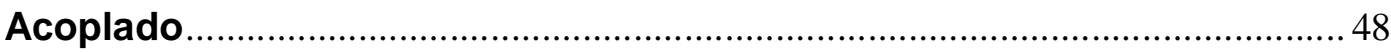

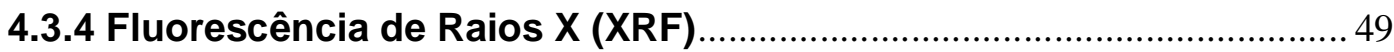

4.4 Análise Estatística e tratamento dos dados ................................................. 51

4.5 Caracterização de um material de referência ............................................. 54

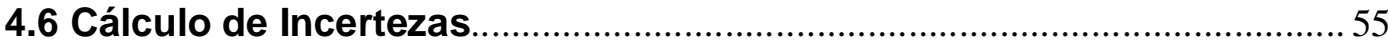

4.7 Incerteza associada ao valor certificado ………....................................... 55

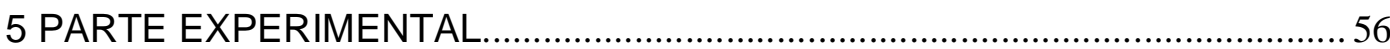

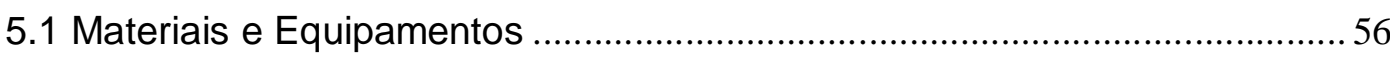

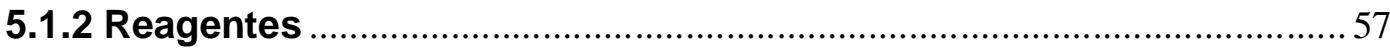

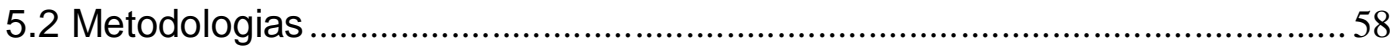

5.2.1 Preparo do Material de Referência ......................................................... 58

5.2.2 Determinação de urânio total pelo método de Davies \& Gray/NBL ... 60 
5.2.2.1 Processo de Titulação do urânio com padrão de dicromato de potássio 60

5.2.3 Determinação de silício total por método gravimétrico

5.2.4 Determinação de impurezas em amostras de $\mathrm{U}_{3} \mathrm{Si2}$ : Processo de dissolução e separação para análise de impurezas em por ICPOES

5.2.4.1 Preparação da resina.

5.2.4.2 Preparação do sistema extrator: Impregnação da resina com TBPfosfato de tri-n-butila

5.2.4.3 Preparação da coluna de separação 62

5.2.4.4 Ativação da resina 62

5.2.4.5 Percolação da solução pela coluna. 62

5.2.4.6 Eluição do urânio retido na coluna

5.2.4.7 Preparo da curva de calibração para ICPOES.

5.3 Preparo da amostra para técnica de WDXRF. 64

5.4 Estudo de homogeneidade. 66

5.5 Estudo de estabilidade. 66

5.6 Caracterização do Material de Referência. 67

6 RESULTADOS E DISCUSSÕES 67

6.1 Resultados da caracterização química, física e composição isotópica

6.2 Resultados do estudo de massa mínima para U por Davis \& Gray e Si por gravimetria

6.3 Resultados do estudo de homogeneidade para U por Davies \& Gray e Si por gravimetria.

6.4 Resultados do estudo de estabilidade em curto e longo prazo para $U$ por Davies \& Gray e Si por gravimetria 72

6.4.1 Representação gráfica dos resultados para U pelo método de Davies

\& Gray e Si pelo método de Gravimetria 72

6.5 Resultados do estudo de homogeneidade para U e Si pelo método WDXRF

6.6 Resultados do estudo de estabilidade em curto e longo prazo para U e Si pelo método WDXRF. 74

6.6.1 Representação gráfica dos resultados para U e Si pelo método de WDXRF 
6.7 Estimativa das incertezas e valor de propriedade para U e Si totais.... 77 6.8 Incerteza expandida associada ao valor de propriedade para urânio e silício totais .78

6.9 Resultados do estudo de massa mínima para impurezas por ICPOES 80 6.10 Resultados do estudo homogeneidade para impurezas por ICPOES 80 6.11 Resultados do estudo de estabilidade em curto e em longo prazo para impurezas por ICPOES

6.11.1 Representação gráfica dos resultados de impurezas pelo método de ICPOES

6.12 Atribuição dos valores de propriedade para as impurezas................ 92

6.13 Estimativa das incertezas para impurezas por ICPOES ...................... 93

6.14 Incerteza associada ao valor de referência para impurezas ............... 94

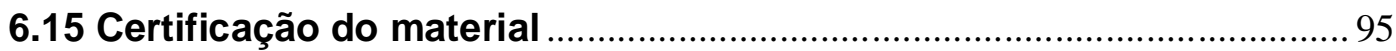

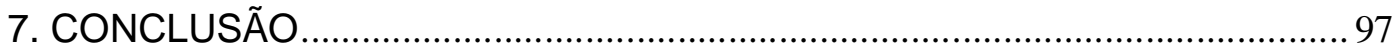

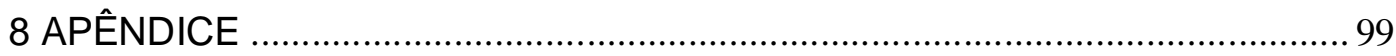

8.1 Ensaios para validação da análise de Impurezas em $\mathrm{U}_{3} \mathrm{Si}_{2}$.................. 99

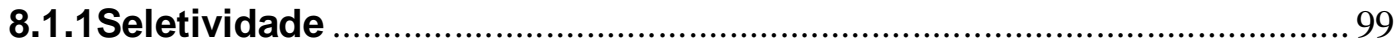

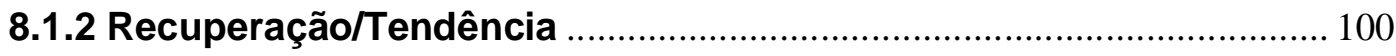

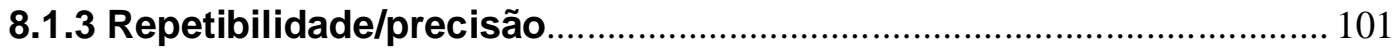

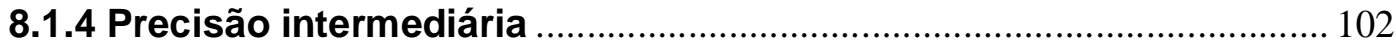

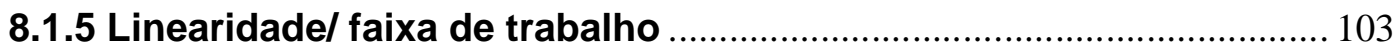

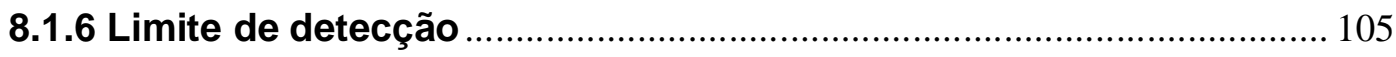

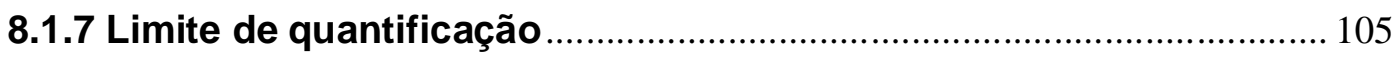

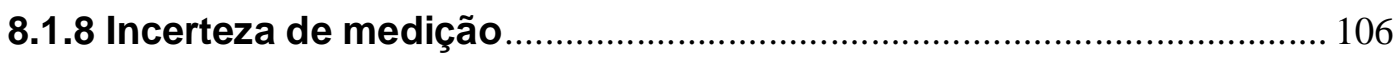

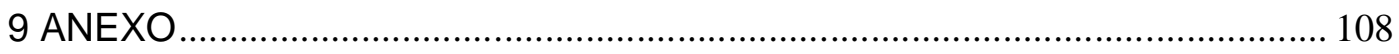

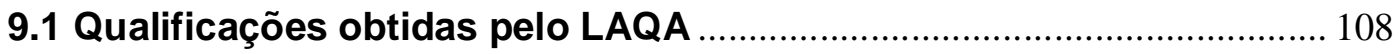

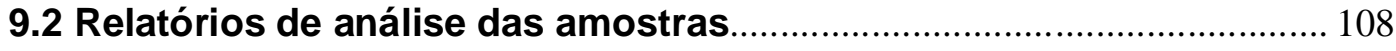

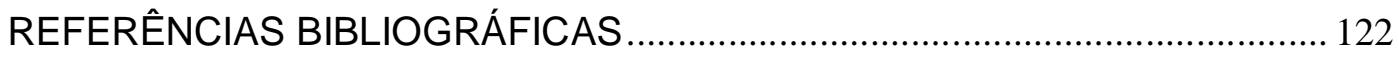




\section{INTRODUÇÃO}

A política nacional de atividades nucleares tem como objetivo assegurar o uso pacífico e seguro da energia nuclear, além de desenvolver a ciência e a tecnologia, nas áreas nuclear e correlatas, para medicina, indústria, agricultura, meio ambiente e geração de energia e, atender ao mercado de equipamentos, componentes e insumos para indústria nuclear e de alta tecnologia (CNEN, 2016).

A principal vantagem de uma Central Térmica Nuclear é a capacidade de geração de energia em grande quantidade com baixo consumo de combustível e de forma constante. Considerando-se, por exemplo, a geração de $1000 \mathrm{MWe}$ por ano, uma central núcleo elétrica consome cerca de 21 toneladas de urânio enriquecido a 4 \% (cerca de 200 toneladas de urânio natural), enquanto que uma central térmica a carvão de mesma capacidade consome cerca de 3 milhões de toneladas de carvão (CNEN, 2016; FGV, 2016).

Em relação ao meio ambiente, o uso da energia nuclear, no mundo, evita a emissão anual de 2,4 bilhões de dióxido de carbono que seriam lançados na atmosfera caso fossem oriundos de fontes térmicas convencionais. Sobe esse enfoque, no contexto do planejamento energético nacional está prevista a ampliação da participação de fontes complementares na matriz elétrica do País, com o objetivo de reduzir o percentual de geração com base hidráulica, por intermédio da contribuição de outras fontes, basicamente as de natureza térmica, e as renováveis (CNEN, 2016; FGV, 2016).

O Brasil registra a sétima maior reserva geológica de urânio conhecida no mundo, com cerca de 309.000 toneladas de concentrado de urânio $\left(\mathrm{U}_{3} \mathrm{O}_{8}\right)$ nos estados da Bahia, Ceará e Minas Gerais, entre outras ocorrências. Estas reservas podem vir a serem maiores se novos trabalhos de prospecção e pesquisa mineral forem realizados, uma vez que os levantamentos disponíveis cobrem apenas entre $25 \%$ e $30 \%$ do território nacional (CNEN, 2016).

Além disso, o Brasil possui o domínio tecnológico de todas as etapas do ciclo do combustível nuclear, desde a mineração até a fabricação do elemento 
combustível, em escala laboratorial ou em usina de demonstração. Com capacidade plena para atendimento da atual demanda de combustíveis para Angra 1 e 2. Este domínio é de vital relevância, pois os elementos combustíveis produzidos, em diferentes características e graus de enriquecimento, são empregados nos reatores de potência, que proporcionam a produção da energia elétrica, e também nos reatores de pesquisa, para a produção de radiofármacos (SANTOS, 2014; IPEN, 2017; CNEN, 2016).

No tocante aos reatores de pesquisa o IEA-R1 do IPEN assim como numerosos reatores de pesquisa, no mundo, utilizam elemento combustível do tipo MTR - Materials Testing Reactor (placas combustíveis contendo núcleos de ligas urânio-alumínio fabricadas por laminação de um conjunto formado por núcleo, moldura e revestimento). O reator IEA-R1 utiliza o pó de $\mathrm{U}_{3} \mathrm{Si}_{2}$ de baixo enriquecimento (20\%), o que possibilitou elevar a densidade de urânio de 2,3 para $3,0 \mathrm{~g} \mathrm{~cm}^{-3}$, chegando até mesmo a atingir $4,8 \mathrm{~g} \mathrm{~cm}^{-3}$ proporcionando níveis de queima superiores a $30 \%$, sem afetar o desempenho sob irradiação (SANTOS, 2014; IPEN, 2017; CNEN, 2016).

No IPEN, o processo de fabricação de elementos combustíveis tipo MTR, tanto do tipo óxido de urânio $\left(\mathrm{U}_{3} \mathrm{O}_{8}\right)$ quanto o siliceto de urânio $\left(\mathrm{U}_{3} \mathrm{Si}_{2}\right)$ se inicia com o material recebido na forma de hexafluoreto de urânio $\left(U_{6}\right)$. Este é processado em todas as etapas (química e mecânico metalúrgicas) para obtenção das placas combustíveis no Centro do Combustível Nuclear-IPEN-SP (IPEN, 2017; NEGRO et.al., 2016).

Cabe ressaltar que a utilização de compostos de alta pureza é uma questão importante para a área nuclear. Todo material destinado ao ciclo do combustível deve atender a especificações rígidas, em termos de seu conteúdo de urânio e de impurezas (SOUZA, 2011), sendo exigida a utilização de metodologias com elevado padrão de qualidade. De acordo com a Norma CNEN-NN-2.02, 1999, as instalações nucleares devem dispor de sistemas de medição que possibilitem determinar os seus inventários de material nuclear.

A qualidade do combustível nuclear está ligada à composição química do minério de urânio, as etapas de processamento, que requer um limite máximo da presença de impurezas ( $\mathrm{Al}, \mathrm{B}, \mathrm{Ca}, \mathrm{Cd}, \mathrm{Co}, \mathrm{Cr}, \mathrm{Cu}, \mathrm{Fe}, \mathrm{Li}, \mathrm{Mg}, \mathrm{Mn}$, Mo, $\mathrm{Ni}, \mathrm{Pb}, \mathrm{Sn}, \mathrm{V}, \mathrm{Zn}, \mathrm{Ba}$ ). Altas concentrações destes elementos comprometem a qualidade e a densidade energética do combustível, sendo 
importante do ponto de vista da economia de nêutrons (TAB. 1) (BINFORD et. al., 1977; ASTM, 1993; ASTM, 2000; ULRICH, 2001; REIS et. al., 2009; SATYANARAYANA e DURANI, 2010; ROSA, 2011; SOUZA et. al., 2012; SILVA, 2012; NAGAR et. al., 2014; ASTM, 2016).

As Tabela 1 e 2 apresentam as especificação de impurezas, urânio e silício totais utilizadas para o controle químico do $\mathrm{U}_{3} \mathrm{Si}_{2}$ no IPEN.

Tabela 1- Limite máximo de impurezas para controle de pó de $\mathrm{U}_{3} \mathrm{Si}_{2}$

\begin{tabular}{c|c}
\hline ELEMENTO & $\begin{array}{c}\text { Concentração Limite Máximo } \\
\text { Especificado } \\
\left(\mu \mathrm{g} \mathrm{g}^{-1} \text { em massa de } \mathrm{U}_{3} \mathrm{Si}_{2}\right)\end{array}$ \\
\hline $\mathrm{Al}$ & 600 \\
\hline $\mathrm{B}$ & 10 \\
\hline $\mathrm{C}$ & 2000 \\
\hline $\mathrm{Cd}$ & 10 \\
\hline $\mathrm{Co}$ & 10 \\
\hline $\mathrm{Cu}$ & 2000 \\
\hline $\mathrm{Fe}+\mathrm{Ni}$ & 1500 \\
\hline $\mathrm{Zn}$ & 1000 \\
\hline $\mathrm{Li}$ & 10 \\
\hline $\mathrm{N}$ & 2500 \\
\hline $\mathrm{O}$ & 7000 \\
\hline $\mathrm{H}$ & 200 \\
\hline Outros Elementos individual & 500 \\
\hline Total & 2500 \\
\hline
\end{tabular}

Fonte: Informação técnica INF.CENC.CEN.046.00, INFT.001.00, baseado em ASTM C1334-1993

Tabela 2 - Concentração especificada de urânio e silício totais para controle de pó de $\mathrm{U}_{3} \mathrm{Si}_{2}$

\begin{tabular}{c|c}
\hline Elemento & $(\%)$ \\
\hline$U$ & 92,4 \\
\hline $\mathrm{Si}$ & $7,4-7,9$
\end{tabular}

Fonte: Informação técnica INF.CENC.CEN.046.00, INFT.001.00, baseado em ASTM C1334-1993 
$\mathrm{Na}$ Literatura existe uma variedade de métodos analíticos utilizando diferentes técnicas instrumentais para a determinação de impurezas em compostos de urânio como: LIBS (Espectrometria de Emissão Óptica com Plasma Induzido por Laser), FAAS (espectrometria Atômica com Forno de Grafite), ICPOES (Espectrometria de Emissão Óptica com Plasma Indutivamente Acoplado), ICP-MS (Espectrometria de Massas com Plasma Indutivamente Acoplado) (FLOYD et. al., 1983; PALMIERI et. al., 1986; ASSAD et. al. 1990; RAMANAIAH, 1998; SATYANARAYANA, 1999; IAEA, 1999; VERNA e RAMAKUMAN, 2007; REIS et. al., 2009; SATYANARAYANA e DURANI, 2010; SOUZA, 2011; SILVA, 2012; NAGAR et, al., 2014).

Quanto às técnicas para a determinação da concentração de urânio total, o método "Davies \& Gray/NBL" (Brunswick Laboratory) é o método de medição de material nuclear normatizado e recomendado pela AIEA (AIGNER et. al. 2001). Este método baseia-se na titulação potenciométrica do urânio, sendo sugerido por Kuhn et. al., 1979 para o controle do teor de urânio do elemento combustível e em materiais nucleares sob salvaguardas, devido à sua seletividade, facilidade de aplicação e também excelente precisão e exatidão.

Por meio de procedimentos químicos com ensaios destrutivos este método pode ser aplicado para análise de urânio metálico, $\cup \mathrm{O}_{2}, \cup_{3}, \mathrm{U}_{3} \mathrm{O}_{8}$, $U_{6}$ e $U_{3} \mathrm{Si}_{2}$ além de outros materiais do ciclo do combustível nuclear. (DAVIES \& GRAY, 1964; ÊBERLE et. al., 1970; CRISTIANO et. al., 2011; ROSA, 2011).

Este método foi validado e é amplamente utilizado nos laboratórios de salvaguarda da CNEN e também no Laboratório de Análises Química e Ambiental (LAQA) - Centro de Química e Meio Ambiente (CQMA) do IPEN para a caracterização do $\mathrm{U}_{3} \mathrm{Si}_{2}$ utilizado na fabricação do combustível nuclear para o reator IEA-R1 / IPEN, e como novo combustível, tipo placa, para o Reator IPEN/MB-01 (COTRIM et. al., 2003; CRISTIANO et. al., 2010).

Deste modo, uma das formas de garantir a qualidade das medições realizadas pelos laboratórios de salvaguarda nuclear é por meio da utilização de materiais de referência (MR) e materiais de referência certificados (MRC).

Os materiais de referência são essenciais para comprovar e verificar a exatidão das medições analíticas, visando garantir sua confiabilidade bem como o desempenho dos laboratórios em programas de comparação 
interlaboratorial (BAM, 2010; CARDOSO, 2010; ABNT ISO GUIA 34, 2012; VIM 2012; ABNT ISO GUIA 35:2012).

Segundo o (VIM, 2012), podemos definir Material de Referência (MR) como um material, suficientemente homogêneo e estável em relação a propriedades específicas, preparado para se adequar a uma utilização pretendida numa medição ou num exame de propriedades qualitativas. Enquanto que os Materiais de Referência Certificados (MRC) são materiais de referência acompanhados de documentação emitida por uma entidade reconhecida, a qual fornece um ou mais valores de propriedades especificadas com as incertezas e as rastreabilidades associadas, utilizando procedimentos válidos.

Os materiais de referência com ou sem valores atribuídos podem ser aplicados para controlar a precisão de medição, enquanto que apenas os materiais de referência com valores atribuídos podem ser utilizados para a calibração ou para o controle da veracidade de medição. (VIM, 2012)

A produção de um MR requer um planejamento experimental detalhado, prevendo-se a quantidade adequada de material para seu uso final e de todas as etapas inerentes ao seu desenvolvimento (SANTANA, 2015): preparo do material; envasamento das amostras, estudos para verificar a homogeneidade do material nos recipientes, avaliação da estabilidade, a qual garantirá sua integridade durante o transporte e estocagem por tempo pré-estabelecido, a caracterização e a certificação dos valores atribuídos às propriedades de interesse do material preparado. (IAEA, 2003-2005; RICHTER et. al., 2005; CARDOSO et. al., 2010; ABNT ISO GUIA 35:2012; VARGA et. al., 2012;SANTANA et. al., 2013, 2015)

Os padrões certificados para urânio utilizados e atualmente disponíveis para sistemas de medição de material nuclear são: CRM 112A: Urânio metálico proveniente do Brunswick Laboratory, US Departmant of Energy - DOE. CRM 124: Óxido de urânio $\left(\mathrm{U}_{3} \mathrm{O}_{8}\right)$ padrão para 24 Elementos de impurezas, proveniente do Brunswick Laboratory, US Departmant of Energy - DOE. Não existe, até o momento, um material de referência ou material de referência certificado de $\mathrm{U}_{3} \mathrm{Si}_{2}$ com especificação para o teor de urânio e silício total e de impurezas. 
Neste contexto o desenvolvimento de um material de referência certificado para análise de urânio e silício total em $\mathrm{U}_{3} \mathrm{Si}_{2}$ e da composição de impurezas contribui de maneira significativa na capacitação técnica dos laboratórios e procedimentos envolvidos no processo analítico. Esse material permitirá colaborar para otimização e aprimoramento das etapas essenciais do processo, como também ajudará a identificar possíveis erros de processo e estimar o grau de incerteza expandida obtida no processo analítico.

Este estudo teve como foco a produção, caracterização e certificação de um material de referência de siliceto de urânio $\left(\mathrm{U}_{3} \mathrm{Si}_{2}\right)$, quanto ao teor de urânio e silício total e de impurezas.

O estudo foi desenvolvido visando à certificação do material utilizando métodos independentes por um único laboratório (Laboratórios de Análises Química e Ambiental (LAQA), do IPEN. O estudo de certificação foi completado com medições realizadas envolvendo laboratórios independentes (Laboratório de Fluorescências de Raios X (LFX), do CQMA-IPEN Laboratório de Caracterização de Urânio (LCU), do CTMSP.

A produção e caracterização do material de referência e todos os estudos para sua certificação foram realizados utilizando o método de DAVIES \& GRAY para determinar o teor de urânio total, a gravimetria para a determinação de silício total e da separação por cromatografia de extração do urânio pela complexação com tributilfosfato e em seguida pela análise por espectrometria de emissão com fonte de plasma induzido (ICPOES) para a determinação das impurezas (DAVIES \& GRAY, 1964).

O Laboratório de LFX utilizou para a técnica de fluorescência de raios $X$ por energia dispersiva (wavelength dispersion $\mathrm{X}$-ray fluorescence technique (WDXRF), validada e implementada para a determinação de silício (Si) total e urânio $(U)$ total e impurezas nas amostras de $U_{3} \mathrm{Si}_{2}$, candidatas a material de referência.

O Laboratório de Caracterização de Urânio, do CTMSP utilizou o método de DAVIES \& GRAY para determinar o teor de urânio total, a gravimetria para a determinação de silício e a espectrometria de massas por termoionização ICP-TIMS para a determinação de impurezas e para composição isotópica de urânio. 


\section{OBJETIVO}

O objetivo desse estudo foi preparar um candidato a material de referência certificado de matriz de siliceto de urânio, $U_{3} \mathrm{Si}_{2}$, quanto a concentração de urânio total, silício total e de impurezas* ${ }^{*}$ dentro dos conceitos e diretrizes da norma ABNT ISO GUIA 35:2012, específica para materiais de referência.

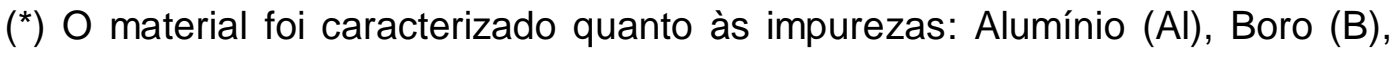
Cálcio (Ca), Cádmio (Cd), Cobalto (Co), Cromo (Cr), Cobre (Cu), Ferro (Fe), Lítio (Li), Magnésio (Mg), Manganês (Mn), Molibdênio (Mo), Níquel (Ni), Chumbo (Pb), Estanho (Sn), Vanádio (V), Zinco (Zn), Bário (Ba).

\section{FUNDAMENTOS TEÓRICOS}

\subsection{Contexto histórico do Combustível Nuclear no IPEN}

A tecnologia para fabricação do elemento combustível de dispersão foi desenvolvida no Brasil com os primeiros estudos realizados em 1959, no Instituto de Energia Atômica (IEA) atual Instituto de Pesquisas Energéticas e Nucleares - IPEN (SANTOS, 2008). Por motivos políticos e militares, o IPEN não foi capaz de adquirir elementos combustíveis do mercado internacional, por muitas décadas, para abastecer o reator de pesquisas IEA-R1. A partir de 1985, o IPEN iniciou os trabalhos de montagem de uma instalação de fabricação de elemento combustível a nível laboratorial, com capacidade para produzir seis elementos de combustível por ano, suprindo o funcionamento do reator IEA-R1 em dois MW e 40 horas por semana (SILVA et. al., 2008).

Em 1988 o IPEN produziu a partir do material físsil usado (pó de $\mathrm{U}_{3} \mathrm{O}_{8}$, disponível no Brasil) 26 barras de elementos combustíveis com $20 \%$ de enriquecimento, para o reator IEA-R1. Com o término dos estoques de óxido de urânio, à crescente demanda de radioisótopos e sua consequente atualização de potência do reator IEA-R1, tornou se vital para o Brasil o desenvolvimento e a produção de novos elementos combustíveis (SNELGROVE et. al., 1987; SILVA et. al., 2008; SILVA, 2013).

A pesquisa para o desenvolvimento do novo elemento combustível iniciou-se em 1997, e assim a tecnologia desenvolvida baseou-se na dispersão 
de siliceto de urânio em alumínio $\left(\mathrm{U}_{3} \mathrm{Si}_{2}-\mathrm{Al}\right)$ com carregamento de urânio de cerca de $3,0 \mathrm{~g} \mathrm{~cm}^{-3}$. Em 1998, a tecnologia do combustível de siliceto de urânio foi implantada, sendo o pó de $\mathrm{U}_{3} \mathrm{Si}_{2}$ importado da França, o que resultou na fabricação de 16 barras de elementos combustíveis de siliceto de urânio entre 1999 e 2000. Levando o Brasil a garantir os esforços para desenvolver o pó $\mathrm{U}_{3} \mathrm{Si}_{2}$ ainda em 1998, visando à plena nacionalização de todo o processo de produção (SILVA et. al., 2008).

\subsection{Compostos de urânio utilizados como combustível nuclear e quantidade e tipo de impurezas que afetam sua qualidade}

O urânio é um importante elemento químico do ponto de vista comercial e tecnológico. Este elemento pertence à série dos actinídeos e está situado no sétimo período da tabela periódica, sendo o último elemento natural da classificação periódica. É encontrado em diversos tipos de rochas, solos, sedimentos, águas superficiais e subterrâneas. Entretanto, ocorre em pequenas concentrações (SEABORG G. T., 1968; EMSLEY T., 2001; AWAN e KHAN, 2015). As principais propriedades do urânio estão apresentadas na Tabela 3.

Tabela 3 - Principais propriedades físicas do urânio

\begin{tabular}{cc}
\hline \multicolumn{1}{c}{ Propriedade } \\
\hline Símbolo & $\mathrm{U}$ \\
Número atômico & 92 \\
Raio atômico $(\mathrm{pm})$ & 240 \\
Massa atômica $\left(\mathrm{g} \mathrm{mol}^{-1}\right)$ & 238,029 \\
Configuração eletrônica & {$[\mathrm{Rn}], 7 \mathrm{~s}^{2}, 5 \mathrm{f}^{3}, 6 \mathrm{~d}^{1}$} \\
Ponto de fusão $\left({ }^{\circ} \mathrm{C}\right)$ & 1135 \\
Ponto de ebulição $\left({ }^{\circ} \mathrm{C}\right)$ & 4131 \\
Densidade $\left(\mathrm{g} \mathrm{mL}^{-1}\right)$ & 18,9 \\
\hline
\end{tabular}

Fonte: https://periodic.lanl.gov/92.shtml

No estado metálico, o urânio é maleável, dúctil, ligeiramente paramagnético, muito denso e apresenta coloração prateada. Em contato com o ar, o urânio tende a apresentar coloração escura devido à formação de uma 
fina camada de óxido. Além disso, entra em ignição espontânea quando finamente dividido, na temperatura ambiente (SEABORG G. T., 1965; EMSLEY T., 2001; AWAN e KHAN, 2015).

O urânio apresenta vários estados de oxidação $(+2,+3,+4,+5$ e +6). Resultando em íons $\mathrm{U}^{3+}$ (vermelho), $\mathrm{U}^{4+}$ (verde), $\mathrm{UO}_{2}{ }^{+}$(instável) e $\mathrm{UO}_{2}{ }^{2+}$ (amarelo), respectivamente. Os estados de oxidação mais comuns são U(IV) e $\mathrm{U}(\mathrm{VI})$, sendo a última forma a mais estável. O U(VI) geralmente está associado ao oxigênio para formar a uranila, $\left(\mathrm{UO}_{2}{ }^{2+}\right)$ (SEABORG G. T., 1965; EMSLEY T., 2001; AWAN e KHAN, 2015).

O urânio tetravalente ocorre em ambientes fortemente redutores como, por exemplo, águas superficiais, brejos ou locais alagados com elevada quantidade de matéria orgânica. Ao contrário do U(VI), os compostos de U(IV) possuem tendência em formar ligações com a matéria orgânica e posteriormente precipitar, desta forma apresentam mobilidade reduzida (SEABORG G. T., 1965; EMSLEY T., 2001; AWAN e KHAN, 2015).

No meio ambiente, o urânio ocorre naturalmente com três isótopos radioativos: ${ }^{238} U,{ }^{235} U$ e ${ }^{234} U$. No entanto, outros isótopos podem ser sintetizados pelo homem em laboratório, reatores de pesquisa e aceleradores de partículas (SEABORG G. T., 1965; EMSLEY T., 2001; AWAN e KHAN, 2015).

Os isótopos naturais do urânio com suas respectivas massas atômicas, abundâncias isotópicas e meias vidas estão apresentadas na Tabela 4.

Tabela 4 - Propriedades dos isótopos de urânio

\begin{tabular}{cccc}
$\begin{array}{c}\text { Isótopos de } \\
\text { Urânio Natural }\end{array}$ & $\begin{array}{c}\text { Massa atômica } \\
\text { (u.m.a.) }\end{array}$ & $\begin{array}{c}\text { Abundância } \\
\text { isotópica } \\
\text { (\%) }\end{array}$ & $\begin{array}{c}\text { Meia vida } \\
\text { (anos) }\end{array}$ \\
\hline${ }^{234} \mathrm{U}$ & 234,0410 & 0,005 & $2,45 \times 10^{5}$ \\
${ }^{235} \mathrm{U}$ & 235,0439 & 0,711 & $7,04 \times 10^{8}$ \\
${ }^{238} \mathrm{U}$ & 238,0508 & 99,283 & $4,47 \times 10^{9}$ \\
\hline
\end{tabular}

Fonte: https://periodic.lanl.gov/92.shtml

O minério de urânio é extraído de várias maneiras: por mina a céu aberto, subterrânea, lixiviação in-situ e mineração de poços. O minério de baixa 
qualidade normalmente contém 0,01 a 0,25 \% de óxidos de urânio (SEABORG G. T., 1965; EMSLEY T., 2001; AWAN e KHAN, 2015).

Após a extração, o minério de urânio é triturado e transformado em pó fino e depois lixiviado com ácido ou álcali. O lixiviado é submetido a uma das várias sequências de precipitação, extração por solvente e troca iônica. A mistura resultante, chamada "yellowcake" (bolo amarelo) - diuranato de sódio (DUS) é um sal que contém urânio na proporção entre 60 a 70\%.(SEABORG G. T., 1965; EMSLEY T., 2001; AWAN e KHAN, 2015).

São várias as etapas de processamento, purificação e conversão com a formação de compostos intermediários de urânio que compõe o ciclo do combustível nuclear. O tetrafluoreto de urânio (UF $)_{4}$. Geralmente, é um composto intermediário e será formado nas conversões de $\mathrm{UF}_{6}$ para $\mathrm{U}_{3} \mathrm{O}_{8}, \mathrm{UO}_{2}$ ou urânio metálico (SEABORG G. T., 1965; EMSLEY T., 2001; AWAN e KHAN, 2015).

O hexafluoreto de urânio $\left(U_{6}\right)$ é a forma na qual o urânio é utilizado para a realização do processo de enriquecimento industrial. Este composto apresenta a vantagem de ser facilmente convertido para os estados sólido, líquido e gasoso (SEABORG G. T., 1965; EMSLEY T., 2001; PALMIERI et. al., 1986; EMSLEY T., 2001; IAEA, 2005; IAEA, 2007; AWAN e KHAN, 2015).

$\mathrm{O} \mathrm{UF}_{6}$ é um produto tóxico que não reage com oxigênio, nitrogênio, dióxido de carbono ou ar seco, mas reage com água ou vapor de água (inclusive umidade do ar), onde ocorre a formação de ácido fluorídrico e outro composto chamado fluoreto de uranila $\left(\mathrm{UO}_{2} \mathrm{~F}_{2}\right)$ (SEABORG G. T., 1965; EMSLEY T., 2001; PALMIERI et. al., 1986; EMSLEY T., 2001; IAEA, 2005; IAEA, 2007; AWAN e KHAN, 2015).

As formas mais comuns de óxido de urânio são $\mathrm{U}_{3} \mathrm{O}_{8}$ e $\cup_{2} \mathrm{Am}_{2}$ bas as formas são sólidas, de baixa solubilidade em água e são relativamente estáveis em uma ampla gama de condições ambientais. $\mathrm{O}_{3} \mathrm{U}_{8}$ é, dependendo das condições, o composto mais estável de urânio e é a forma mais comumente encontrada natureza (AWAN e KHAN, 2015).

Para os reatores de pesquisa, a maior parte dos elementos combustíveis tipo MTR utilizados foram ligas de urânio-alumínio (U-Al) contendo 18 \% em peso de urânio altamente enriquecido (93\% em peso de ${ }^{235} \mathrm{U}$ ) (TRAVELLI, 1980). 
Contudo esse nível de enriquecimento permitia o uso do urânio para armas nucleares, o que representava um risco associado ao desvio desses combustíveis durante a fabricação, transporte e estocagem. (CUNNINGHAM et. al., 1956, 1958; KAUFMAN et. al., 1962; HOLDEN, 1967; BINFORD et. al., 1977; SNELGROVE et. al., 1978; STAHL et. al., 1978; GIETZEN et al., 1978; TRAVELLI, 1980; USNRC, 1988; IAEA, 2005; IAEA, 2007).

Em 1978, devido à preocupação com a proliferação de armas nucleares, foi lançado pela IAEA o Programa (RERTR) Reduced Enrichment for Research and Test Reactors (Redução do Enriquecimento para Reatores de Pesquisa e Teste) o qual impôs a restrição ao comércio de urânio enriquecido acima de 90 \% em ${ }^{235} U$. Deste modo, tornou-se necessário o aumento da quantidade de urânio em cada elemento combustível para não diminuir a reatividade e a vida útil dos núcleos dos reatores, abaixando o grau de enriquecimento para $20 \%$ em ${ }^{235}$ U (CUNNINGHAM et. al., 1956, 1958; KAUFMAN et. Al., 1962; HOLDEN, 1967; BINFORD et. al., 1977; STAHL et. al., 1978; GIETZEN et al., 1978; TRAVELLI, 1980; USNRC, 1988; SNELGROVE et. al., 1997; IAEA, 2005; IAEA, 2007; AWAN e KHAN, 2015).

Por este motivo, houve a necessidade de desenvolver novos tipos de combustível com maior densidade de urânio e fracamente enriquecido ou LEU (low enriched uranium-baixo enriquecimento de urânio) uma vez que reatores de pesquisa requerem taxas de enriquecimento de $12 \%$ a 19,75 \% no isótopo ${ }^{235} \mathrm{U}$, como o reator IEA R1, do IPEN.

Para os combustíveis existentes, as densidades de urânio tipo LEU foram qualificadas até $2,3 \mathrm{~g} \mathrm{~cm}^{-3}$ para o combustível de UAI-AI, até $3,2 \mathrm{~g} \mathrm{~cm}^{-3}$ para o combustível de $\mathrm{U}_{3} \mathrm{O}_{8}-\mathrm{Al}$, e até $3,7 \mathrm{~g} \mathrm{~cm}^{-3}$ para o combustível de $\mathrm{UZrH}_{\mathrm{x}}$ (TRAVELLI, 1980; USNRC, 1988; AWAN e KHAN, 2015).

No caso dos novos combustíveis, como o combustível de dispersão $\mathrm{U}_{3} \mathrm{Si}_{2}$-Al foi qualificado para densidades de urânio até $4,8 \mathrm{~g} \mathrm{~cm}^{-3}$ (TRAVELLI, 1980; USNRC, 1988; AWAN e KHAN, 2015).

Além da alta densidade de urânio, a pureza do material combustível é outro item de extrema importância.

Os compostos de urânio podem apresentar diversas impurezas. Entre elas estão alguns elementos que possuem elevada secção de choque de captura de nêutrons térmicos. Ao capturar neutros, a taxa de reação e a 
eficiência do reator para a produção de energia irão diminuir. Os elementos que possuem maiores secções de choque de captura de nêutrons térmicos são: Gd, B, Cd, Li, Ag, Dy, Sm e Eu (FLOYD et. al., 1983; PALMIERI et. al., 1986; ASSAD et. al. 1990; RAMANAIAH, 1998; MALHOTRA e SATYANARAYANA, 1999; IAEA, 1999; VERNA e RAMAKUMAN, 2007; REIS et. al., 2009; SATYANARAYANA e DURANI, 2010; NAGAR et, al., 2014).

Elementos como $\mathrm{Na}, \mathrm{P}, \mathrm{Mg}$, Si, Al, $\mathrm{Ca}, \mathrm{Mo}, \mathrm{Fe}, \mathrm{Cr}, \mathrm{Mn}, \mathrm{K}$ e $\mathrm{Ni}$,se presentes como impurezas, podem afetar os processos de transformação metalúrgica as características do produto final (FLOYD et. al., 1983; PALMIERI et. al., 1986; ASSAD et. al. 1990; RAMANAIAH G.V., 1998; MALHOTRA e SATYANARAYANA, 1999; IAEA, 1999; VERNA P., RAMAKUMAR K.L., 2007; REIS et. al., 2009; SATYANARAYANA e DURANI, 2010; NAGAR et, al., 2014).

As concentrações das impurezas metálicas no combustível devem estar abaixo dos níveis máximos permitidos especificados para obter a densidade necessária para os grânulos e também reduzir a perda de nêutrons. A determinação quantitativa desses elementos em urânio de grau nuclear é, portanto, necessária antes da sua utilização como combustível nuclear (ASTM, 1993; ASTM, 2000; REIS et. al., 2009; SATYANARAYANA e DURANI, 2010; NAGAR et, al., 2014; ASTM, 2016).

A Tabela 5 apresenta as especificações da ASTM - American Society for Testing Materials (Comitê de Padrões Americanos para Testes e Materiais) em limite máximo de concentração de impurezas para o controle químico do $\mathrm{U}_{3} \mathrm{O}_{8}$ e $\mathrm{UO}_{2}$ de grau nuclear.

Tabela 5 - Especificações padrão da ASTM, ASTM C1334-1993 para $\cup_{3} \mathrm{O}_{8} \mathrm{e}$ $\mathrm{UO}_{2}$, ASTMC1334-2000, ASTM C1334-2016 (grau nuclear)

\begin{tabular}{|c|c|c|c|}
\hline \multirow[b]{2}{*}{ ELEMENTOS } & \multicolumn{3}{|c|}{ Limite Máximo $\left(\mu \mathrm{g} \mathrm{g}^{-1} \mathrm{U}\right)$} \\
\hline & $\begin{array}{c}\text { ASTM C1334-1993 } \\
\mathrm{U}_{3} \mathrm{O}_{8} \mathrm{e} \mathrm{UO}_{2}\end{array}$ & $\begin{array}{c}\text { ASTM C1334-2000 } \\
\mathrm{U}_{3} \mathrm{O}_{8}\end{array}$ & $\begin{array}{c}\text { ASTM C1334-2016 } \\
\mathrm{U}_{3} \mathrm{O}_{8} \text { e UO } \\
\end{array}$ \\
\hline $\mathrm{Al}$ & 600 & 150 & 150 \\
\hline B & 10 & - & 2 \\
\hline $\mathrm{Ba}$ & $\leq 500$ & 5 & 5 \\
\hline $\mathrm{C}$ & 2000 & - & - \\
\hline $\mathrm{Ca}+\mathrm{Mg}$ & $\leq 500$ & 150 & 150 \\
\hline
\end{tabular}




\begin{tabular}{|c|c|c|c|}
\hline $\mathrm{Cd}$ & 10 & - & - \\
\hline $\mathrm{Cl}$ & $\leq 500$ & 100 & 100 \\
\hline Co & 10 & 80 & 80 \\
\hline $\mathrm{Cr}$ & $\leq 500$ & 100 & 100 \\
\hline $\mathrm{Cu}$ & 2000 & 100 & 100 \\
\hline $\mathrm{F}$ & 7000 & 100 & 100 \\
\hline $\mathrm{Fe}$ & $\leq 500$ & 150 & 150 \\
\hline $\mathrm{Fe}+\mathrm{Ni}$ & 1500 & - & - \\
\hline $\mathrm{H}$ (total) & 200 & - & - \\
\hline $\mathrm{Li}$ & 10 & - & - \\
\hline $\mathrm{Mn}$ & $\leq 500$ & 50 & 50 \\
\hline Mo & $\leq 500$ & 200 & 200 \\
\hline $\mathrm{N}$ & 2500 & - & - \\
\hline $\mathrm{Ni}$ & 500 & 80 & 80 \\
\hline$P$ & $\leq 500$ & 100 & 100 \\
\hline $\mathrm{Pb}$ & $\leq 500$ & 40 & 40 \\
\hline $\mathrm{Si}$ & $\leq 500$ & 200 & 200 \\
\hline Sn & $\leq 500$ & - & - \\
\hline $\mathrm{Na}$ & $\leq 500$ & 20 & 20 \\
\hline $\mathrm{Ta}$ & $\leq 500$ & 200 & 200 \\
\hline Th & $\leq 500$ & 10 & 10 \\
\hline $\mathrm{Ti}$ & $\leq 500$ & 50 & 50 \\
\hline $\mathrm{V}$ & $\leq 500$ & 10 & 10 \\
\hline$W$ & $\leq 500$ & 100 & 100 \\
\hline $\mathrm{Zn}$ & $\leq 500$ & 20 & 20 \\
\hline
\end{tabular}

Fonte: ASTM C1334-1993,ASTM C1334-2000, ASTM C1334-2016

Os compostos de urânio que são usualmente analisados para a determinação de impurezas metálicas são os óxidos $\mathrm{U}_{3} \mathrm{O}_{8}, \cup_{2}, \cup \mathrm{U}_{3}$, os 
fluoretos $\mathrm{UF}_{4}$ e UF 6 , o urânio metálico e outros compostos como o diuranato de amônio (DUA) e o nitrato de uranilo (NU) (FLOYD et. al., 1983; PALMIERI et. al., 1986; ASSAD et. al. 1990; RAMANAIAH G.V.,1998).

$\mathrm{O}$ desenvolvimento recente dos combustíveis a base de $\mathrm{U}_{3} \mathrm{Si}_{2}$ e urâniomolibdênio e a escassez de materiais de referência na área fez com que fosse necessária a adoção das especificações de impurezas dos demais compostos de urânio para estas ligas, a fim de caracterizar quimicamente os novos elementos combustíveis. (FLOYD et. al., 1983; PALMIERI et. al., 1986; ASSAD et. al. 1990; RAMANAIAH G.V., 1998; MALHOTRA e SATYANARAYANA, 1999; IAEA, 1999; VERNA e RAMAKUMAR, 2007; REIS et. al., 2009; SATYANARAYANA e DURANI, 2010; NAGAR et. al., 2014).

Os países adotaram as especificações da ASTM para $\mathrm{U}_{3} \mathrm{O}_{8}, \mathrm{UO}_{2}$ e com base na eficiência do combustível queimado em seus reatores de pesquisa, para estabelecerem as especificações para o combustível nuclear à base de ligas de $\mathrm{U}_{3} \mathrm{Si}_{2}$ e U-Mo, sistema este adotado também pelo IPEN. Como pode ser observado na Tabela 1 as especificações técnicas para o controle químico do $\mathrm{U}_{3} \mathrm{Si}_{2}$ utilizado na fabricação da placa combustível do reator IEA-R1 do IPEN, também foram baseadas na ASTM C1334-1993.

Assim, as concentrações de impurezas ou micro constituintes que pode estar presentes ou que possam ser tolerados são muito específicas e dependentes dos diferentes tipos de materiais de combustível. A presença de $\mathrm{Fe}$, Co e $\mathrm{Ni}$ fornecem uma indicação de contaminação que pode ocorrer durante o processo de fabricação ou presença de equipamentos desgastados (VERNA e RAMAKUMAR, 2007; REIS et. Al., 2009; SATYANARAYANA e DURANI, 2010; NAGAR et. al., 2014).

O controle do conteúdo de $\mathrm{Cd}$ é importante do ponto de vista da economia de nêutrons. Metais alcalinos como cálcio e magnésio e também ferro tendem a formar óxidos que afetam preferencialmente a relação oxigênio / metal na matriz de combustível (VERNA e RAMAKUMAR, 2007; REIS et. Al., 2009; SATYANARAYANA e DURANI, 2010; NAGAR et. al., 2014), alcalinos terrosos, alguns elementos de terras raras, além de manganês e cobalto, entre outros, também podem ser ativados no processo de produção de radionuclídeos após a irradiação no reator (FLOYD et. Al., 1983; PALMIERI et. al., 1986; ASSAD et. al., 1990; RAMANAIAH G. V., 1998; MALHOTRA e 
SATYANARAYANA, 1999; IAEA, 1999; VERNA e RAMAKUMAR, 2007; REIS et. al., 2009; SATYANARAYANA e DURANI, 2010; NAGAR et. al., 2014).

Nesse contexto, a determinação de elementos de impureza em compostos de urânio representa uma parte importante do programa de controle de qualidade usado para determinar as especificações químicas, já que o conteúdo dos elementos de impurezas é responsável pela corrosão das placas de combustível, atuando como venenos nucleares, pois possuem grandes cortes transversais de nêutrons que resultam na diminuição da energia nuclear (SATYANARAYANA e DURANI, 2010; NAGAR et. al., 2014).

Várias técnicas foram e são utilizadas para determinar elementos de impurezas, além da análise espectroquímica. Os métodos disponíveis para a determinação de metais em nível de traços em vários materiais nucleares são: a espectroscopia de absorção atômica de chama (FAAS), cromatografia de íons (IC), espectrometria ótica de emissão com plasma acoplado indutivamente (ICPOES), espectrometria de massa com plasma acoplado indutivamente (ICPMS) etc. (FLOYD et. al., 1983; PALMIERI et. al., 1986; ASSAD et. al. 1990; RAMANAIAH G.V., 1998; MALHOTRA e SATYANARAYANA., 1999; IAEA, 1999; VERNA e RAMAKUMAR, 2007; REIS et. al., 2009; SATYANARAYANA e DURANI, 2010; NAGAR et. al., 2014).

Entre todas essas técnicas, a ICPOES e ICP-MS são as técnicas multielementares mais versáteis e rápidas, com alta taxa de transferência de amostra, calibração linear a intervalos longos, menores limites de detecção e menos interferências espectroscópicas (VERNA e RAMAKUMAR, 2007; REIS et. al., 2009; SATYANARAYANA e DURANI, 2010; NAGAR et. al., 2014).

Contudo, ambas as técnicas necessitam da separação da matriz de urânio antes da quantificação quando a concentração do analito se apresentar em nível de traços e ultratraços, já que o espectro de urânio denso interferirá severamente com a precisão e exatidão das medições. Uma diluição alta também pode diminuir a concentração de analito abaixo do limite de detecção do instrumento. Para análise por ICP-MS, recomenda-se a análise de soluções com dissolução total para o conteúdo sólido $\leq 0,1 \%$. (VERNA e RAMAKUMAR, 2007; REIS et. Al., 2009; SATYANARAYANA e DURANI, 2010; NAGAR et. al., 2014). 


\subsection{Produção do elemento combustível de dispersão de pó de $\mathrm{U}_{3} \mathrm{Si}_{2}$}

Os elementos combustíveis tipo MTR são formados por um conjunto de placas combustíveis, montadas com espaços entre si, para permitir a passagem de um fluxo de água utilizado como refrigerante e moderador. As placas combustíveis consistem de um núcleo, contendo o material físsil, que é totalmente revestido com alumínio e são fabricadas adotando-se a tradicional técnica de montagem: núcleo, moldura, revestimentos e posterior laminação, esta técnica é conhecida internacionalmente com o nome de "Picture Frame Technique" (CUNNINGHAM et. al., 1957; JUNIOR, 2013).

As técnicas de metalurgia do pó são utilizadas na fabricação dos núcleos das placas combustíveis, compostos de cermets ou briquetes, compósitos cerâmico-metálicos, utilizando pó de $\mathrm{U}_{3} \mathrm{Si}_{2}$ enriquecido a $20 \%$ no isótopo ${ }^{235} \mathrm{U}$ (material combustível nuclear), em conjunto com pó de alumínio (material estrutural da matriz do núcleo) (CUNNINGHAM et. al., 1957; JUNIOR, 2013).

O elemento combustível para o reator tipo MTR é um conjunto de 18 placas combustíveis paralelas entre si, montadas formando um conjunto denominado elemento combustível. A tecnologia de fabricação das placas combustíveis e a geometria do elemento combustível são basicamente os mesmos para todos os reatores desse tipo, diferindo apenas nas dimensões da placa combustível, no tocante a espessura, e as dimensões do elemento combustível.

De modo geral, o processo de fabricação de elementos combustíveis, sejam do tipo siliceto de urânio $\left(\mathrm{U}_{3} \mathrm{Si}_{2}\right)$, pode ser dividido nas seguintes etapas principais: 
Figura 1- Processo de fabricação de combustíveis para reatores do tipo MTR

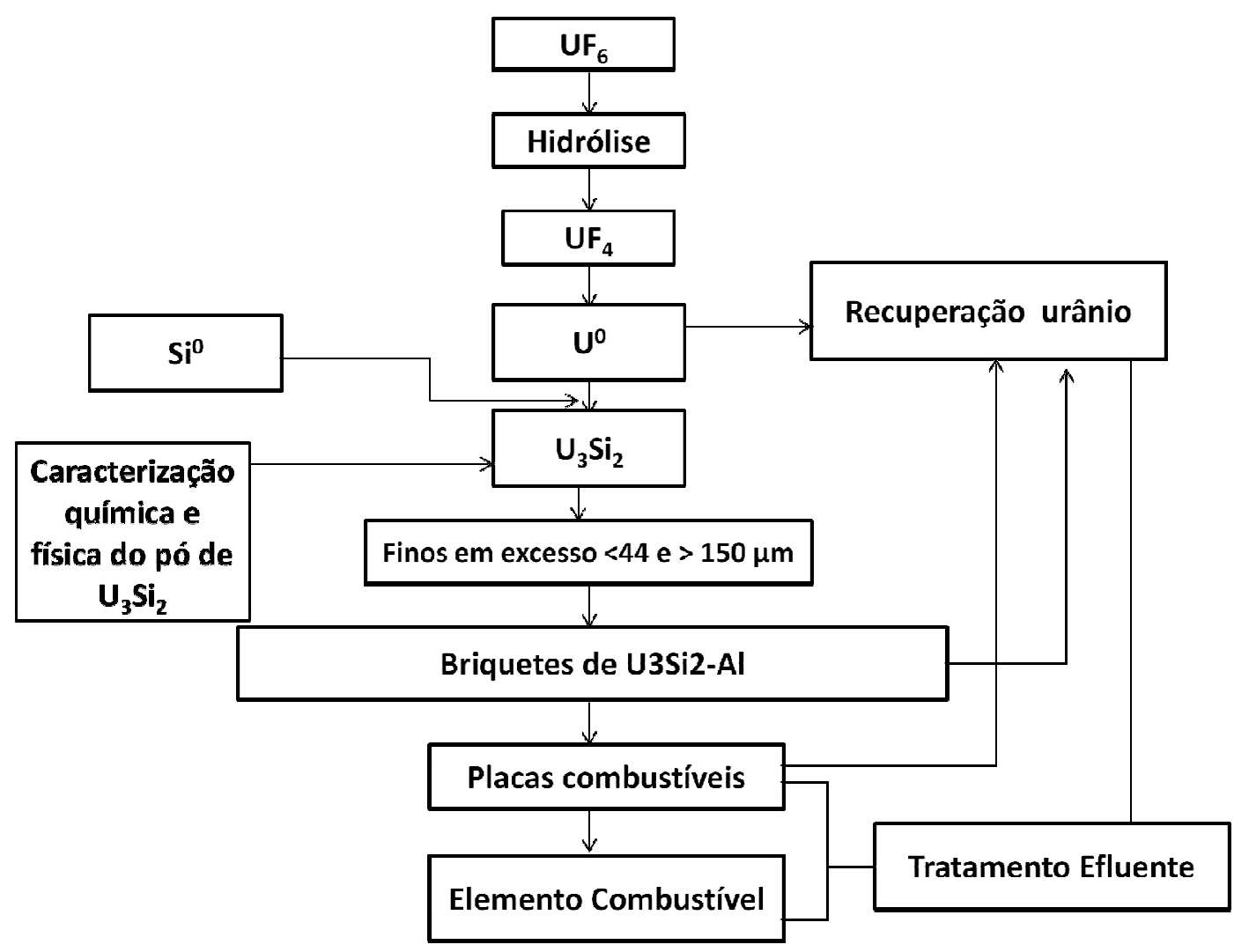

Fonte: Adaptado de JUNIOR, 2013

Na Figura 1 é apresentado de forma simplificada o processo de fabricação de elementos combustíveis adotado pelo IPEN-CNEN/SP.

A rota que adota o $\bigcup_{3} \mathrm{Si}_{2}$ como matéria-prima para a dispersão é a mais moderna, recentemente implantada. No IPEN o processo de fabricação de combustíveis, do tipo siliceto de urânio $\left(\mathrm{U}_{3} \mathrm{Si}_{2}\right)$, inicia-se com o processamento do $\mathrm{UF}_{6}$ (JUNIOR, 2013).

O UF 6 enriquecido é obtido do Centro Tecnológico da Marinha, na sua unidade de Aramar (CTM-Aramar), São Paulo-SP, na forma de gás em cilindros tipo 5A, com peso líquido máximo $25 \mathrm{~kg}$.

O gás de $U_{6}$ é transferido para o interior do reator de hidrólise, onde reage com água, formando a solução de fluoreto de uranilo $\left(\mathrm{UO}_{2} \mathrm{~F}_{2}\right)$, (Figura 2). 
Figura 2 - Processo de fabricação do UF4

Linha exaustão

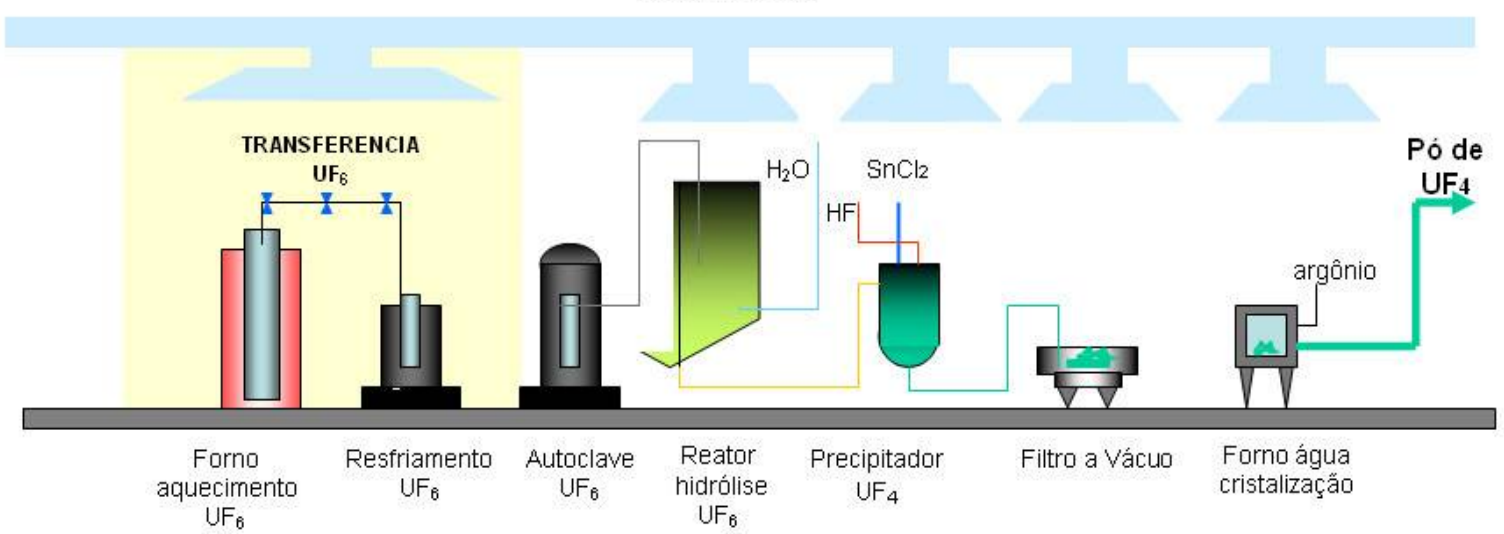

Fonte: JUNIOR, 2013

A solução de fluoreto de uranilo oriunda do reator de hidrólise é transferida para o reator de precipitação de $U_{4}$. $O$ urânio em solução é reduzido a $\mathrm{U}^{4+}$ com cloreto de estanho $\mathrm{II}$, e em seguida é precipitado na forma de $\mathrm{UF}_{4}$ mediante a adição de HF.

Após secagem, o pó de $U_{4}$ é reduzido a urânio metálico, por meio de uma reação magnésiotermia em uma bomba de redução.

O urânio metálico é, posteriormente, processado com silício metálico por fusão em forno de indução para obtenção do $\mathrm{U}_{3} \mathrm{Si}_{2}$.

\section{Figura 3 - Processo de fabricação de urânio metálico}

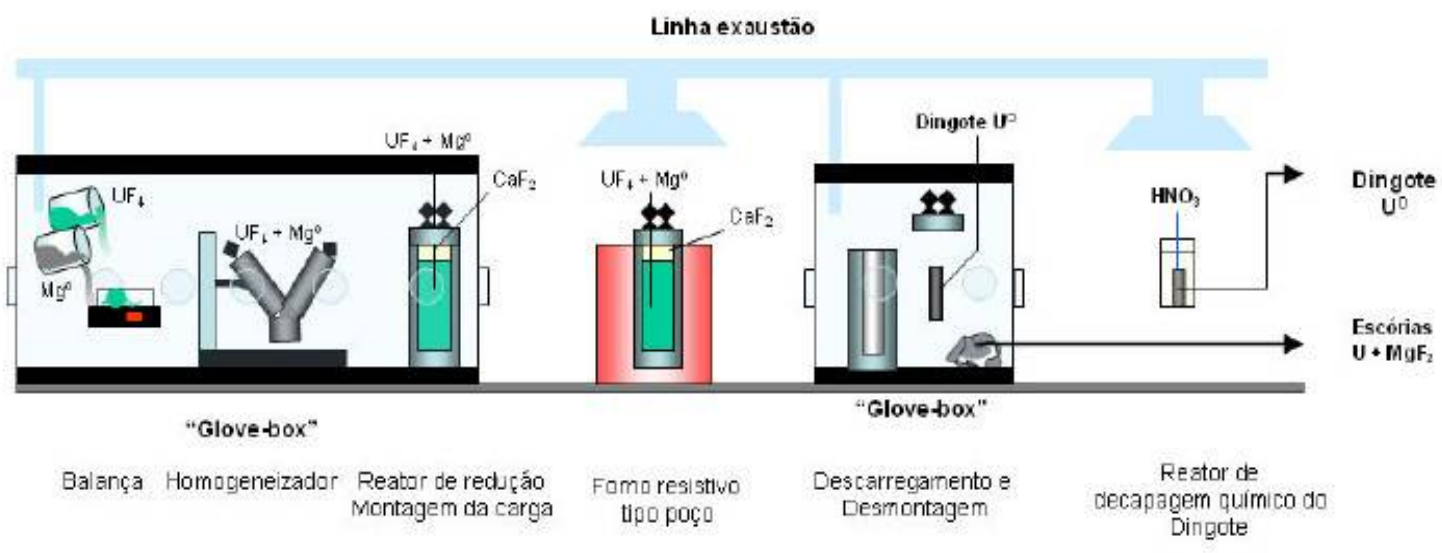

Fonte: JUNIOR, 2013

Nesse processo, para a preparação da carga de fusão as massas de grânulos de $\mathrm{Si}^{0}$ e pedaços de $\mathrm{U}^{0}$ são pesados na proporção 92,5 \% em peso de 
$\mathrm{U}^{0}$ e $7,5 \%$ em peso de $\mathrm{Si}^{0}$. A fusão é realizada num forno de indução equipado com um sistema de vácuo e controle de atmosfera (Figura 4). A carga é preparada colocando-se os pedaços de $\mathrm{U}^{0}$ num cadinho de zircônia. $\mathrm{O} \mathrm{Si}^{0}$ é acondicionado entre os pedaços de $U^{0}$.

\section{FIGURA 4- Processo de fabricação de siliceto de urânio}

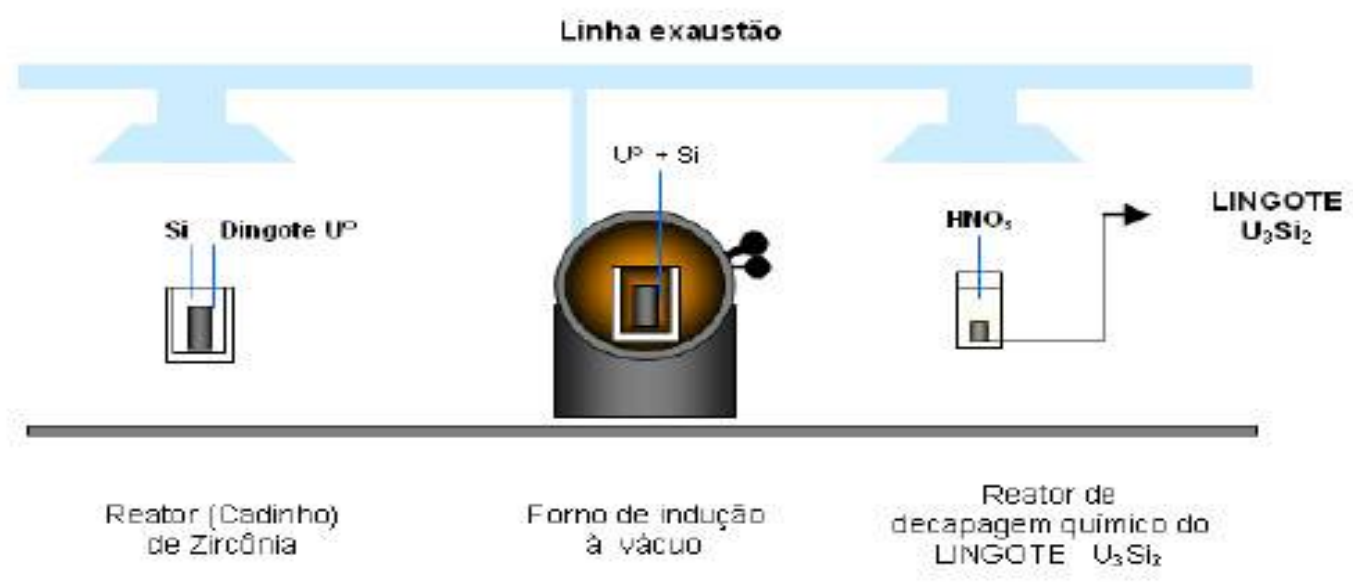

Fonte: JUNIOR, 2013

Quando o cadinho é preenchido, o forno é fechado e evacuado e, posteriormente, preenchido com argônio até que seja atingida a pressão de 500 mbar. Depois que a carga é fundida, o forno é desligado e o banho é solidificado no próprio cadinho. $O$ lingote obtido na fusão é retirado do cadinho e separado da escória (Figura 4).

$\mathrm{O}$ lingote de $\mathrm{U}_{3} \mathrm{Si}_{2}$ é transferido para uma glove box com atmosfera inerte, de argônio, já que o $\mathrm{U}_{3} \mathrm{Si}_{2}$ é pirosfórico e submetido à moagem preliminar, obtendo-se grânulos menores de $4 \mathrm{~mm}$ com a menor fração de finos $(<44 \mu \mathrm{m})$ possível. Esta operação é realizada com o auxílio de um triturador. Uma vez realizada a moagem preliminar, o material é colocado diretamente sobre um conjunto de peneiras (de $4 \mathrm{~mm}$ e $150 \mu \mathrm{m}$ ) em realizado o peneirado manualmente. Os grânulos de diâmetro superior a $4 \mathrm{~mm}$ são novamente triturados. Os grânulos entre $4 \mathrm{~mm}$ e $150 \mu \mathrm{m}$ são coletados para a moagem fina e as partículas menores do que $150 \mu \mathrm{m}$ são coletadas separadamente para posterior classificação granulométrica. 
A moagem do $U_{3} \mathrm{Si}_{2}$ posterior à moagem preliminar é realizada manualmente. $O$ material coletado durante a moagem preliminar (entre $4 \mathrm{~mm}$ e $150 \mu \mathrm{m}$ ) e o superior a $150 \mu \mathrm{m}$ proveniente do peneiramento (descrito a seguir) é processado nesta etapa. A moagem é realizada cuidadosamente, com peneiramentos intermediários, para classificação do pó na faixa 150-44 $\mu \mathrm{m}$.

É permitida uma fração de finos, abaixo de $44 \mu \mathrm{m}$, máxima de $20 \%$ em peso. A fração acima da especificação é recolhida num recipiente, sendo enviada novamente para o sistema de moagem final. A fração na faixa especificada (entre $150 \mu \mathrm{m}$ e $44 \mu \mathrm{m}$ ) é recolhida e armazenada e a fração fina $(<44 \mu \mathrm{m})$ é recolhida e armazenada separadamente.

A glove box contém um sistema de peneiramento vibratório, a qual efetua a separação de três frações granulométricas, maior do que $150 \mu \mathrm{m}$, entre 150 e $44 \mu \mathrm{m}$ e menor do que $44 \mu \mathrm{m}$. A composição do lote de pó de $\mathrm{U}_{3} \mathrm{Si}_{2}$ é ajustada para um máximo de teor de finos de $20 \%$ em peso, que é o máximo especificado.

A próxima etapa do processo é a fabricação dos núcleos das placas combustíveis, que contém o material físsil, o siliceto de urânio $\mathrm{U}_{3} \mathrm{Si}_{2}$. Esse núcleo é obtido por meio de técnicas de metalurgia do pó e é denominado briquete. Inicialmente, a massa e composição do briquete são calculadas com base nos valores analisados de urânio total e enriquecimento isotópico do pó de $\mathrm{U}_{3} \mathrm{Si}_{2}$.

\subsubsection{Confiabilidade de resultados analíticos para controle do pó de $\mathrm{U}_{3} \mathrm{Si}_{2}$}

A qualidade no contexto dos laboratórios analíticos considera a execução de atividades técnicas e administrativas onde são organizadas e planejadas, desde a amostragem até o lançamento do relatório final contendo os resultados analíticos. Seu principal objetivo é garantir a confiabilidade dos resultados, segundo parâmetros de repetibilidade, reprodutibilidade e rastreabilidade das medições (NBR ISO/IEC 17025:2017).

Assim, quando se trata de laboratórios analíticos o sistema de qualidade são acreditados segundo a NBR ISO/IEC 17025:2017 - Requisitos gerais para competência de laboratórios de ensaio e calibração, buscando a competência 
do laboratório para produzir dados e resultados tecnicamente válidos tanto em território nacional como internacional.

Quando comparada a série 9000 a NBR ISO/IEC 17025:2017 amplia a exigência não só para os serviços prestados no laboratório, mas também para a competência do pessoal envolvido no processo, seja na realização de atividades gerenciais ou técnicas permitindo à emissão de resultados de ensaio e calibração confiáveis com níveis de incerteza adequados a finalidade pretendida.

\subsection{Rastreabilidade metrológica}

O termo rastreabilidade metrológica pode ser interpretado como a capacidade que um resultado de medição estar relacionado a uma referência por meio de uma cadeia ininterrupta e documentada de calibração, cada uma contribuindo para a incerteza de medição (VIM, 2012).

Padrão de medição e/ou calibração se refere a definição de uma grandeza que apresenta um valor determinado e uma incerteza de medição associada utilizada como referência (VIM, 2012). Neste sentido a realização da definição de uma grandeza pode ser fornecida por um sistema de medição, uma medida materializada ou um material de referência.

O uso de padrões de medição frequentemente é utilizado para obtenção de valores medidos e incertezas de medição associadas para outras grandezas da mesma natureza, estabelecendo assim uma rastreabilidade metrológica através da calibração de outros padrões, instrumentos de medição ou sistemas de medição (VIM, 2012).

Assim é possível estabelecer uma hierarquia (Figura 5) entre os padrões onde a incerteza associada ao padrão define sua posição na hierarquia e pode Ihe conferir denominações diferentes em função de suas qualidades metrológicas e incertezas da seguinte forma (VIM, 2012):

$\checkmark$ Padrão de Medição Internacional: é aquele reconhecido internacionalmente apresentando a incerteza mais baixa sendo utilizado como referência para todas as medições do mundo;

$\checkmark$ Padrão de Medição Nacional: é aquele reconhecido como o padrão de referência no país, por apresentar o mais alto valor metrológico. 
Geralmente é mantido nos Institutos Nacionais de Metrologia e dele derivam as medições de sua grandeza no território;

$\checkmark$ Padrão de Medição de Referência: é aquele que possui a menor incerteza em sua finalidade e serve para calibrar outros padrões que vão realizar finalidade semelhante. Deste modo, este padrão de maior qualidade metrológica é a referência e deve ser calibrado por um laboratório externo que disponha de padrões superiores ao mesmo;

$\checkmark$ Padrão de Medição de Trabalho: é aquele utilizado nas rotinas de calibração, controle de instrumentos, sistemas de medição. Evitando o uso desnecessário ou frequente do padrão de referência e postergando sua deterioração o que poderia colocar em risco a rastreabilidade metrológica da grandeza apresentada pelo mesmo.

\section{FIGURA 5 - Hierarquia dos padrões metrológicos}

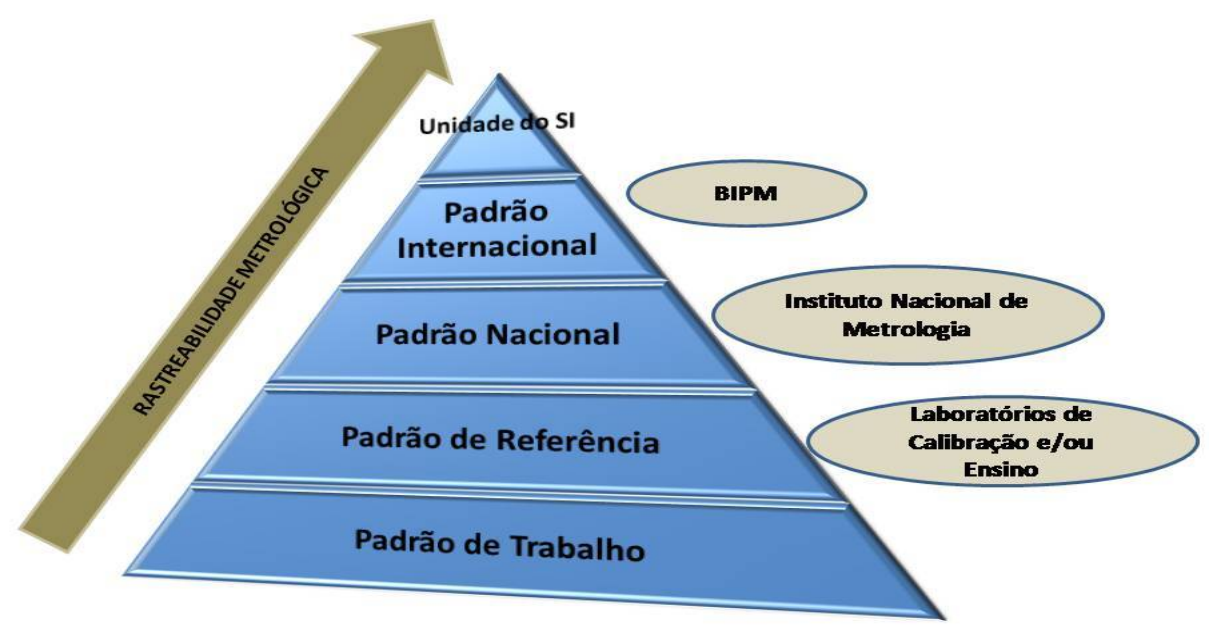

Fonte: VIM, 2012

\subsection{Material de Referência}

Materiais de referência (MR) e materiais de referência certificados $(\mathrm{MRC})$ são largamente utilizados para verificação da exatidão de medições analíticas, visando a garantir a sua confiabilidade e rastreabilidade (ABNT ISO GUIA 35:2012; VIM, 2012). 
Segundo a ABNT ISO GUIA 30:2016, na área analítica os materiais podem se conceituados como: materiais de referência (MR) e materiais de referência certificados (MRC), ambos são materiais que representam a matriz que se deseja monitorar, devem ser suficientemente homogêneos e estáveis em relação a propriedades específicas e preparados de modo que sua utilização atenda ao propósito da medição ou do exame de propriedades qualitativas.

Os MRC são caracterizados por um procedimento metrologicamente válido para uma ou mais propriedades especificadas, acompanhado de um certificado que fornece o valor da propriedade especificada, sua incerteza associada e uma declaração de rastreabilidade metrológica podendo ser utilizados em validação de metodologias (ABNT ISO GUIA 35:2012; VIM, 2012).

MR pode ser considerado como um termo genérico, pois abrange uma classe de materiais, cujo uso pode incluir a calibração de um sistema de medição, a avaliação de um procedimento de medição, a atribuição de valores a outros materiais e o controle de qualidade. Um MR só pode ser utilizado para uma única finalidade em uma dada medição (ABNT ISO GUIA 35:2012).

No entanto, não existem MR e MRC para todas as análises químicas realizadas em laboratórios além, disso os mesmos se encontram disponíveis apenas para as técnicas analíticas rotineiras e para um número reduzido de matrizes (CARDOSO et. al., 2010; SANTANA, 2013).

Os materiais de referência apresentam um elevado custo, tendo em vista que as etapas de certificação são demoradas e dispendiosas. Poucos são produzidos no Brasil e, a maioria, é produzida por países como os EUA, Inglaterra, Alemanha e Austrália entre outros (CARDOSO et. al., 2010).

A produção de um MR requer um planejamento experimental detalhado, prevendo-se a quantidade adequada de material para sua execução e de todas as etapas de estudos inerentes a ele, os quais são (CARDOSO et. al., 2010):

Preparo do material; envasamento das amostras, com verificação da homogeneidade do material nos frascos; estabelecimento da estabilidade, que garantirá ao material sua integridade durante o transporte e estocagem por tempo pré-estabelecido e a certificação dos valores atribuídos às propriedades de interesse do material preparado (CARDOSO et. al., 2010; SANTANA, 2013). 
$\mathrm{Na}$ área nuclear os materiais de referência podem ser divididos em quatro categorias (CRISTIANO et. al., 2011):

1) Materiais destinados à análise química destrutiva, certificados para conteúdos elementares de $\mathrm{U}$ e/ou $\mathrm{Pu}$;

2) Materiais destinados à análise isotópica destrutiva por espectrometria de massas, certificado para razões e conteúdos isotópicos;

3) Materiais destinados às análises não destrutivas, certificados para razões e conteúdos isotópicos;

4) Materiais destinados à análise de impurezas.

\section{PRODUÇÃO DE MATERIAIS DE REFERENCIA}

A produção de um MRC requer um planejamento antecipado a fim de avaliar a viabilidade do projeto. Uma parte indispensável para avaliar a viabilidade do projeto refere-se à quantidade de material necessária, aos estudos de homogeneidade, estabilidade e caracterização. Incluindo também a escolha dos métodos de medição apropriados para tais estudos.

\subsection{Estudo de homogeneidade}

O estudo de homogeneidade tem o intuito de demonstrar que o lote produzido é suficientemente homogêneo para garantir a qualidade do material, e verificar a variação que pode existir entre os recipientes do lote (ABNT ISO GUIA 35:2012; SANTANA, 2013).

O estudo de homogeneidade realizado após o envase geralmente ocorre por meio aleatório, e é realizado em duas etapas: entre os recipientes e dentro do recipiente. $O$ estudo entre os recipientes fornecerá a variação da homogeneidade existente entre os mesmos e é computada de acordo com a equação 1 (ABNT ISO GUIA 35:2012;SANTANA, 2013).

$$
s_{b b}^{2}=s_{A}^{2}=\frac{M Q_{\text {entre }}-M Q_{\text {dentro }}}{n^{\mathrm{o}}}
$$


Onde $\mathrm{s}^{2}{ }_{\mathrm{bb}}=$ variância da homogeneidade entre os recipientes; $\mathrm{s}_{\mathrm{A}}^{2}=$ variância da homogeneidade dentro do recipiente; $M Q_{\text {entre }}=$ média quadrática entre as partes; $M Q_{\text {dentro }}=$ média quadrática dentro da parte; $\mathrm{n}_{0}=$ número de replicatas. E assim, para a avaliação da incerteza assume-se que $s^{2}$ bbé idêntica $\mathrm{a} \mathrm{u}^{2} \mathrm{bb}$.

Em casos em que o método de medição escolhido, apresentar repetibilidade insuficiente ou o material não permitir uma sub amostragem é recomendado utilizar a seguinte equação:

$$
u_{b b}=\sqrt{\frac{M Q_{\text {dentro }}}{n}} \sqrt[4]{\frac{2}{v_{M Q_{\text {dentro }}}}}
$$

Onde: $\mathrm{u}_{b b}=$ incerteza da homogeneidade; $\mathrm{MQ}_{\text {dentro }}=$ média quadrática dentro dos frascos; $n$ = número de repetições; $;^{\text {MQdentro }}=$ graus de liberdade de $M Q_{\text {dentro. }}$

A utilização destas fórmulas é dependente dos valores do desvio padrão da homogeneidade $\left(\mathrm{s}_{\mathrm{bb}}\right)$ e do desvio padrão de repetibilidade $\left(\mathrm{s}_{\mathrm{r}}\right)$. Quando $\mathrm{s}_{\mathrm{bb}}$ for menor que $s_{r}$, é adequado aplicar a equação (2), pois esta expressão se baseia na amplitude de um intervalo de confiança de $95 \%$, levando em consideração à variância de repetibilidade das medições utilizadas no estudo de homogeneidade entre os recipientes (ABNT ISO GUIA 35:2012;SANTANA, 2013).

A técnica estatística utilizada para determinar a variabilidade entre os recipientes e dentro do recipiente é a Análise de Variâncias - ANOVA.

\subsection{Estudo de estabilidade}

O ensaio de estabilidade visa identificar eventuais alterações da propriedade em estudo, em um período de tempo compatível com o uso do material produzido. Esse estudo é feito no material já embalado, lacrado e em condições que simulem seu armazenamento e transporte. Entre os principais fatores estudados estão: a temperatura, umidade, contaminação externa, entre outros. 
Para tanto, são avaliadas eventuais alterações temporais no parâmetro em questão. Desta forma, o teste de estabilidade é realizado com seleção aleatória de recipientes sob duas condições distintas (BAM, 2010; ABNT ISO GUIA 35:2012; SANTANA, 2013):

1- Condições de armazenamento;

2- Condições de transporte.

1- As condições específicas de armazenamento são avaliadas pelo estudo de estabilidade em longo prazo, geralmente durante um período de tempo de 24 a 36 meses. Recomenda-se selecionar uma faixa de temperatura que atenda as condições de uso do material de tal modo que algum grau de instabilidade que possa ser detectado seja insignificante. O número mínimo de recipientes usados deve estar em torno de 10 a 12 para cada temperatura, com pelo menos 5 a 6 pontos no tempo considerando-se o lote produzido (BAM, 2010; ABNT ISO GUIA 35:2012; SANTANA, 2013).

2- $O$ estudo de estabilidade em curto prazo é realizado com objetivo de identificar a existência de alterações, nas propriedades de um material de referência durante o transporte sob condições especificadas. Neste caso são utilizadas diferentes faixas de temperatura a fim de estudar o efeito da mesma sobre os níveis de propriedade do material. Desta forma, recomenda-se selecionar entre 6 a 10 recipientes, para cada temperatura, por um período de 1 a 2 meses com 3 a 5 pontos no tempo (BAM, 2010; ABNT ISO GUIA 35:2012; SANTANA, 2013).

Existem dois esquemas experimentais para a realização do estudo de estabilidade. O modelo clássico e o modelo isócrono.

No caso do modelo clássico os recipientes individuais são deixados ao mesmo tempo sob condições idênticas e avaliados no transcorrer do tempo determinado para cada faixa de temperatura (exemplo 2 recipientes permanecem a $5{ }^{\circ} \mathrm{C}$ por 7 dias e após são analisados). Assim, o ensaio é realizado sob condições de reprodutibilidade o que pode acarretar uma incerteza relativa elevada, pois é considerada a instabilidade do sistema de medição (BAM, 2010; ABNT ISO GUIA 35:2012; SANTANA, 2013).

O modelo isócrono de estudo de estabilidade tem sido cada vez mais empregado, pois reduz a dispersão dos pontos no tempo e proporciona uma incerteza relativa menor, já que considera a diferença entre a repetibilidade e a 
reprodutibilidade do método de medição adotado. Neste modelo os recipientes permanecem nas temperaturas de referência pela ordem de tempo, do maior para o menor e são analisados ao final do período estabelecido (por exemplo, o frasco a $5^{\circ} \mathrm{C}$ é deixado primeiro a 2 meses e após, a 1 mês no final são analisados no mesmo dia) (BAM, 2010; ABNT ISO GUIA 35:2012; SANTANA, 2013).

A estimativa da incerteza devida à estabilidade em curto prazo (usts) e longo prazo (ults) é obtida multiplicando-se o valor do erro padrão (s(b1)) da variável $X$ obtido na análise de regressão linear dos dados de estabilidade para $o$ analito testado por um tempo de $t$ (meses), conforme a equação 3 (BAM, 2010; ABNT ISO GUIA 35:2012; SANTANA, 2013):

$$
\begin{gathered}
U_{s t s}=s(b 1) \times t \\
U_{l t s}=s(b 1) \times t
\end{gathered}
$$

Onde: $u_{\text {sts }}=$ incerteza para estabilidade em curto prazo; $u_{\mathrm{lts}}=$ incerteza para estabilidade em longo prazo; $(b 1)=$ desvio padrão de $b 1 ; t=$ tempo em meses.

\subsection{Métodos Analíticos Empregados para Caracterização dos Elementos de Interesse}

É conveniente que o método de medição empregado para o estudo de homogeneidade tenha repetibilidade e seletividade satisfatórias. Para um estudo de estabilidade em que amostras são medidas em dias diferentes, a seletividade e a reprodutibilidade do método de medição são de fundamental importância. Portanto, os métodos para estudos de homogeneidade e estabilidade não são, necessariamente, os mesmos (BAM, 2010; ABNT ISO GUIA 35:2012; SANTANA, 2013).

Isto não constitui um problema desde que a rastreabilidade dos resultados dos estudos de homogeneidade e estabilidade e a caracterização em relação a uma referência comum sejam estabelecidas. Tal referência pode ser um material que seja adequado para a avaliação de várias calibrações ou 
resultados de diferentes métodos de medição. Assegurar a rastreabilidade de todas as medições em um projeto de certificação constitui um importante requisito (BAM, 2010; ABNT ISO GUIA 35:2012; SANTANA, 2013).

Para a medição dos elementos de interesse presentes neste material foram utiilizadas as seguintes técnicas analiticas:

\subsubsection{Método de Titulação Potenciométrica - Davies \& Gray}

O método de Davies \& Gray, publicado em 1964, consiste na redução do urânio (VI) para urânio (IV) com ferro (II) em ácido fosfórico. O excesso de ferro (II) é oxidado seletivamente com ácido nítrico, usando molibdênio (VI) como catalisador. O urânio (IV) é então determinado na presença de inúmeras substâncias que interfeririam em outro método, por titulação com cromo (VI). Em 1970 foi publicada uma modificação para esta titulação que resultou na obtenção de excelente precisão e exatidão do procedimento original (ÊBERLE et. al., 1970).

Essa modificação consiste da adição de vanadil (IV) que entra no mecanismo de oxidação do urânio (IV) por cromo (VI), acelerando o processo de titulação, tornando-a a melhor definida (DAVIES \& GRAY, 1964; CRISTIANO et. al., 2011; ROSA, 2011).

Pela sua seletividade, facilidade de aplicação e excelente precisão e exatidão, esse procedimento foi sugerido para o controle do teor de urânio em materiais nucleares sob salvaguardas (DAVIES \& GRAY, 1964; CRISTIANO et. al., 2011; ROSA, 2011).

A concentração de urânio é obtida a partir da quantidade total (sólido e solução) do padrão primário de $\mathrm{K}_{2} \mathrm{Cr}_{2} \mathrm{O}_{7}$ consumido na titulação. $\mathrm{O}$ padrão certificado pelo National Institute of Standards and Tecnology (NIST) estabelecerá a rastreabilidade da medição conforme a especificação da American Chemical Society para materiais de pureza analítica e com os critérios de padrão primário da Analitycal Chemistry Section da International Union of Pure and Applied Chemistry - IUPAC (THOMPSON et. al., 2006).

Equação química a seguir: 
$U(V I)+2 \mathrm{Fe}(\mathrm{II}) \stackrel{\mathrm{H}_{3} \mathrm{PO}_{4}}{\longrightarrow} U(\mathrm{IV})+2 \mathrm{Fe}(\mathrm{III})$

$2 \mathrm{Fe}(\mathrm{II})+\mathrm{HNO}_{3}+2 \mathrm{H}^{+} \stackrel{\mathrm{Mo}(\mathrm{VI})}{\longrightarrow} 2 \mathrm{Fe}(\mathrm{III})+\mathrm{HNO}_{2}+\mathrm{H}_{2} \mathrm{O}$

$\mathrm{HNO}_{2}+\mathrm{NH}_{2} \mathrm{SO}_{3} \mathrm{H} \rightarrow \mathrm{H}_{2} \mathrm{SO}_{4}+\mathrm{N}_{2} \uparrow+\mathrm{H}_{2} \mathrm{O}$

$3 U(I V)+2 C r(V I) \stackrel{V(I V)}{\longrightarrow} 3 U(V I)+2 C r(I I I)$

A concentração de urânio total é dada pela seguinte fórmula:

$$
\% U=\frac{(m d \times f d)}{\left(\frac{\text { maliq. }}{1000}\right)} \times\left(\frac{m s o l}{m a}\right) \times 100
$$

Onde:

\% U: é a porcentagem de urânio encontrada após titulação com dicromato de potássio;

md: é a massa da pesagem da solução de dicromato de potássio $\left(\mathrm{K}_{2} \mathrm{Cr}_{2} \mathrm{O}_{7}\right)$; fd: é o fator de diluição;

maliq: é a massa da alíquota de solução preparada de siliceto de urânio $\left(\mathrm{U}_{3} \mathrm{Si}_{2}\right)$;

msol: é a massa da solução de siliceto de urânio preparada $(\mathrm{g})$;

ma: é a massa da amostra de siliceto de urânio utilizada (g).

\subsubsection{Determinação do Silício por Gravimetria}

O silício total foi determinado por gravimetria, através da dissolução de uma alíquota das amostras sólidas $\mathrm{U}_{3} \mathrm{Si}_{2}$, a partir da hidrofluorização, seguida pela insolubilização de sílica. O resultado é obtido através da medição da massa de Si contendo impurezas (mi); volatilização do tetrafluoreto de silício; resíduo contendo impurezas medidos (mf) e, finalmente, o cálculo da \% de Si puro na amostra, considerando a diferença entre mi e mf e (ma) massa da amostra sólida e o fsi $=$ fator gravimétrico $\mathrm{Si} / \mathrm{SiO}_{2}=0,467481$, (equação 5) (FURMAN, 1975; IT-ATN NQ-24, 2008). 


$$
\% \mathrm{Si}=\frac{(\mathrm{mi}-\mathrm{mf}) \times \mathrm{f}_{\mathrm{Si}} \times 100}{\mathrm{ma}}
$$

\subsubsection{Espectrometria de Emissão Óptica com Plasma Indutivamente Acoplado}

A técnica de ICPOES é baseada na medida da intensidade da radiação emitida, quando um átomo ou íon excitado pelo plasma retorna ao seu estado fundamental. A excitação da espécie ocorre quando seus elétrons mais externos têm seu nível de energia aumentado, passando do estado fundamental para o excitado, devido a colisão com elétrons ou íons argônio existentes no plasma (SKOOG, et al., 1998; GINÉ ROSIAS, 1998).

O elétron não é estável em níveis mais altos de energia, portanto retorna a seu estado fundamental, emitindo a energia que foi absorvida, sob a forma de energia luminosa. Os elétrons da espécie emitem linhas espectrais, tantas quantas forem suas possíveis transições; as linhas espectrais é que vão determinar o espectro de cada elemento, a intensidade de cada linha vai depender da probabilidade de transição, e do número de átomos que atinge um determinado estado excitado.

A luz emitida é focalizada para uma lente que tem a função de ampliar e focalizar a zona de descarga luminosa do plasma quando projetada sobre a fenda de entrada, promovendo melhor iluminação da rede de difração. Uma vez tendo passado pela lente, a luz emitida vai em direção à fenda de entrada do separador de linhas e chega ao monocromador, onde um prisma ou uma rede de difração isola a linha 25 medida (Montaser e Golightly, 1992) .

Em amostras com matrizes complexas, a escolha da linha isenta de sobreposições é necessária para funcionamento ideal da técnica. Essa é uma das razões pelas quais a linha de maior intensidade nem sempre seja a escolhida.

A técnica de ICPOES é uma técnica multielementar, executa grande número de determinações em muito pouco tempo, além de poder ser aplicada a diferentes concentrações, devido a possibilidade de escolha de linhas.

As impurezas presentes no $\bigcup_{3} \mathrm{Si}_{2}$ podem ser determinadas por separação cromatográfica em coluna preenchida com uma resina não-ionica (material suporte - Amberlite XAD 4), utilizando tributilfosfato (TBP) como agente 
quelante para o urânio, o qual é retido na coluna enquanto as impurezas são eluidas com uma solução de ácido nítrico a 5,5 M. E posteriormente sua concentração será determinada por método de curva analítica pela técnica de Espectrometria de Emissão Óptica com Plasma Indutivamente Acoplado ICPOES (COTRIM et. al., 2002; KAKAZU et. al., 2011).

O cálculo final da concentração das impurezas na amostra será dado pela equação 6:

$$
\mathrm{C}=\frac{\mathrm{C}_{\mathrm{o}} \cdot \mathrm{V}_{\mathrm{e}}}{\mathrm{M}_{\mathrm{a}}}
$$

Onde:

$\mathrm{C}=$ concentração da impureza analisada na amostra inicial e é dada em $\mu \mathrm{g} \mathrm{g}^{-1}$ amostra;

Co = concentração obtida na leitura do equipamento, dada em $\mu \mathrm{g} \mathrm{mL}^{-1}$ do eluído;

Ve = volume do eluído $(100 \mathrm{~mL})$;

$\mathrm{Ma}=$ massa da amostra pesada inicialmente $(\mathrm{g})$.

As condições de operação do equipamento são apresentadas na Tabela 6.

Tabela 6 - Condições de operação do equipamento

\begin{tabular}{|c|c|}
\hline \multicolumn{2}{|c|}{ Parametros do ICPOES } \\
\hline Gás refrigerante $(\mathrm{Ar})\left(\mathrm{L} \mathrm{min}^{-1}\right)$ & 15,0 \\
\hline Gás auxiliar (Ar) $\left(\mathrm{L} \mathrm{min}^{-1}\right)$ & 0,75 \\
\hline Pressão do nebulizador (bar) & 3,2 \\
\hline Potência do plasma (W) & 1200 \\
\hline Fluxo de amostra (mL $\left.\min ^{-1}\right)$ & 1 \\
\hline
\end{tabular}

Fonte: COTRIM et. al., 2002; KAKAZU et. al., 2011.

\subsubsection{Fluorescência de Raios X (XRF)}

$\mathrm{Na}$ espectrometria de fluorescência de raios $X$, os raios- $X$ são produzidos pela interação entre um feixe primário de raios- $X$ e a amostra de aerossóis. Na maioria dos casos, a fonte é um tubo de raios-x, mas alternativamente poderia ser um material radioativo (por exemplo, urânio, rádio e tório) ou síncrotron (acelerador de partículas cíclico). Há dois tipos de 
espectrômetros que utilizam tubo de raios X: Energia dispersiva (EDXRF) e Comprimento de onda dispersiva (WDXRF) (MULLER, 1972; JENKIS et. al., 1972; KUHN et. al., 1979; TERTIAN et. al., 1982).

A técnica analítica nuclear de fluorescência de raios $X(X R F)$ tem sido utilizada para a avaliação quali-quantitativa da composição química em vários tipos de amostras, de interesse agropecuário, agroindustrial, geológico e ambiental. Esta técnica, por ser não destrutiva e instrumental, e por permitir a análise de vários elementos simultaneamente, de modo rápido e a baixo custo, tem um elevado potencial de aplicação em várias áreas, onde há necessidade de correlação entre os elementos essenciais e tóxicos. Este texto tem por objetivo uma introdução à fluorescência de raios $X(X R F)$ e as suas variantes principais: por dispersão de energia (ED-XRF), por dispersão de comprimento de onda (WD-XRF) e por reflexão total (TXRF) (KUMPULAINEN, 1980).

Neste trabalho será descrita apenas a técnica analítica de fluorescência de raios $X$ por energia dispersiva (EDXRF), que foi utilizada para analisar elementos traços nas amostras contendo partículas de aerossol atmosférico. Nesta técnica, os elementos presentes na amostra que foi iluminada com raiosx (primário) emitirão radiação de raios-x (secundário) fluorescentes com energias discretas que são característicos para cada elemento.

Cada raio-X com energia diferente tem origem em uma transição eletrônica diferente em um átomo do material. Assim, através da medida das energias da radiação emitidas por uma amostra, é possível determinar quais elementos estão presentes. Por meio das medidas das intensidades da radiação em cada faixa de energias, é possível determinar quanto de cada elemento está presente nas amostras (MULLER, 1972; JENKIS et. al., 1972; KUHN et. al., 1979; TERTIAN et. al., 1982).

Classifica-se a fluorescência de raios $X$ como uma técnica de emissão atômica, fundamentada no efeito fotoelétrico. Assim, quando um átomo é submetido a um processo de irradiação utilizando-se uma fonte de raios $X$ (tubos de raios $X$, indução por partícula, radioisótopos naturais, luz síncrotron e outros), um elétron pode ser ejetado das camadas eletrônicas mais internas do átomo (Muller, 1972; Jenkis et. al., 1972; Kuhn et al., 1979; Tertian et al., 1982).

Para estabilização desse estado de excitação, os elétrons das camadas eletrônicas mais externas ocupam rapidamente as vacâncias geradas, 
liberando a diferença de energia existente entre os dois níveis de energia. A radiação emitida para cada transição é característica para cada elemento presente na amostra, Figura 6. Deste modo, a energia emitida por determinado elemento pode ser utilizada para identificá-lo. (JENKIS et. al., 1972; MULLER, R., 1972; SKOOG et. al., 2002).

Figura 6 - Modelo esquemático demonstrando o efeito fotoelétrico e a ocorrência de raios $\mathrm{X}$

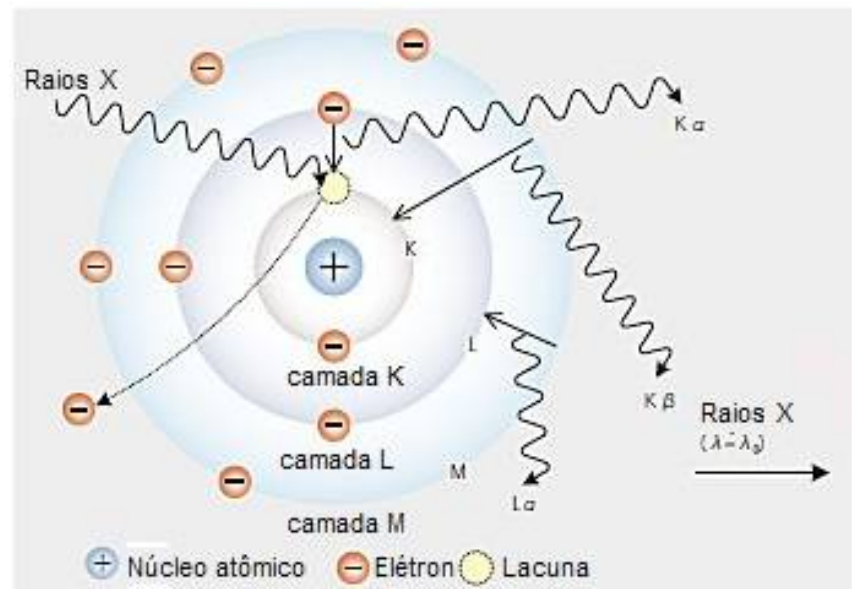

Extraído de:

http://www.shimadzu.com.br/analitica/produtos/elemental/raios_x/eds/edx7000_ 8000-1.shtml

\subsection{Análise Estatística e tratamento dos dados}

Os modelos estatísticos utilizados devem atender aos objetivos do projeto baseando-se na natureza dos dados (distribuição da normalidade testes probabilísticos, avaliação de dados discrepantes, avaliação da tendência, emprego de testes estatísticos de hipóteses para comprovar a homogeneidade e estabilidade) (ABNT NBR ISO/IEC 17043:2011; ABNT ISO GUIA 35:2012; SANTANA, 2013).

A distribuição da normalidade é avaliada por testes estatísticos probabilísticos que verificam se a população de dados apresenta uma distribuição normal. Existem vários testes e são realizados em função do $\mathrm{n}$ de amostragem (ISO 5725-2, 2005; ABNT NBR ISO/IEC 17043:2011; ABNT ISO GUIA 35:2012; SANTANA, 2013). 
Os resultados discrepantes podem ocorrer entre o conjunto de dados e convém que sejam descartados ou, em algumas situações como erros de cálculo, estes podem ser substituídos por dados corrigidos. O ideal é que sejam aplicados pelo menos dois testes estatísticos antes da remoção dos dados. É indicado que os valores discrepantes em variâncias (ordens de magnitude diferentes) só sejam removidos em casos extremos, isto é, quando forem incompatíveis com o conjunto de dados. Normalmente, novas medições adicionais não são aceitáveis, pois as condições em que os dados foram obtidos não são mais as mesmas para todos os resultados (AMC, 1989a e 1989b; ABNT:NBR ISO/IEC 17043:2011; ABNT ISO GUIA 35:2012; SANTANA, 2013).

Os resultados obtidos no estudo de homogeneidade podem ser avaliados através da ferramenta estatística ANOVA-análise de variâncias fator único, desde que seja utilizado um método de medição com precisão compatível com a técnica de medição utilizada e se possível com um conjunto de dados que apresente um $n>10$. A população de dados deve apresentar distribuição normal com variâncias da mesma ordem de magnitude. A ANOVA está disponível na maioria dos softwares estatísticos, e neste caso considerase como homogêneo o material que apresentar 0 valor do teste

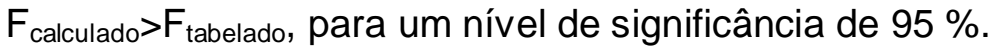

No caso do resultado da homogeneidade dentro do recipiente é considerado significativo, quando o desvio padrão de repetibilidade de medição, possivelmente em conjunto com a homogeneidade entre recipientes, for suficientemente pequeno.

Assim pode ser demonstrado que, se o desvio padrão de repetibilidade for comparável àquele do estudo de homogeneidade e da caracterização do material (por exemplo, a determinação do valor da propriedade), isto significa que este requisito está sendo atendido no que concerne à repetibilidade de medição (ABNT ISO GUIA 35:2012).

Deste modo, o efeito da heterogeneidade entre os recipientes pode ser reduzido tomando-se múltiplos recipientes em cada ponto no tempo. Essa abordagem pode ser necessária quando o desvio padrão de homogeneidade $s_{b b}$ é igual ou maior que a repetibilidade da medição. Se uma tendência for 
observada, isto significa, geralmente, que o material não poderá ser certificado (ABNT ISO GUIA 35:2012).

Para a avaliação dos dados obtidos pelo estudo de estabilidade, a análise de tendências é freqüentemente utilizada. Neste caso procura-se verificar a adequação dos dados ao modelo linear empregando-se o teste $F$ (VAN DER VEEN e PAUWELS, 2001; LISINGUER, 2001; ABNT ISO GUIDE 35:2012).

O modelo linear é expresso pela seguinte equação:

$$
Y=\beta_{0}+\beta_{1} X+\varepsilon
$$

Onde: $\beta_{0}$ é o coeficiente linear, $\beta_{1}$ o coeficiente de regressão, e $\varepsilon$ indica o componente de erro aleatório, $X$ variável independente, indicará o tempo e $Y$ variável dependente, indicará o valor de propriedade do MR.

Desta forma se o material for estável $\beta_{1}$ tenderá para zero. Como são utilizados mais de um recipiente por ponto no tempo e devido à repetição da medição mais de um valor de $Y$ estará disponível para cada $X$, logo é recomendável que estes aspectos sejam incluídos no modelo de estudo, podendo ser utilizado no caso de tendência o resultado médio de todos os recipientes no tempo X (VAN DER VEEN e PAUWELS, 2001; LISINGUER, 2001; ABNT ISO GUIDE 35:2012).

A avaliação da significancia de regressão dos dados se dará por meio de softwares de estátisitca, os quais irão fornecer uma tabela para o test $F$ (ABNT ISO GUIA 35:2012) (Tabela 7). 
Tabela 7 - Análise da variância para regressão linear

\begin{tabular}{ccccc}
\hline Fonte de variação & $\begin{array}{c}\text { Graus } \\
\text { lberdade }\end{array}$ & $\begin{array}{c}\text { Soma } \\
\text { quadrática } \\
S Q\end{array}$ & $\begin{array}{c}\text { Média } \\
\text { quadrática } \\
M Q\end{array}$ & $F$ \\
\hline Devido à regressão & 1 & $\sum_{i=1}^{n}\left(\hat{Y}_{i}-\bar{Y}\right)^{2}$ & $M Q r e g$ & $F=\frac{M Q_{\text {reg }}}{s^{2}}$ \\
$\begin{array}{c}\text { Sobre a regressão } \\
\text { (residual) }\end{array}$ & $n-2$ & $\sum_{i=1}^{n}\left(Y_{i}-\hat{Y}_{i}\right)^{2}$ & $s^{2}=\frac{S Q}{n-2}$ & \\
$\begin{array}{c}\text { Total, corrigido para } \bar{Y} \\
\text { médio }\end{array}$ & $n-1$ & $\sum_{i=1}^{n}\left(Y_{i}-\bar{Y}\right)^{2}$ & \\
\end{tabular}

Fonte:ABNT ISO GUIA 35:2012

A vantagem de se empregar a tabela $F$, ao invés do método utilizando o teste $t$, é que a mesma é gerada pela maioria dos softwares e pode ser estendida a outros modelos de regressão, o que a torna amplamente aplicável (ABNT ISO GUIA 35:2012).

Convém que para a certificação de um material seja adotado um critério baseado na incerteza (esperada) associada ao valor da propriedade do material de referência, no tempo (desejado) de prateleira e na tendência durante este período (ABNT ISO GUIA 35:2012).

Se a tendência for significativa durante o tempo (desejado) de prateleira com relação à incerteza associada ao valor da propriedade do MR, o material não poderá ser certificado devido à ausência de estabilidade ou, então, recomenda-se diminuir o tempo de prateleira (ABNT ISO GUIA 35:2012).

\subsection{Caracterização de um material de referência}

Os materiais de referência podem ser caracterizados baseando-se na exatidão de uma medida, com a melhor estimativa possível do "valor verdadeiro". Além disso, a precisão da medida não deve apresentar um desvio maior do que a sua incerteza de medição declarada (ABNT ISO GUIA 35:2012).

São apresentados na ABNT ISO GUIA 17034 (2017), algumas abordagens para a caracterização de alguns grupos de MR. A norma sugere a utilização de quatro abordagens básicas para a caracterização, as quais podem 
ser implementadas de diversas formas por produtores e órgãos de certificação como as que se seguem:

1. Medição por meio de um método (primário) único em um laboratório único;

2. Medição por meio de dois ou mais métodos de referência independentes em um laboratório, ou vários laboratórios;

3. Medição por meio de uma rede de laboratórios empregando um ou mais métodos com rastreabilidade;

4. Uma abordagem com método específico que fornece apenas os valores de propriedade específicos do método, utilizando uma rede de laboratórios (ABNT ISO GUIA 17034:2017).

Este material foi caracterizado por meio das técnicas de Davies \& Gray, gravimetria e ICPOES.

\subsection{Cálculo de Incertezas}

A estimativa da incerteza é geralmente realizada segundo os princípios estabelecidos pelo Guia para a Expressão da Incerteza de Medição ISO-GUM (GUM, 2008). O procedimento é baseado na identificação e quantificação, da influência de cada parâmetro analítico utilizado durante o processo de medição (ULRICH, 2011; GUM, 2008; VIM, 2012).

Assim, o cálculo é realizado a partir da identificação dos parâmetros intermediários da mensuração e as possíveis dispersões envolvidas nessa medição; combinação das contribuições de cada parâmetro para o cálculo da incerteza padrão combinada; aplicação do fator abrangência, $k$, para o cálculo da incerteza expandida, $U$, até a apresentação dos resultados (GUM, 2008, MOREIRA, 2010).

Este cálculo pode ser realizado por softwares, planilhas geradas por excel ou guias para cálculo de incertezas (ULRICH, 2011; SANTANA, 2013).

\subsection{Incerteza associada ao valor certificado}

O cálculo da incerteza do valor certificado de um material de referência considera a incerteza da homogeneidade, estabilidade a longo e curto prazo e a incerteza da caracterização do lote. Para tanto se recomenda utilizar a 
incerteza padrão combinada, já que esta leva em consideração todos os fatores que contribuem para a incerteza associada aos valores de propriedade do MRC (ABNT ISO GUIA 35:2012; VIM, 2012).

Logo a equação 8 expressa a incerteza associada ao valor de propriedade do material de referência:

$$
U_{\mathrm{MRC}}=k \sqrt{u_{\mathrm{car}}^{2}+u_{\mathrm{bb}}^{2}+u_{\mathrm{lts}}^{2}+u_{\mathrm{sts}}^{2}}
$$

Onde: $k$ = fator de abrangência baseado em um nível de confiança ideal de $95 \% ; u_{c a r}=$ incerteza de caracterização do mensurando obtida pela técnica analítica usada; $u_{b \boldsymbol{b}}=$ incerteza padrão da homogeneidade entre frascos; $u_{l t s}=$ incerteza padrão da estabilidade em longo prazo; $u_{s t s}=$ incerteza padrão da estabilidade em curto prazo. As principais fontes de incerteza são a incerteza de caracterização do material, a incerteza de homogeneidade, a incerteza de estabilidade a longo prazo e a incerteza de estabilidade a curto prazo.

\section{PARTE EXPERIMENTAL}

Para o desenvolvimento deste estudo foram utilizados os seguintes materiais, equipamentos e reagentes:

\subsection{Materiais e Equipamentos}

Béqueres de vidro borosilicato e polipropileno $400 \mathrm{~mL}$; Bastão de vidro; Colunas cromatográficas de vidro borosilicato com $18,0 \mathrm{~cm}$ de altura $\times 1,5 \mathrm{~cm}$ de diâmetro interno, leito de $20 \mathrm{~mL}$ e reservatório de $35 \mathrm{~mL}$; Dessecador de vidro borosilicato a vácuo com sílica gel; Erlenmeyer de vidro borosilicato 125 $\mathrm{mL}$; Estante suporte para funil de vidro; Funil de vidro borosilicato; Frascos de polipropileno com tabaque e tampa de rosca de $100 \mathrm{~mL}$; Algodão hidrófilo; Minicondensador de vidro borosilicato; Provetas de vidro borosilicato de $10 \mathrm{~mL}$ e $100 \mathrm{~mL}$; Tubos de polipropileno de $15 \mathrm{~mL}, 30 \mathrm{~mL}$ e $50 \mathrm{~mL}$; Pipeta de Pasteur de polipropileno.

Espectrômetro de emissão ótica com plasma indutivamente acoplado (ICPOES) Spectro Arcos CCD (Spectro Analytical Instruments 
Co,Kleve,Alemanha); Espectrômetro de fluorescência de raios X, A Rigaku Co., modelo RIX 3000; Balança analítica de 5 casas modelo ME 4145, (Sartorius, Brasil), precisão analítica $0,00001 \mathrm{~g}$; Balança digital de 2 casas modelo AS5500C (Marte, Brasil), precisão analítica $0,01 \mathrm{~g}$; Micropipetas automáticas (Wheaton, Suiça) $1-10 \mathrm{~mL}, 1-100 \mu \mathrm{L}, 1-10 \mu \mathrm{L}$; Chapa aquecedora modelo Q.313. A.21 Quimis Instrumentação Cientifica; pHmetro digital PG2000 sensibilidade 99,9\%, precisão de 0,05\%, eletrodo com sistema de referência $\mathrm{Ag} / \mathrm{AgCl}$ (GEHAKA Indústria e Comércio Eletroeletrônico LTDA, Brasil), Forno mufla digital modelo $\mathrm{F} 43$ precisão $1{ }^{\circ} \mathrm{C}$ (Eletrolab, Brasil), Estufa analógica precisão $1,3^{\circ} \mathrm{C}$ (Ética Equipamentos Científicos, Brasil); Analisador elementar LECO, modelo TCHEN600.

\subsubsection{Reagentes}

Ácido clorídrico P.A. da marca Merck ( $\mathrm{HCl})$; Ácido fosfórico P. A. da marca Merck $\left(\mathrm{H}_{3} \mathrm{PO}_{4}\right)$; Ácido nítrico P. A. da marca Merck $\left(\mathrm{HNO}_{3}\right)$; Ácido sulfâmico P. A. da marca Merck $\left(\mathrm{NH}_{2} \mathrm{SO}_{3} \mathrm{H}\right)$; Ácido sulfúrico P. A. da marca Merck $\left(\mathrm{H}_{2} \mathrm{SO}_{4}\right)$; Ácido Bórico P.A. da marca Merck $\left(\mathrm{H}_{3} \mathrm{BO}_{3}\right)$; Acetona P. A. da marca J. T. Backer; Água de alta pureza, com resistividade de $18,2 \mathrm{M} \Omega \mathrm{cm}$ a $25 \stackrel{\circ}{\circ}$ obtida pelo sistema Barnstead - Easypure, modelo D7031 (Barnstead Thermolyne, USA; Molibdato de amônio P. A. da marca Merck $\left(\left(\mathrm{NH}_{4}\right)_{6} \mathrm{Mo}_{7} \mathrm{O}_{24} \cdot 4 \mathrm{H}_{2} \mathrm{O}\right)$; Sulfato ferroso pureza $98 \%$ da marca Merck $\left(\mathrm{FeSO}_{4}\right)$; Sulfato de vanadil pureza $98 \%$ da marca Merck $\left(\mathrm{VOSO}_{4}\right)$; Dicromato de potássio pureza 99,8 \% da marca Merck $\left(\mathrm{K}_{2} \mathrm{Cr}_{2} \mathrm{O}_{7}\right)$; Metanol P. A. da marca Merck; Hidróxido de sódio pureza $98 \%$ da marca Merck $(\mathrm{NaOH})$; Fosfato de trin-butila P. A. da marca Aldrich Chemical (TBP); Resina Amberlite® XAD $420-$ 60 mesh, não iônica macroreticular da marca Rohm \& Haas $\left(800 \mathrm{~m}^{2} \mathrm{~g}^{-1}\right)$; Pó de cera C, Hoechst; Gás Argônio pureza 99,99 \%.

Padrões: CRM 112A: Óxido de urânio $\left(\mathrm{U}_{3} \mathrm{O}_{8}\right)$ proveniente do New Brunswick Laboratory, Departament of Energy D.O.E. CRM 124: Óxido de urânio $\left(\mathrm{U}_{3} \mathrm{O}_{8}\right)$ padrão para 24 Elementos de impurezas, proveniente do Brunswick Laboratory, Departament of Energy D. O.E (USA). 
Amostra: $1,580 \mathrm{Kg}$ de Pó de $\mathrm{U}_{3} \mathrm{Si}_{2}$, lote EULAB, Identificação: UNSI0515, fabricado pelo CCN IPEN-CNEN/SP em 09/12/2015.

\subsection{Metodologias}

A seguir são descritas as metodologias utilizadas para a dissolução e análise das amostras do material de referência de $\mathrm{U}_{3} \mathrm{Si}_{2}$ preparado.

\subsubsection{Preparo do Material de Referência}

O processo para a produção do material de estudo, 1,580 kg de Pó de $\mathrm{U}_{3} \mathrm{Si}_{2}$, foi realizado e fabricado pelo CCN IPEN-CNEN/SP em 09/12/2015, a partir do refugo de materiais de processo contendo urânio natural, conforme parte das etapas descritas no organograma da Figura 1 a Figura 4, redução a $\mathrm{U}^{0}$ e fusão com $\mathrm{Si}^{0}$, seguido do processo de moagem, conforme detalhamento citado nas páginas 35 a 37, processo de fabricação de siliceto de urânio.

A etapa de homogeneização foi realizada nos laboratórios do $\mathrm{CCN}$ em um homogeneizador mecânico modelo T2F Powder Blending (Willy A. Bachofen, Alemanha) pelo período de uma hora. Todas as estas etapas de preparo foram realizadas em um laboratório devidamente higienizado contendo um sistema de filtragem de ar central, ante-sala para paramentação adequada (EPI's foram utilizados adequadamente) e sistema de ar condicionado Figura 7.

O teor de umidade foi determinado em triplicata com cerca de 2,0 $\mathrm{g}$ de amostra, por meio da secagem em estufa a $150^{\circ} \mathrm{C} \pm 1^{\circ} \mathrm{C}$.

O estudo granulométrico foi realizado pelo $\mathrm{CCN}$, obtido por meio do método de análise de peneiração a seco ASTM B124-19, de acordo com as especificações adotadas pelo Centro para qualificação do Pó de $\mathrm{U}_{3} \mathrm{Si}_{2}$. 
Figura 7 - Fluxograma de Preparo do Material

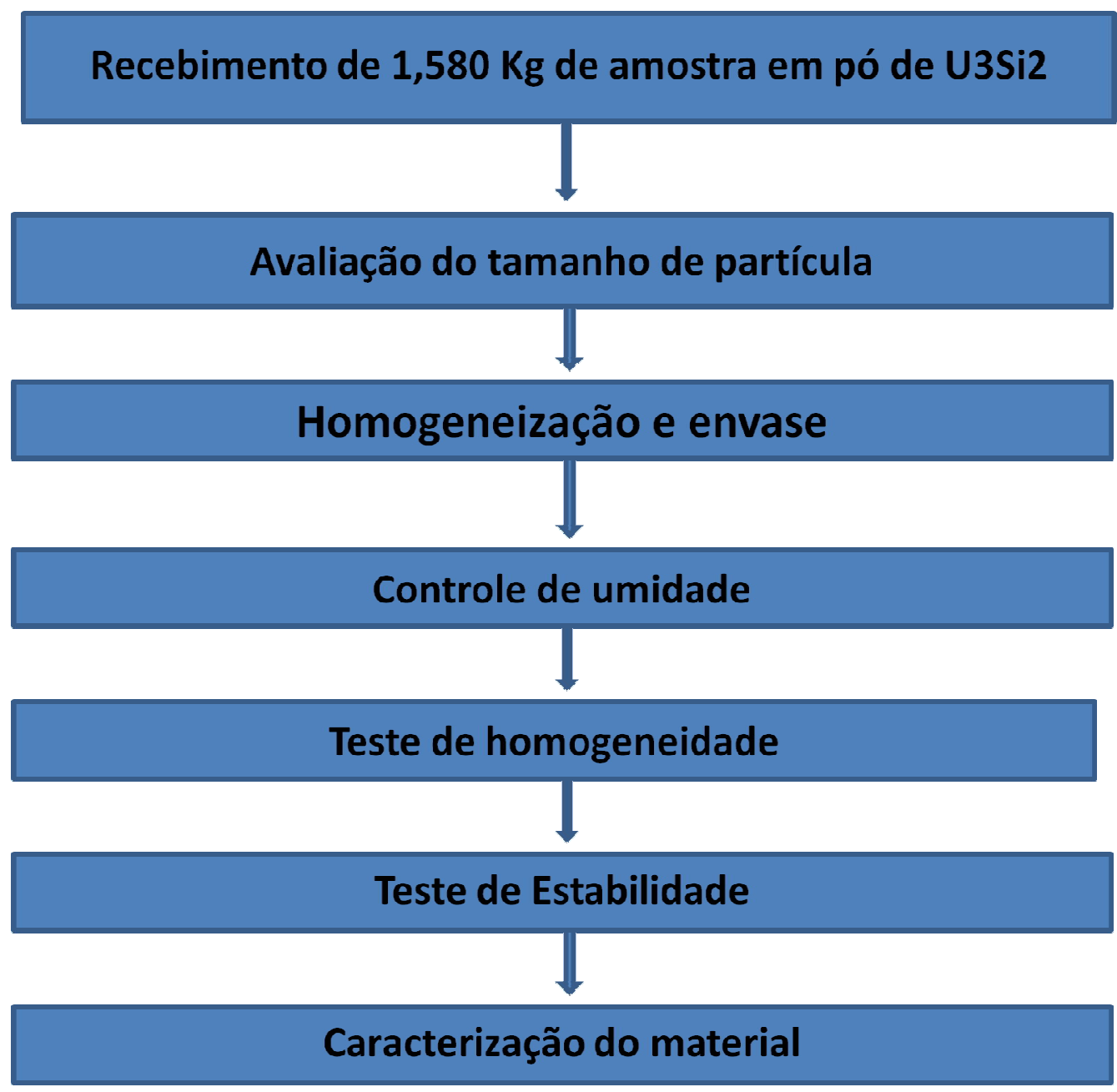

Fonte: Autora da tese

O preparo do material incluiu os testes de homogeneidade, massa mínima e estabilidade a curto e longo prazo. As etapas de preparo constituemse de homogeneização, envase, rotulação, estudo de massa mínima, estudo de homogeneidade, estudo de estabilidade e caracterização do material.

A seleção e armazenamento dos frascos para os estudos de homogeneidade e estabilidade foram processados no Centro de Química e Meio Ambiente, em sala reservada e devidamente higienizada e preparada para este fim. Deve ser salientado que todo material processado está contabilizado (o material foi transferido da contabilidade do CCN para contabilidade de salvaguardas do CQMA) sob salvaguardas. 


\subsubsection{Determinação de urânio total pelo método de Davies \& Gray/NBL}

Para a dissolução da amostra foram pesados $1,2 \mathrm{~g}$ de pó de $\mathrm{U}_{3} \mathrm{Si}_{2}$ em erlenmeyer de $250 \mathrm{~mL}$. Em seguida adicionou-se $10 \mathrm{~mL}$ de solução contendo o ácido clorídrico e ácido nítrico, "água régia" na proporção de 3:1. O erlenmeyer foi colocado em chapa de aquecimento ajustada em $40^{\circ} \mathrm{C}$ durante 30 minutos. Após resfriamento foram adicionados $5 \mathrm{~mL}$ de ácido sulfúrico concentrado e a solução retornou ao aquecimento por mais 40 minutos para completar 0 processo de dissolução (DAVIES \& GRAY, 1964; NBL-AS-U(E)-1, 2006).

Após o resfriamento adicionou-se $30 \mathrm{~mL}$ de ácido sulfúrico $0,5 \mathrm{~N}$ e procedeu-se a filtração para separação do silício, lavando-se o papel de filtro médio com ácido sulfúrico $0,5 \mathrm{~N}$, até a separação total não excedendo o volume final de solução de urânio de $90 \mathrm{~mL}$.

\subsubsection{Processo de Titulação do urânio com padrão de dicromato de potássio}

Uma alíquota retirada da solução final de urânio preparada conforme 0 item 5.2.2 foi ajustada para $22 \mathrm{mg}$ de urânio por mililitro de solução de acordo com o método (DAVIES \& GRAY, 1964; NBL-AS-U(E)-1, 2006), foi levada a secura em béquer de $400 \mathrm{~mL}$. Após resfriamento, foi colocada no béquer uma barra magnética e adicionados $14 \mathrm{~mL}$ de água deionizada e $40 \mathrm{~mL}$ de ácido fosfórico.

O béquer foi colocado em agitador magnético e procedeu-se a adição de $5 \mathrm{~mL}$ de solução de ácido sulfâmico 1,5 M. Em seguida foi adicionado $5 \mathrm{~mL}$ de solução de sulfato de Fe(II) no centro do béquer,após aguardar 30 segundos para reação. Adicionou-se $10 \mathrm{~mL}$ de solução oxidante de $\mathrm{HNO}_{3}$.

Verificou-se o ponto de reação quando o material atingiu coloração amarronzada, o agitador foi desligado por 3 minutos.

Após o intervalo de 3 minutos o material voltou a ser agitado onde foi adicionada $100 \mathrm{~mL}$ de solução de sulfato de vanadilo. Neste momento, foi inserido o eletrodo do pHmetro na solução e iniciou-se a titulação, manualmente, adicionando-se por gotejamento um solução padrão de dicromato de potássio previamente pesada (registrando a massa inicial)em uma pisseta, até a faixa de medição do pHmetro estar entre 580 a 605 mV. Ao 
término da titulação, a pisseta contendo solução padrão de dicromato de potássio foi novamente pesada e registrou-se a massa final para o calculo da concentração de urânio conforme equação 4 do item 4.3.1.

\subsubsection{Determinação de silício total por método gravimétrico}

Foi utilizado $1,2 \mathrm{~g}$ de pó de $\mathrm{U}_{3} \mathrm{Si}_{2}$ para determinação de silício total por gravimetria indireto, como é descrito no item 4.3.2. (IT-ATN NQ-24, 2008).

\subsubsection{Determinação de impurezas em amostras de $\mathrm{U}_{3} \mathrm{Si2}$ : Processo de dissolução e separação para análise de impurezas em por ICPOES}

As impurezas foram determinadas após o processo químico de separação aplicando a técnica de cromatografia de extração e posterior análise do eluído pelo método de ICPOES. A seguir são descritas as etapas do processo (COTRIM et. al., 2002; KAKAZU et. al., 2011).

\subsubsection{Preparação da resina}

O sistema cromatográfico utilizou a resina Amberlite XAD-4/TBP, para a montagem das colunas para a extração e separação do urânio das impurezas.

Pesou-se em um béquer de vidro $140 \mathrm{~g}$ de resina. OBS: Essa quantidade de resina é suficiente para o preparo de 4 colunas cromatografias para extração, nas dimensões: tamanho $(47 \mathrm{~cm})$; diâmetro $(1,5 \mathrm{~cm})$ e com o volume de reservatório $(250 \mathrm{~mL})$ e de leito $(60 \mathrm{~mL})$.

Em seguida, a resina foi previamente lavada, em "batch" com uma sequência, de soluções:

1ํ Solução contendo $70 \%$ (140mL) água e $30 \%$ (60 mL) metanol (v/v);

$2^{\circ}$ Solução contendo $50 \% \mathrm{NaOH}$ a $2 \mathrm{M}(100 \mathrm{~mL})$ e $50 \%$ metanol $(100 \mathrm{~mL}) 1: 1$ $(\mathrm{v} / \mathrm{v})$;

$3^{\circ}$ Solução contendo $50 \%$ água deionizada $(100 \mathrm{~mL})$ e $50 \%$ metanol $(100 \mathrm{~mL})$ $1: 1(\mathrm{v} / \mathrm{v})$;

4 Solução contendo $50 \% \mathrm{HCl} 2 \mathrm{M}(100 \mathrm{~mL})$ e $50 \%$ metanol $(100 \mathrm{~mL})$ 1:1 $(\mathrm{v} / \mathrm{v})$; 
50 Solução contendo $70 \%$ água deionizada (140 mL) e $30 \%$ metanol (60 mL) $(\mathrm{v} / \mathrm{v})$;

Após este pre-tratamento a resina foi seca em estufa a $60^{\circ} \mathrm{C}$ por aproximadamente 10 horas.

\subsubsection{Preparação do sistema extrator: Impregnação da resina com TBP- fosfato de tri-n-butila}

A resina pré-lavada e seca foi impregnada com TBP de pureza superior a $97 \%$, na proporção de $1,2 \mathrm{~mL}$ de TBP para cada $1 \mathrm{~g}$ de resina XAD-4 seca, diluído na proporção de $1 \mathrm{~g}$ de resina XAD-4 seca para 2,5 mL de Acetona.

A resina permaneceu na solução sob agitação, com barra magnética, por aproximadamente 1 hora em mesa agitadora sob aquecimento a $30{ }^{\circ} \mathrm{C}$

A secagem foi realizada a temperatura ambiente sob capela de exaustão até a resina ficar totalmente desagregada.

\subsubsection{Preparação da coluna de separação}

Uma coluna de extração foi preparada com aproximadamente $35 \mathrm{~g}$ de resina previamente impregnada com TBP, até a altura de $22 \mathrm{~cm}$. Algodão é utilizado na montagem da coluna, no fundo e no topo após o preenchimento com resina.

\subsubsection{Ativação da resina}

A resina foi condicionada com $120 \mathrm{~mL}$ de solução de $\mathrm{HNO}_{3} 5,5 \mathrm{M}$ a uma vazão de $2 \mathrm{~mL} \mathrm{~min}^{-1}$. A solução coletada foi descartada em frasco identificado para rejeito de ácido nítrico.

\subsubsection{Percolação da solução pela coluna}

Uma amostra de $2 \mathrm{~g}$ de siliceto de urânio, foi dissolvida como descrito no item 5.2.2, foi levada à secura, em béquer de teflon de $100 \mathrm{~mL}$, a $60^{\circ} \mathrm{C} \mathrm{e}$, em seguida, foi retomada com $20 \mathrm{~mL}$ de solução de ácido nítrico 5,5 M. Esta solução foi quantitativamente percolada na coluna cromatográfica em meio 
nítrico 5,5 M. O efluente da coluna foi coletado em 3 frações $\left(1^{\text {a }} 10 \mathrm{~mL}, 2^{2} 50\right.$ $\mathrm{mL}, 3^{\mathrm{a}}-50 \mathrm{~mL}$ ) em tubos de centrifuga de $50 \mathrm{~mL}$.

Para o branco foram percolados e coletados $50 \mathrm{~mL}$ de ácido nítrico a 5,5 $\mathrm{M}$, em uma única fração nas mesmas condições de fluxo.

\subsubsection{Eluição do urânio retido na coluna}

O urânio retido na coluna foi eluído com $300 \mathrm{~mL}$ de água deionizada, a um fluxo de 1 gota por segundo. A solução eluida foi coletada e identificada como rejeito contendo urânio natural. Para verificar a eluição completa do urânio, uma alíquota de $5 \mathrm{~mL}$ foi coleta em um béquer e adicionada 2 gotas de uma solução de ferrocianeto de potássio a $2 \%$, verificando-se a coloração. A coloração marrom é indicativa de presença de urânio no eluente.

\subsubsection{Preparo da curva de calibração para ICPOES}

Foram preparados 6 pontos de curva a partir de padrões analíticos certificados para análise pela técnica de ICPOES. (Merck, Supelco - $1000 \mathrm{mg}$ $\mathrm{mL}^{-1}$ ) em meio contendo ácido nítrico $1 \%$ para $\mathbf{A l}, \mathbf{B}, \mathbf{B a}, \mathbf{C a}, \mathbf{C d}, \mathbf{C o}, \mathbf{C r}, \mathbf{C u}$, $\mathrm{Fe}, \mathrm{Li}, \mathrm{Mg}, \mathrm{Mn}, \mathrm{Mo}, \mathrm{Ni}, \mathrm{Pb}, \mathrm{V}, \mathrm{Zn}$.

Para o elemento Sn os 6 pontos da solução da curva analítica foram preparados em meio contendo ácido clorídrico $10 \%$ para evitar interferentes.

Nas Tabelas 8 e 9 são apresentadas as concentrações utilizadas para a construção da curva analítica. 
Tabela 8- Concentrações dos elementos, considerados como impurezas, utilizadas para a preparação das Curvas analíticas

\begin{tabular}{|c|c|c|c|c|c|c|}
\hline \multirow[b]{2}{*}{ Elemento } & \multicolumn{6}{|c|}{$\begin{array}{l}\text { Concentração do Elemento em } \mathrm{HNO}_{3} 10 \% \\
\text { Por ponto da curva analítica }\left(\mu \mathrm{g} \mathrm{mL}{ }^{-1}\right)\end{array}$} \\
\hline & P1 & P2 & P3 & P4 & P5 & P6 \\
\hline Al & 50 & 25 & 5 & 2,5 & 0,5 & 0,25 \\
\hline B & 1 & 0,5 & 0,1 & 0,05 & 0,01 & 0,005 \\
\hline $\mathrm{Ba}$ & 10 & 5 & 1 & 0,5 & 0,1 & 0,05 \\
\hline $\mathrm{Ca}$ & 10 & 5 & 1 & 0,5 & 0,1 & 0,05 \\
\hline Cd & 1 & 0,5 & 0,1 & 0,05 & 0,01 & 0,005 \\
\hline Co & 1 & 0,5 & 0,1 & 0,05 & 0,01 & 0,005 \\
\hline $\mathrm{Cr}$ & 5 & 2,5 & 0,5 & 0,25 & 0,05 & 0,025 \\
\hline $\mathrm{Cu}$ & 10 & 5 & 1 & 0,5 & 0,1 & 0,05 \\
\hline $\mathrm{Fe}$ & 50 & 25 & 5 & 2,5 & 0,5 & 0,25 \\
\hline Li & 1 & 0,5 & 0,1 & 0,05 & 0,01 & 0,005 \\
\hline Mg & 5 & 2,5 & 0,5 & 0,25 & 0,05 & 0,025 \\
\hline Mn & 10 & 5 & 1 & 0,5 & 0,1 & 0,05 \\
\hline Mo & 5 & 2,5 & 0,5 & 0,25 & 0,05 & 0,025 \\
\hline $\mathbf{N i}$ & 5 & 2,5 & 0,5 & 0,25 & 0,05 & 0,025 \\
\hline $\mathrm{Pb}$ & 10 & 5 & 1 & 0,5 & 0,1 & 0,05 \\
\hline V & 5 & 2,5 & 0,5 & 0,25 & 0,05 & 0,025 \\
\hline $\mathrm{Zn}$ & 10 & 5 & 1 & 0,5 & 0,1 & 0,05 \\
\hline
\end{tabular}

Fonte: autora da tese

Tabela 9 - Concentração para preparação da curva analítica para o elemento Sn em meio $\mathrm{HCl} 10 \%$.

\section{Concentração do Elemento Estanho por ponto da curva analítica}

$\left(\mu \mathrm{g} \mathrm{mL}^{-1}\right)$

\begin{tabular}{ll|c|c|c|c|c}
\hline Elemento & P1 & P2 & P3 & P4 & P5 & P6 \\
\hline Sn & 25 & 2,5 & 0,25 & 1,0 & 0,5 & 0,25 \\
\hline
\end{tabular}

Fonte: autora da tese

\subsection{Preparo da amostra para técnica de WDXRF}

As amostras de $\mathrm{U}_{3} \mathrm{Si}_{2}$ foram preparadas na forma de pastilhas prensadas, denominadas neste estudo de pó- prensado (PR). Este processo foi realizado no LFX/CQMA (Metodologia segue PO-LFX-0903.004) de acordo com as seguintes etapas: $1,8 \mathrm{~g}$ de amostra de $\mathrm{U}_{3} \mathrm{Si}_{2}$ mais $0,5 \mathrm{~g}$ de cera (pó de cera $C$, Hoechst) foi transferida para uma garrafa de polietileno $\left(5 \mathrm{~cm}^{3}\right)$ e homogeneizada em um misturador mecânico para 5 min (Spex Mixer / Mill). A mistura foi compactada numa prensa hidráulica utilizando uma pressão de 20 
MPa durante 1 segundo numa base de ácido bórico (1,5 $\mathrm{g}$ de $\mathrm{H}_{3} \mathrm{BO}_{3}$, anteriormente comprimido com $100 \mathrm{MPa}$ durante 10 segundos; obtendo amostras pressionadas com 25,01 $\pm 0,01 \mathrm{~mm}$ de diâmetro e $5 \pm 1 \mathrm{~mm}$ de espessura e colocadas no suporte da amostra do espectrômetro, (SCAPIN et. al., 2011).

As amostras alimentadas prensadas (PR) foram analisadas usando 0 método da curva de calibração. As curvas de calibração individuais para Si e U também foram obtidas utilizando seis amostras de controle. Para cada material foram obtidas três medidas para SiKa e para linhas ULa, corrigidas pela Equação 9, com software acoplado ao espectrômetro (SCAPIN et. al., 2011).

$$
W_{i}=\left(a I_{i} * b I_{i}+c\right)\left(1+K+\sum A_{i j} F_{j}+\sum Q_{i j} F_{j} F_{k}+\sum \frac{R_{i j} F_{j}}{1+W_{i}}\right)+\sum D_{i j k} F_{j} F_{k}+C
$$

Onde: Wi é o valor de quantificação, a, b, coeficientes da curva de calibração c, li intensidade de raios- $X$, termo constante de $\mathrm{K}$, coeficiente de correção de absorção / absorção de Aij, valor de análise de Fj ou intensidade de raios-X do componente de correção, redução de absorção de Qij / excitação coeficiente (correção secundária), coeficiente de correção de excitação de Rij, coeficiente de correção de sobreposição de Bij, coeficiente de correção de absorção de dij / excitação e C é o termo constante. Foram utilizadas as seguintes condições de operação para SiKa e ULa (Tabela 10):

Tabela 10 - Condições de medição do espectrômetro WDXRF (RigakuCo., Modelo RIX 3000)

\begin{tabular}{ccc}
\hline & SiKa & ULa \\
Colimador & $160 \mathrm{Im}$ & $160 \mathrm{Im}$ \\
Cristal Analisador & $\mathrm{LiF}(200)$ & PET (111) \\
Detetor & FPC & SC \\
Contagem tempo (s) & 40 & 20 \\
Posição Bragg (2h) & 109,025 & 26,125 \\
Excitação (kV vs. mA) & 40930 & 40930 \\
\hline
\end{tabular}

LiF - Fluoreto de lítio, PET pentaeritritol, detector de cintilação SC - Nal / TI, contador proporcional de fluxo FPC.

Fonte: SCAPIN et al., 2011. 


\subsection{Estudo de homogeneidade}

Após a etapa de homogeneização o lote de material de $U_{3} \mathrm{Si}_{2}$ foi dividido em 60 frascos contendo cada um $27 \mathrm{~g}$ de material, os quais foram devidamente envasados em embalagens de vidro âmbar com tampa plástica de rosca. $O$ estudo de homogeneidade foi realizado tomando-se 3 replicatas de 8 frascos aleatoriamente e 3 replicatas de 1 frasco para o estudo dentro do frasco após envase das amostras.

Após a dissolução e diluição foram realizadas três titulações em cada uma das replicatas retiradas de cada frasco selecionado para as determinações de urânio total e silício total. Os resultados obtidos foram avaliados quanto à normalidade pelo teste de Shapiro-Wilks, presença de valores discrepantes (outliers) pelos testes de Grubbs e Cocrhan, e a homogeneidade foi demonstrada pela análise de variâncias (ANOVA).

Para determinar os teores de impurezas foram realizadas três pesagens de 2,0 g cada dos mesmos 8 frascos mencionados anteriormente. As amostras permaneceram a temperatura de $23 \pm 1{ }^{\circ} \mathrm{C}$ do início até o fim do estudo. Os resultados obtidos foram utilizados para análise estatística (ANOVA-fator único) a fim de indicar a homogeneidade do material ou se seria necessária uma nova etapa de homogeneização.

A análise comparativa realizada, utilizando a técnica de fluorescência de raios $X$ foi conduzida com $3,0 \mathrm{~g}$ de amostras em triplicata do conjunto de frascos anteriores selecionados para o estudo de homogeneidade. Os resultados obtidos também sofreram tratamento estatístico por (ANOVA-fator único) (SCAPIN et. al., 2011).

\subsection{Estudo de estabilidade}

O estudo de estabilidade foi realizado em curto prazo por meio do planejamento isócrono, simulando as possíveis condições de temperatura que poderiam ocasionar variação dos elementos de interesse no material produzido, durante o transporte e armazenamento. Assim, selecionou-se aleatoriamente 18 frascos do lote, os quais permaneceram nas temperaturas 
de 5,23 , e $50{ }^{\circ} \mathrm{C}$, pelo período de $0,1,3,6,12$ meses e foram analisados por meio de planejamento isócrono.

Para a avaliação dos resultados obtidos no teste de estabilidade foi utilizada ANOVA para análise de regressão linear e o Teste-t.

A estimativa da incerteza devido à estabilidade em curto prazo e longo prazo (usts/ulsts) foi obtida multiplicando-se o valor do erro padrão $(s(b 1))$ da variável $\mathrm{X}$, obtido na ANOVA, dos resultados do teste de estabilidade, pelo tempo t de $Y$ meses de estudo (ABNT ISO GUIA 35:2012).

\subsection{Caracterização do Material de Referência}

O material de referência foi caracterizado por meio da determinação dos teores de urânio, silício e impurezas, por medição realizadas no LAQA e também se considerando os estudos de homogeneidade e estabilidade em curto e longo prazo realizado.

\section{RESULTADOS E DISCUSSÕES}

\subsection{Resultados da caracterização química, física e composição isotópica}

A caracterização química do lote de pó de $\mathrm{U}_{3} \mathrm{Si}_{2}$ EULAB, Identificação: UNSI05, utilizado como matéria prima para o preparo do material de referência foi realizada por meio da determinação dos teores de urânio e silício, da análise de impurezas e dos gases $\mathrm{H}, \mathrm{N}_{2}, \mathrm{O}_{2}, \mathrm{C}, \mathrm{S}$ (Tabela 11) e Composição Isotópica (SKOOG; HOLLER; NIEMAN, 2002).

A caracterização química foi realizada no Laboratório de Análises Química e Ambiental (LAQA), Laboratório de Fluorescência de Raio X (LFX) do CQMA, segundo relatórios nำ 90/16, nº 119/16 (LAQA); № 057/17 (LFX) (Anexo 9). Este laboratório atende a caracterização e qualificação química do elemento combustível. 
Tabela 11 - Caracterização Química do lote de pó de $\mathrm{U}_{3} \mathrm{Si}_{2} \mathrm{EULAB}$, Identificação: UNSI05

\begin{tabular}{|c|c|}
\hline ELEMENTO & $\begin{array}{c}\text { Concentração Média } \pm \text { DP } \\
\left(\mu \mathrm{g} \mathrm{g}{ }^{-1} \text { massa de } U_{3} \mathrm{Si}_{2}\right)\end{array}$ \\
\hline $\mathrm{Al}$ & $144 \pm 1$ \\
\hline B & $1 \pm 0,1$ \\
\hline $\mathrm{Ca}$ & $1 \pm 0,1$ \\
\hline $\mathrm{Cd}$ & $0,3 \pm 0,1$ \\
\hline Co & $0,3 \pm 0,1$ \\
\hline $\mathrm{Cr}$ & $28 \pm 1$ \\
\hline $\mathrm{Cu}$ & $27 \pm 0,5$ \\
\hline $\mathrm{Fe}$ & $359 \pm 0,5$ \\
\hline $\mathrm{Li}$ & $0,2 \pm 0,1$ \\
\hline $\mathrm{Mg}$ & $7,6 \pm 0,3$ \\
\hline $\mathrm{Mn}$ & $100 \pm 0,5$ \\
\hline Mo & $3 \pm 0,1$ \\
\hline $\mathrm{Ni}$ & $14 \pm 0,3$ \\
\hline $\mathrm{Pb}$ & $4 \pm 0,1$ \\
\hline Sn & $9 \pm 0,1$ \\
\hline V & $5 \pm 0,1$ \\
\hline $\mathrm{Zn}$ & $8 \pm 0,1$ \\
\hline $\mathrm{Ba}$ & $1 \pm 0,1$ \\
\hline $\mathrm{N}$ & $122 \pm 15$ \\
\hline $\mathrm{O}$ & $1250 \pm 25$ \\
\hline $\mathrm{H}$ & $44 \pm 11$ \\
\hline $\mathrm{C}$ & $0,05 \pm 0,02(\%)$ \\
\hline$S$ & $0,04 \pm 0,01(\%)$ \\
\hline Composição & (\%) \\
\hline$U$ & $91,8 \pm 0,1$ \\
\hline $\mathrm{Si}$ & $7,6 \pm 0,1$ \\
\hline
\end{tabular}

Fonte: autora da tese; Ref: Relatórios de análise interno: oํ 90/16, № 119/16 (LAQA); no 057/17 (LFX) (Anexo 9).

Os elementos $\mathrm{H}, \mathrm{N}_{2}, \mathrm{O}_{2}, \mathrm{C}, \mathrm{S}$, foram determinados por adsorção na região do infravermelho e o Nitrogênio por condutividade térmica (SKOOG; HOLLER; NIEMAN, 2002). (Relatório de Análise no 119/16, Laboratório de Análises Química e Ambiental (LAQA)).

Quanto ao teor de umidade: O Pó de $\mathrm{U}_{3} \mathrm{Si}_{2}$ em estudo apresentou ser estável quanto ao teor de umidade com uma variação de 0,0001 \% em relação ao peso inicial da amostra. 
Quanto à composição granulométrica (ASTM B124-19): o Pó de $\mathrm{U}_{3} \mathrm{Si}_{2}$ apresentou-se entre 150 a $44 \mu \mathrm{m}$, com máximo de $20 \%$ em peso de partículas menores que $44 \mu \mathrm{m}$.

A razão isotópica de urânio foi determinada por espectrometria de massas por termo ionização, utilizando o método da evaporação total. A determinação foi realizada no Laboratório de Caracterização de Urânio do Centro de Tecnologia da Marinha SP, sob responsabilidade do Dr. Olívio Pereira de Oliveira Jr. Os resultados de 3 amostras independentes são apresentados na Tabela 12.

Tabela 12 - Composição Isotópica de Urânio do lote utilizado

\begin{tabular}{c|c|c|c|c|c}
\hline \multicolumn{3}{c|}{ Razão Isotópica } & \multicolumn{3}{c}{ Fração Mássica } \\
\multicolumn{2}{|c|}{$(\%)$} \\
\hline $\mathrm{n}\left({ }^{234} \mathrm{U}\right) / \mathrm{n}\left({ }^{238} \mathrm{U}\right)$ & $\mathrm{n}\left({ }^{235} \mathrm{U}\right) / \mathrm{n}\left({ }^{238} \mathrm{U}\right)$ & $\mathrm{n}\left({ }^{236} \mathrm{U}\right) / \mathrm{n}\left({ }^{238} \mathrm{U}\right)$ & $\mathrm{m}\left({ }^{234} \mathrm{U}\right) / \mathrm{m}(\mathrm{U})$ & $\mathrm{m}\left({ }^{235} \mathrm{U}\right) / \mathrm{m}(\mathrm{U})$ & $\mathrm{m}\left({ }^{236} \mathrm{U}\right) / \mathrm{m}(\mathrm{U})$ \\
\hline 0,0000585 & 0,007343 & - & 0,0057 & 0,7197 & - \\
$(70)^{*}$ & $(19)^{*}$ & - & $(10)^{*}$ & $(27)^{*}$ & - \\
\hline
\end{tabular}

*A incerteza de medição: incerteza expandida, apresentada entre parênteses. Fonte: Relatório CTMSP/LCU nº 08/2017

Os resultados observados na Tabela 12 demonstram que o lote de material produzido é majoritariamente composto por urânio natural como uma leve contaminação por urânio enriquecido $(0,005) \quad \mathrm{m}\left({ }^{234} \mathrm{U}\right) / \mathrm{m}\left({ }^{238} \mathrm{U}\right) /$ $\left.0,711 \mathrm{~m}\left({ }^{235} \mathrm{U}\right) / \mathrm{m}\left({ }^{238} \mathrm{U}\right)\right)$.

\subsection{Resultados do estudo de massa mínima para U por Davis \& Gray e Si por gravimetria}

Para os elementos urânio e silício, o estudo da massa mínima foi realizado com 6 porções da amostra, por meio de determinações totais com intervalo de massa de 0,5 a 1,2 g, e 2,5 a 3,2 g respectivamente por meio das técnica de Davies \& Gray e gravimétrica. Os resultados estão apresentados na figura 6.

Observou-se que o valor médio do desvio era igual a 0,16 0,04\% (U total), que representa uma variação de 0,05 a 0,28 \% sobre o peso, e 0,35 \pm $0,7 \%$ (Si total), que variam 0,08-0,84\% (Figura 8). 
Figura 8 - Gráficos do desvio padrão relativo obtido na determinação de U e Si no intervalo de massa estudado
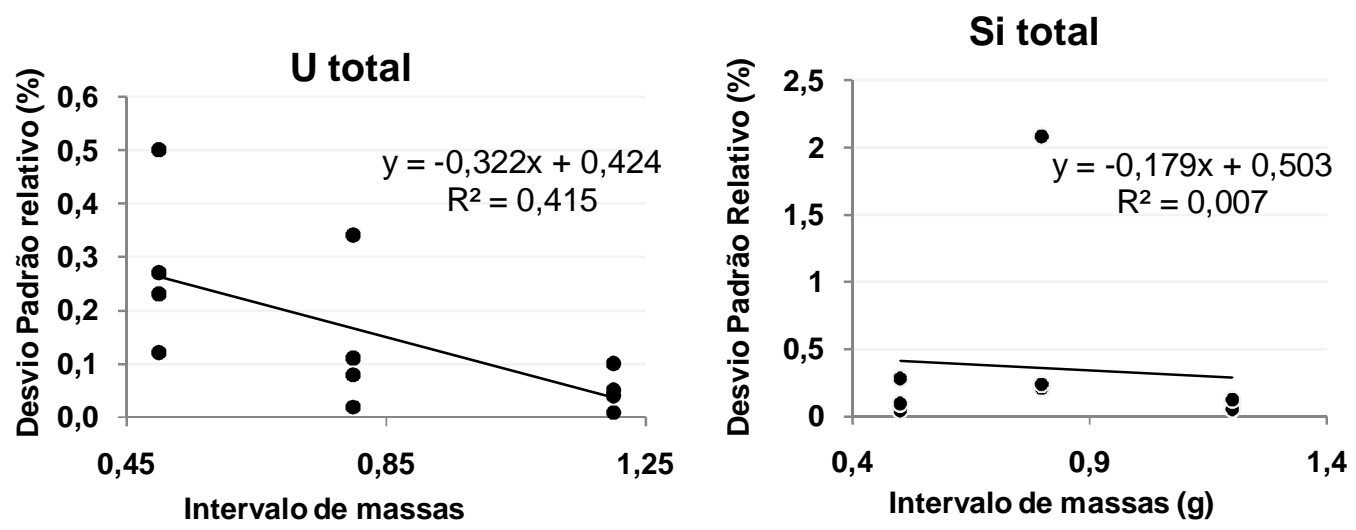

Fonte: Autora da tese

O DPR \% foi maior que o sr (desvio padrão de repetibilidade), para todas as massas utilizadas, optando-se por $1,2 \mathrm{~g}$ como a massa ideal.

\subsection{Resultados do estudo de homogeneidade para U por Davies \& Gray e Si por gravimetria}

Foram selecionados 08 frascos e realizadas três pesagens de $1,2 \mathrm{~g}$ de cada frasco, para determinar os teores de urânio e silício. Os resultados obtidos foram submetidos à análise estatística (ANOVA-fator único) a fim de indicar a homogeneidade do material ou se seria necessária uma nova etapa de homogeneização.

$\mathrm{Na}$ Tabela 13 são apresentados os resultados obtidos no estudo de homogeneidade, após aplicação da estatística ANOVA fator único. 
Tabela 13 - Resultados do estudo de homogeneidade referente à concentração média, variância, desvio padrão, DPR e resultados da ANOVA, calculados na determinação de urânio total por titulometria e silício total por gravimetria nas amostras preservadas a temperatura de $23 \pm 1{ }^{\circ} \mathrm{C}$

\begin{tabular}{ccc}
\hline \multirow{2}{*}{ Frascos $\left(\mathbf{n}^{\circ}\right)$} & Concentração (\%) \\
\cline { 2 - 3 } & Urânio total & Silício total \\
\hline 7 & $91,80 \pm 0,12$ & $7,61 \pm 0,03$ \\
15 & $91,75 \pm 0,06$ & $7,61 \pm 0,01$ \\
23 & $91,67 \pm 0,30$ & $7,63 \pm 0,02$ \\
27 & $91,79 \pm 0,07$ & $7,59 \pm 0,01$ \\
31 & $91,76 \pm 0,23$ & $7,58 \pm 0,02$ \\
36 & $91,90 \pm 0,17$ & $7,57 \pm 0,04$ \\
38 & $91,60 \pm 0,15$ & $7,58 \pm 0,02$ \\
58 & $91,76 \pm 0,16$ & $7,63 \pm 0,01$ \\
\hline Média \pm DP & $\mathbf{9 1 , 7 5 \pm 0 , 1 6}$ & $\mathbf{7 , 6 0 \pm 0 , 0 2}$ \\
\hline Variância & 0,032 & 0,0006 \\
DPR \% & 0,2 & 0,3 \\
F $_{\text {calculado }}$ & $\mathbf{0 , 5 3}$ & $\mathbf{2 , 3 2}$ \\
$\mathrm{F}_{\text {tabelado }}$ & 2,66 & 2,66 \\
valor-P & 0,59 & 0,68 \\
Incerteza & gl(total)= 23 & $\mathbf{0 , 0 4}$ \\
homogeneidade (ubb) & \multicolumn{2}{c}{} \\
\hline $\mathrm{n}=24 ;$ DPR \% - desvio padrão relativo percentual, F-valor obtido para teste de \\
Fisher, valor-P para 95\% de confiança, gl-grau de liberdade. \\
Fonte: autora da tese
\end{tabular}

Os resultados obtidos através da ANOVA para o U e Si apresentados na Tabela 12 confirmaram não haver diferenças significativas entre eles avaliando-

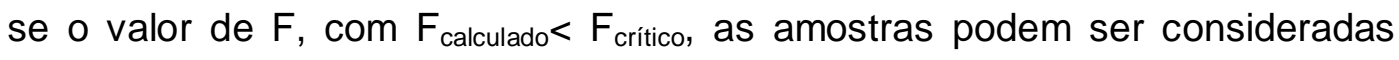
homogêneas para os elementos estudados.

A análise de tendência foi realizada através da regressão linear via excel $\AA$, demonstraram não haver tendência nos resultados obtidos (Tabela13), avaliando-se o valor-P (probabilidade do valor do teste $t$ tabelado ser $\geq$ ao teste t calculado), ou seja, valor-p adotado ao nível de significância (igual a 0,05) dever ser maior que 0,05 , para indicar que não há tendência. 


\subsection{Resultados do estudo de estabilidade em curto e longo prazo para U por Davies \& Gray e Si por gravimetria}

Os resultados obtidos no estudo de estabilidade do material preservado a diferentes temperaturas são mostrados na Tabela 14, após aplicação da estatística de regressão linear via excel®.

Tabela 14 - Resultados do estudo de estabilidade, referente à concentração média, desvio padrão, resultados do estudo de regressão, calculados na determinação de urânio total e silício total, em \%, nas amostras

\begin{tabular}{|c|c|c|}
\hline \multirow{2}{*}{ Temperatura } & \multicolumn{2}{|c|}{ Concentração (\%) } \\
\hline & U total & Si total \\
\hline $5 \pm 2{ }^{\circ} \mathrm{C}$ & $91,92 \pm 0,03$ & $7,61 \pm 0,05$ \\
\hline $23 \pm 1^{\circ} \mathrm{C}$ & $91,96 \pm 0,1$ & $7,58 \pm 0,02$ \\
\hline $50 \pm 2^{\circ} \mathrm{C}$ & $91,94 \pm 0,1$ & $7,56 \pm 0,04$ \\
\hline Media \pm DP & $91,94 \pm 0,08$ & $7,58 \pm 0,04$ \\
\hline DPR (\%) & 0,09 & 0,52 \\
\hline Valor-P (95\%) & 0,46 & 0,06 \\
\hline Inclinação $\left(b_{1}\right)$ & $-2,84 \mathrm{E}-14$ & $-2,66 E-15$ \\
\hline $\begin{array}{l}\text { Erro padrão Inclinação } \\
\qquad\left(s\left(b_{1}\right)\right)\end{array}$ & 0,01 & 0,0003 \\
\hline$\left|b_{1}\right|<t(0,95, n-2)^{*} s\left(b_{1}\right)$ & $2,84 E-14<0,036$ & $2,66 E-15<0,006$ \\
\hline Usts & 0,03 & 0,004 \\
\hline Ults & 0,10 & 0,02 \\
\hline
\end{tabular}

$\mathrm{n}=12$; usts = incerteza de estabilidade em curto prazo; ults = incerteza de estabilidade em longo prazo.

Fonte: autora da tese

De acordo com os dados estatísticos obtidos por meio do cálculo da inclinação da reta de regressão b1, foram: $|\mathrm{b} 1|=2,84 \mathrm{E}-14<\mathrm{t} 0,95, \mathrm{n}-2 \mathrm{X}$ $s(b 1)=0,036$, para o elemento $U$ total e $|b 1|=2,66 E-15<t 0,95, n-2 X$ $s(b 1)=0,006$ para o elemento Si total. Portanto foi confirmada a estabilidade para amostras mantidas no intervalo de temperatura de 5 a $50{ }^{\circ} \mathrm{C}$.

\subsubsection{Representação gráfica dos resultados para U pelo método de Davies \& Gray e Si pelo método de Gravimetria}

As figuras 9 e 10 apresentadas abaixo ilustram graficamente os resultados obtidos, como que foi descrito no item 6.4. 
Figura 9 - Gráfico dos resultados da análise de regressão para o estudo de estabilidade para silício em diferentes temperaturas e períodos de tempo

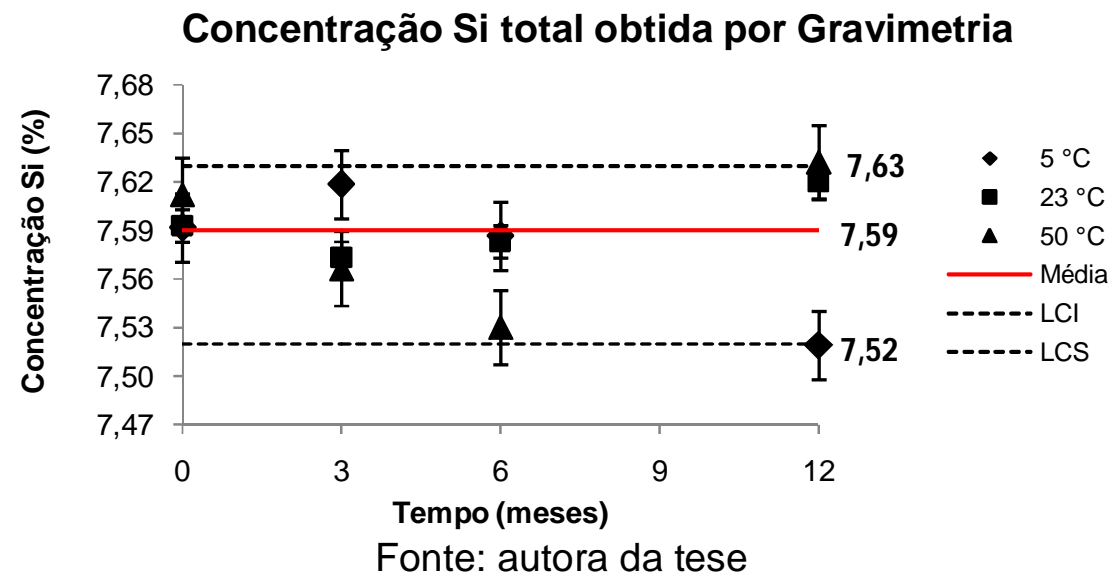

Figura 10 - Gráfico dos resultados da análise de regressão para o estudo de estabilidade para urânio em diferentes temperaturas e períodos de tempo

Concentração U total obtida por Davies \& Gray

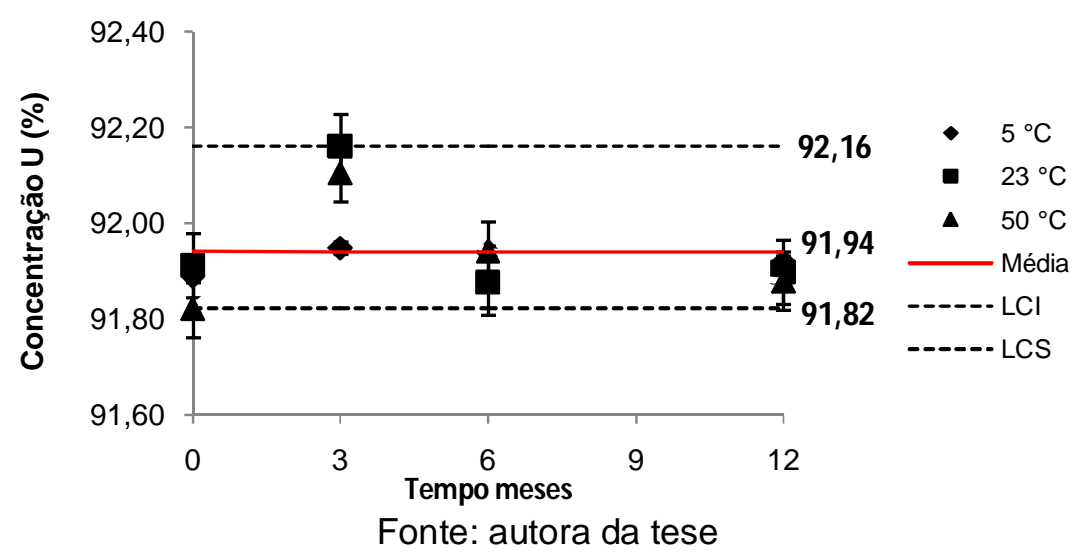

6.5 Resultados do estudo de homogeneidade para U e Si pelo método WDXRF

Os resultados obtidos para o estudo de homogeneidade pelo método WDXRF são apresentados na Tabela 15. 
Tabela 15 - Resultados do estudo de homogeneidade referente à concentração, média, variância, desvio padrão, DPR e resultados da ANOVA, calculados na determinação de urânio e silício totais, em \%, nas amostras a temperatura de $23 \pm 1{ }^{\circ} \mathrm{C}$ analisadas por WDXRF

\begin{tabular}{|c|c|c|c|}
\hline \multirow{2}{*}{ Frasco $\left(n^{\circ}\right)$} & \multicolumn{3}{|c|}{ Concentração (\%) } \\
\hline & & Urânio total & Silício total \\
\hline 7 & & $91,17 \pm 0,03$ & $7,80 \pm 0,001$ \\
\hline 15 & & $91,18 \pm 0,01$ & $7,80 \pm 0,001$ \\
\hline 23 & & $91,16 \pm 0,02$ & $7,81 \pm 0,001$ \\
\hline 27 & & $91,17 \pm 0,02$ & $7,80 \pm 0,001$ \\
\hline 31 & & $91,16 \pm 0,02$ & $7,80 \pm 0,001$ \\
\hline 36 & & $91,18 \pm 0,02$ & $7,80 \pm 0,002$ \\
\hline 38 & & $91,18 \pm 0,02$ & $7,80 \pm 0,002$ \\
\hline 58 & & $91,18 \pm 0,02$ & $7,80 \pm 0,001$ \\
\hline Média $\pm \mathrm{DP}$ & & $91,18 \pm 0,01$ & $7,80 \pm 0,0004$ \\
\hline Variância & & 0,00008 & 0,000003 \\
\hline DPR $\%$ & & 0,01 & 0,005 \\
\hline $\mathrm{F}_{\text {calculado }}$ & & 2,78 & 0,54 \\
\hline$F_{\text {tabelado }}$ & $\mathrm{gl}($ total $)=23$ & 3,47 & 3,47 \\
\hline valor-P & & 0,08 & 0,59 \\
\hline ubb & & 0,003 & 0,0003 \\
\hline
\end{tabular}

$\mathrm{n}=12$; DPR \%-desvio padrão relativo percentual, F-valor obtido para teste deFisher, valor-P para $95 \%$ de confiança, gl-grau de liberdade, ubb = incerteza de homogeneidade.

Fonte: autora da tese

Os resultados obtidos por meio da ANOVA para o $\mathrm{U}$ e Si totais obtidos por WDXRF confirmaram não haver diferenças significativas entre eles avaliando-se o valor de $F$, com $F_{\text {calculado }}<F_{\text {crítico, as amostras podem ser }}$ consideradas homogêneas para os elementos estudados.

\subsection{Resultados do estudo de estabilidade em curto e longo prazo para U e Si pelo método WDXRF}

A análise de tendência foi realizada através da regressão linear via excel®, demonstrando não haver tendência nos resultados obtidos (Tabela 16), avaliando-se o valor-P (probabilidade do valor do teste $\mathrm{t}$ tabelado ser $\geq$ ao teste 
t calculado), ou seja, valor-p adotado ao nível de significância (igual a 0,05) dever ser maior que 0,05 , para indicar que não há tendência.

Tabela 16 - Resultados do estudo de estabilidade, referente à média, desvio padrão, resultados do estudo de regressão, calculados na determinação de urânio total e silício total, em \%, nas amostras analisadas por WDXRF

\begin{tabular}{ccc}
\hline \multirow{2}{*}{ Temperatura } & \multicolumn{2}{c}{ Concentração $(\%)$} \\
\cline { 2 - 3 } & U total & Si total \\
\hline $5 \pm 2{ }^{\circ} \mathrm{C}$ & $91,15 \pm 0,02$ & $7,80 \pm 0,002$ \\
$23 \pm 1{ }^{\circ} \mathrm{C}$ & $91,18 \pm 0,02$ & $7,80 \pm 0,002$ \\
$50 \pm 2{ }^{\circ} \mathrm{C}$ & $91,14 \pm 0,02$ & $7,80 \pm 0,002$ \\
\hline Media $\pm \mathrm{DP}$ & $\mathbf{9 1 , 1 6 \pm 0 , 0 2}$ & $\mathbf{7 , 8 0} \pm \mathbf{0 , 0 0 2}$ \\
\hline DPR \% & 0,02 & 0,03 \\
Valor- $P(95 \%)$ & 0,1 & 0,44 \\
Inclinação $\left(b_{1}\right)$ & $-0,002$ & 0 \\
Erro padrão Inclinação & 0,0006 & 0,0001 \\
$\left(s\left(b_{1}\right)\right)$ & $|\mathbf{0 , 0 0 2}|<\mathbf{0 , 0 0 5}$ & $\mathbf{0} 0 \mathbf{0 , 0 0 0 5}$ \\
$\left|b_{1}\right|<t(0,95, n-2)^{*} s\left(b_{1}\right)$ & $\mathbf{0 , 0 0 3 6}$ & $\mathbf{0 , 0 0 0 3}$ \\
usts & $\mathbf{0 , 0 1 5}$ & $\mathbf{0 , 0 0 1}$ \\
ults &
\end{tabular}

$\mathrm{n}=12$; usts = incerteza de estabilidade em curto prazo; ults = incerteza de estabilidade em longo prazo.

Fonte: autora da tese

Observando-se resultados obtidos por meio do cálculo da inclinação da reta de regressão $b 1$, foram: $|\mathrm{b} 1|=-0,002<\mathrm{t0}, 95, \mathrm{n}-2 \times \mathrm{s}(\mathrm{b} 1)=0,005,|\mathrm{~b} 1|=0<$ t0,95, $n-2 \times s(b 1)=0,0005$, para os elementos $U$ total e $\mathrm{Si}$ total, respectivamente. Portanto foi confirmada a estabilidade para amostras mantidas no intervalo de temperatura de $5 \pm 2{ }^{\circ} \mathrm{C}, 23 \pm 1^{\circ} \mathrm{C}$ e $50 \pm 2{ }^{\circ} \mathrm{C}$, para as amostras analisadas por WDXRF.

Observando-se os resultados apresentados nas TABELAS 14 e 15, nota-se uma variação em torno de 0,57 \% para o elemento urânio e 0,20 \% para o elemento silício a partir dos resultados obtidos pela técnica de WDXRF, esta variação pode estar associado à maior sensibilidade analítica obtida para a determinação de urânio pela técnica de titulometria e de silício por gravimetria, pois possíveis interferentes como $\mathrm{Ag}, \mathrm{Hg}, \mathrm{V}, \mathrm{Pt}, \mathrm{Rh}, \mathrm{Os}, \mathrm{Ir}, \mathrm{F}$ e I quando presentes em quantidade na ordem de miligramas são eliminados em 
quantidades significativas durante as etapas de preparo da amostra (FURMAN, 1975).

\subsubsection{Representação gráfica dos resultados para U e Si pelo método de WDXRF}

Os resultados do teste de ANOVA para a regressão linear, apresentados na Tabelas 14 e 15, mostraram que para os elementos analisados por WDXRF, $F$ calculado foi menor que $F$ crítico, e o valor de $p$, maior que 0,05, e, portanto, não foi verificada tendência, nem durante o processo de medição, nem em função da ordem do tempo de exposição, confirmando-se as conclusões obtidas a partir dos gráficos de regressão linear.

Nas figuras 11 e 12 apresentamos resultados, conforme descrito no item 7.5, onde LCI corresponde ao menor valor encontrado para o analito e LCS o maior valor encontrado.

Figura 11 - Gráfico dos resultados da análise de regressão para o estudo de estabilidade para urânio em diferentes temperaturas e períodos de tempo por WDXRF

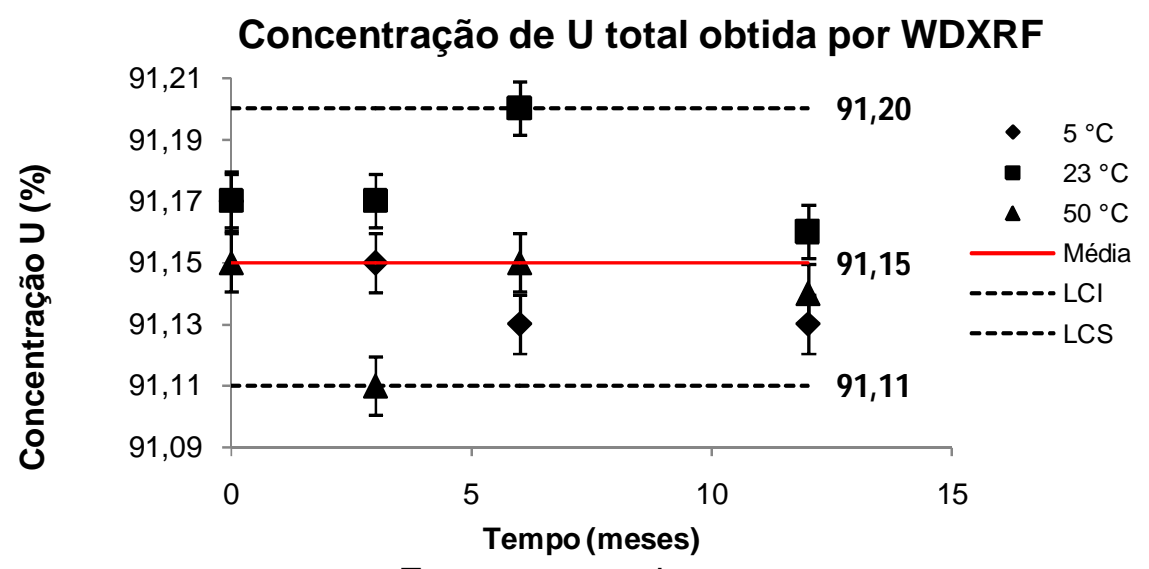

Fonte: autora da tese 
Figura 12 - Gráfico dos resultados da análise de regressão para o estudo de estabilidade para silício em diferentes temperaturas e períodos de tempo WDXRF

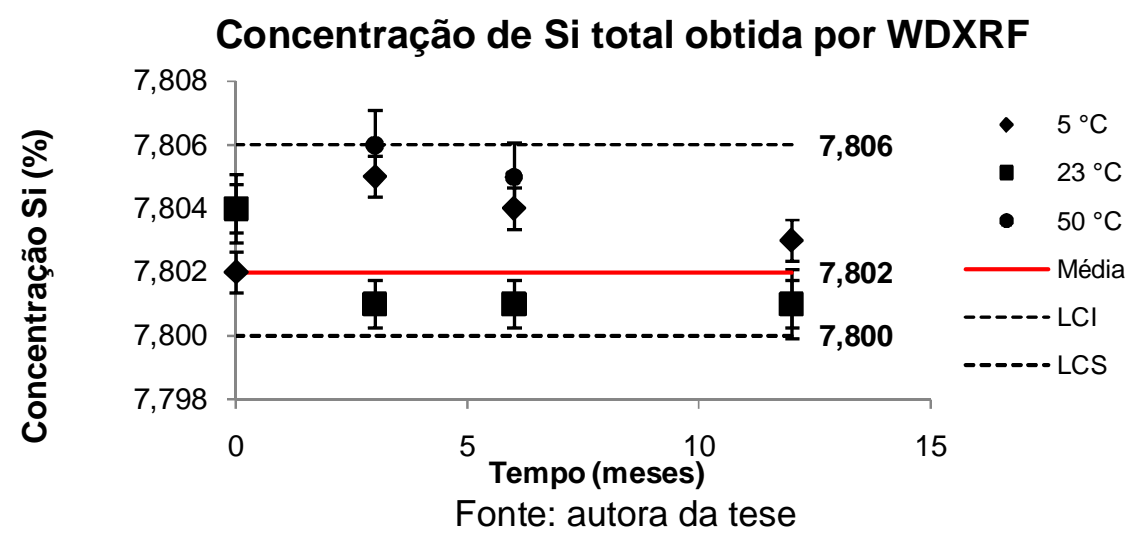

A aplicação do método de WDXRF ao estudo de estabilidade em longo prazo corroborou os resultados obtidos pelos métodos de Davies \& Gray e gravimetria, ressaltando que não houve mudanças significativas na concentração dos elementos estudados durante o período do teste. Garantindo, então, que o candidato a material de referência de $\mathrm{U}_{3} \mathrm{Si}_{2}$ é suficientemente estável para ser armazenado à temperatura ambiente, sem alterações significativas na composição dos elementos estudados.

\subsection{Estimativa das incertezas e valor de propriedade para U e Si totais}

A incerteza para caracterização foi estimada usando-se o cálculo da incerteza expandida para determinação de Urânio e Silício, realizado em uma planilha do programa Windows Excel ${ }^{\circledR}$ desenvolvida no laboratório, baseada no GUM.

Os cálculos foram realizados com o valor das concentrações médias das amostras de candidato a material de referência e do material de referência certificado 129A-óxido de urânio $\left(\mathrm{U}_{3} \mathrm{O}_{8}\right.$ natural) para ensaio padrão isotópico e ensaio padrão em fração mássica $=0,847698 \pm 0,000090 \mathrm{~kg} \mathrm{U}$ $\mathbf{k g}^{-1}$.

Os resultados da incerteza de medição obtidos podem ser observados nas Tabelas 17 e 18 para os métodos analíticos utilizados nas medições dos elementos de interesse. 
A incerteza padrão de homogeneidade foi calculada de acordo com a equação (2) como descrito no item 4.9. Sua escolha foi determinada porque o $\mathrm{s}_{\mathrm{r}}$ - desvio padrão de repetibilidade foi maior do que o desvio padrão de homogeneidade $\mathrm{s}_{\mathrm{bb}}$, para as amostras.

A incerteza padrão de estabilidade foi calculada considerando as incertezas de estabilidade em curto prazo e em longo prazo (equação 3).

Tabela 17- Estimativa das incertezas padrão combinadas para os elementos $U$ total por Davies \& Gray e Si total por gravimetria

\begin{tabular}{ccccc}
\hline Elemento & $\mathbf{u}_{\mathrm{car}}$ & $\mathbf{u}_{\mathrm{bb}}$ & $\mathbf{u}_{\text {sts }}$ & $\mathbf{u}_{\text {tss }}$ \\
& $\%$ & $\%$ & $\%$ & $\%$ \\
\hline $\mathrm{U}$ & 0,24 & 0,04 & 0,003 & 0,10 \\
\hline $\mathrm{Si}$ & 0,03 & 0,005 & 0,004 & 0,02
\end{tabular}

Ucar = incerteza de caracterização; ubb = incerteza de homogeneidade; usts = incerteza de estabilidade em curto prazo e ults = incerteza de estabilidade em longo prazo.

Fonte: autora da tese

Tabela 18 - Estimativa das incertezas padrão combinadas para os elementos $U$ total e Si total por WDXRF

\begin{tabular}{ccccc}
\hline \multirow{2}{*}{ Elemento } & $\mathbf{u}_{\text {car }}$ & $\mathbf{u}_{\mathbf{b b}}$ & $\mathbf{u}_{\text {sts }}$ & $\mathbf{u}_{\text {Its }}$ \\
& $\%$ & $\%$ & $\%$ & $\%$ \\
\hline $\mathrm{U}$ & 0,05 & 0,03 & 0,004 & 0,015 \\
\hline $\mathrm{Si}$ & 0,004 & 0,0003 & 0,0003 & 0,001 \\
\hline
\end{tabular}

Ucar = incerteza de caracterização; ubb = incerteza de homogeneidade; usts = incerteza de estabilidade em curto prazo e ults = incerteza de estabilidade em longo prazo.

Fonte: autora da tese

\subsection{Incerteza expandida associada ao valor de propriedade para urânio e silício totais}

A equação 8 expressa como foi calculada a incerteza associada ao valor de propriedade do material produzido neste trabalho. Para este cálculo $k$ é o fator de abrangência, o qual foi arredondado de 1,96 para 2, assim nas Tabelas 19 e 20 são apresentados os valores referentes à concentração média e 
incerteza associada ao valor de referência do material produzido analisado respectivamente pelos métodos de Davies \& Gray, gravimetria e WDXRF:

$$
U_{M R}=k \sqrt{u_{c a r}^{2}+u_{b b}^{2}+u_{s t s}^{2}+u_{l t s}^{2}}
$$

Tabela 19- Estimativa da incerteza expandida associada $U(\%)$ ao valor de propriedade das amostras de $U$ total por Davies \& Gray e Si total por gravimetria em \% para um nível de confiança de $95 \%(k=2)$

\begin{tabular}{lcc}
\hline Elemento & $\begin{array}{c}\text { Valor de referência } \\
(\%)\end{array}$ & $\begin{array}{c}\text { Incerteza associada } \\
\mathbf{U}(\%)\end{array}$ \\
\hline $\mathrm{U}$ & $(91,8 \pm 0,5)$ & 0,5 \\
$\mathrm{Si}$ & $(7,6 \pm 0,1)$ & 0,1 \\
\hline
\end{tabular}

Fonte: autora da tese

O valor da concentração do urânio total e silício total foram obtidos na caracterização do material, representando o valor médio de $n=24$.

Tabela 20 - Estimativa da incerteza expandida associada $U$ (\%) ao valor de propriedade das amostras de U total e Si total em \% por WDXRF para um nível de confiança de $95 \%(\mathrm{k}=2)$

\begin{tabular}{lcc}
\hline Elemento & $\begin{array}{c}\text { Valor de referência } \\
(\%)\end{array}$ & $\begin{array}{c}\text { Incerteza associada } \\
\mathbf{U}(\%)\end{array}$ \\
\hline $\mathrm{U}$ & $(91,2 \pm 0,1)$ & 0,1 \\
$\mathrm{Si}$ & $(7,8 \pm 0,1)$ & 0,1 \\
\hline
\end{tabular}

Fonte: autora da tese

Os valores adotados como referência e incerteza expandida foram os apresentados na tabela 19, obtidos pelas técnicas de Davies \& Gray e gravimetria por se tratarem de técnicas sensíveis e largamente utilizadas na área de salvaguardas nucleares. 


\subsection{Resultados do estudo de massa mínima para impurezas por ICPOES}

O ensaio de massa mínima para impurezas foi realizado em triplicata e apresentou os seguintes resultados em ug g $^{-1}$ :

Tabela 21- Resultados do estudo de massa mínima para impurezas de $\bigcup_{3} \mathrm{Si}_{2}$

\begin{tabular}{|c|c|c|c|c|}
\hline \multirow{2}{*}{ Elemento } & \multirow{2}{*}{ LDM ug $g^{-1}$} & \multirow{2}{*}{$\frac{\text { Amostra 2,0 g }}{u g ~ g^{-1}}$} & \multirow{2}{*}{$\frac{\text { Amostra 1,5 g }}{u_{\mathrm{g} \mathrm{g} \mathrm{g}}^{-1}}$} & \multirow{2}{*}{$\frac{\text { Amostra 0,75 g }}{\mathrm{ug} \mathrm{g}^{-1}}$} \\
\hline & & & & \\
\hline $\mathrm{Al}$ & 0,001 & 143,53 & 110,86 & 56,57 \\
\hline B & 0,11 & 0,89 & 0,00 & 0,00 \\
\hline $\mathbf{C a}$ & 0,003 & 1,04 & 0,97 & 0,51 \\
\hline Cd & 0,00004 & 0,27 & 0,43 & 0,14 \\
\hline Co & 0,02 & 0,27 & 0,00 & 0,00 \\
\hline $\mathrm{Cr}$ & 0,24 & 28,49 & 22,84 & 8,36 \\
\hline $\mathrm{Cu}$ & 0,07 & 28,84 & 24,15 & 25,88 \\
\hline $\mathrm{Fe}$ & 0,01 & 359,82 & 346,73 & 248,57 \\
\hline Li & 0,04 & 0,15 & 0,00 & 0,00 \\
\hline Mg & 0,0002 & 6,82 & 3,93 & 2,26 \\
\hline Mn & 0,0003 & 98,49 & 86,09 & 48,32 \\
\hline Mo & 0,0005 & 2,68 & 2,26 & 0,84 \\
\hline $\mathrm{Ni}$ & 0,006 & 14,18 & 13,14 & 13,46 \\
\hline $\mathrm{Pb}$ & 0,03 & 4,12 & 0,00 & 0,00 \\
\hline Sn & 0,11 & 9,17 & 0,00 & 0,00 \\
\hline V & 0,01 & 4,77 & 0,00 & 0,00 \\
\hline $\mathrm{Zn}$ & 0,04 & 8,23 & 7,22 & 6,78 \\
\hline $\mathrm{Ba}$ & 0,03 & 0,97 & 0,00 & 0,00 \\
\hline
\end{tabular}

Fonte: Autora da tese

Observando-se resultados da tabela 21 consideramos $2,0 \mathrm{~g}$ de $\mathrm{U}_{3} \mathrm{Si}_{2}$ como a massa ideal para a determinação de impurezas na matriz já que elementos importantes como, $\mathrm{Li}, \mathrm{Ba}, \mathrm{B}, \mathrm{Co}, \mathrm{V}, \mathrm{Pb}$ e Sn presentes em massas menores não apresentaram resultados próximos do limite de detecção do equipamento (ICPOES) para o método analítico de separação via coluna cromatográfica adotado.

\subsection{Resultados do estudo homogeneidade para impurezas por ICPOES}

Os resultados obtidos através da ANOVA para os elementos considerados como impurezas apresentados na (Tabela 22) confirmaram não 
haver diferenças significativas entre eles avaliando-se o valor de $\mathrm{F}$, deste modo, quando obtemos $F_{\text {calculado }}<F_{\text {crítico, as amostras podem ser consideradas }}$ homogêneas para o elemento estudado.

A análise de tendência foi realizada através da regressão linear utilizando o programa Excel®, demonstrando não haver tendência nos resultados obtidos na Tabela 22, avaliando-se o valor-P (probabilidade do valor do teste $t$ tabelado ser $\geq$ ao teste $t$ calculado), ou seja, valor-p adotado ao nível de significância (igual a 0,05) dever ser maior que 0,05, para indicar que não há tendência.

Observando todos os elementos, o cádmio foi único a apresentar uma diferença sutil nos resultados de variância o que pode ser percebido pelo desvio padrão relativo acima de $10 \%$, percentual considerado adequado para materiais de referência segundo THOMPSON et. al., 2006.

No entanto não foi suficiente para alterar a homogeneidade do elemento dentro do material.

\subsection{Resultados do estudo de estabilidade em curto e em longo prazo para impurezas por ICPOES}

Para o estudo de estabilidade, selecionou-se aleatoriamente 12 frascos do lote, analisados em triplicata, os quais permaneceram nas temperaturas de $5 \pm 2{ }^{\circ} \mathrm{C}, 23 \pm 1{ }^{\circ} \mathrm{C}$ e $50 \pm 2{ }^{\circ} \mathrm{C}$, pelo período de $0,1,3,6,12$ meses e foram analisados por meio de planejamento isócrono.

$\mathrm{Na}$ Tabela 23 são apresentados os resultados obtidos no estudo de estabilidade, após aplicação da estatística de regressão linear utilizando o programa Excel®.

Observando-se os dados na Tabela 23, o desvio padrão de $b_{1}$ e utilizando-se o fator $\mathrm{t}$ correspondente ao $\mathrm{n}$ amostral (número de graus de liberdade ideal para $n-2), b_{1}$ foi testado com o Teste t quanto à significância, atendendo-se a condição $|\mathrm{b} 1|<\mathrm{t} 0,95, \mathrm{n}-2 \times \mathrm{s}(\mathrm{b} 1)$, comprovando que a inclinação é insignificante e nenhuma instabilidade é confirmada, para um nível de confiança de $95 \%$. 
Assim temos que para todos os elementos o valor de $|\mathrm{b} 1|<t 0,95, \mathrm{n}-2$ é menor que o desvio padrão s(b1). Portanto foi confirmada a estabilidade dos elementos analisados. 
Tabela 22 - Concentração, média, desvio padrão, DPR e resultados da ANOVA, calculados na determinação de impurezas, em $\mu \mathrm{g} \mathrm{g}^{-1}$ em massa de $\mathrm{U}_{3} \mathrm{Si}_{2}$, nas amostras, a temperatura de $23 \pm 1{ }^{\circ} \mathrm{C}$

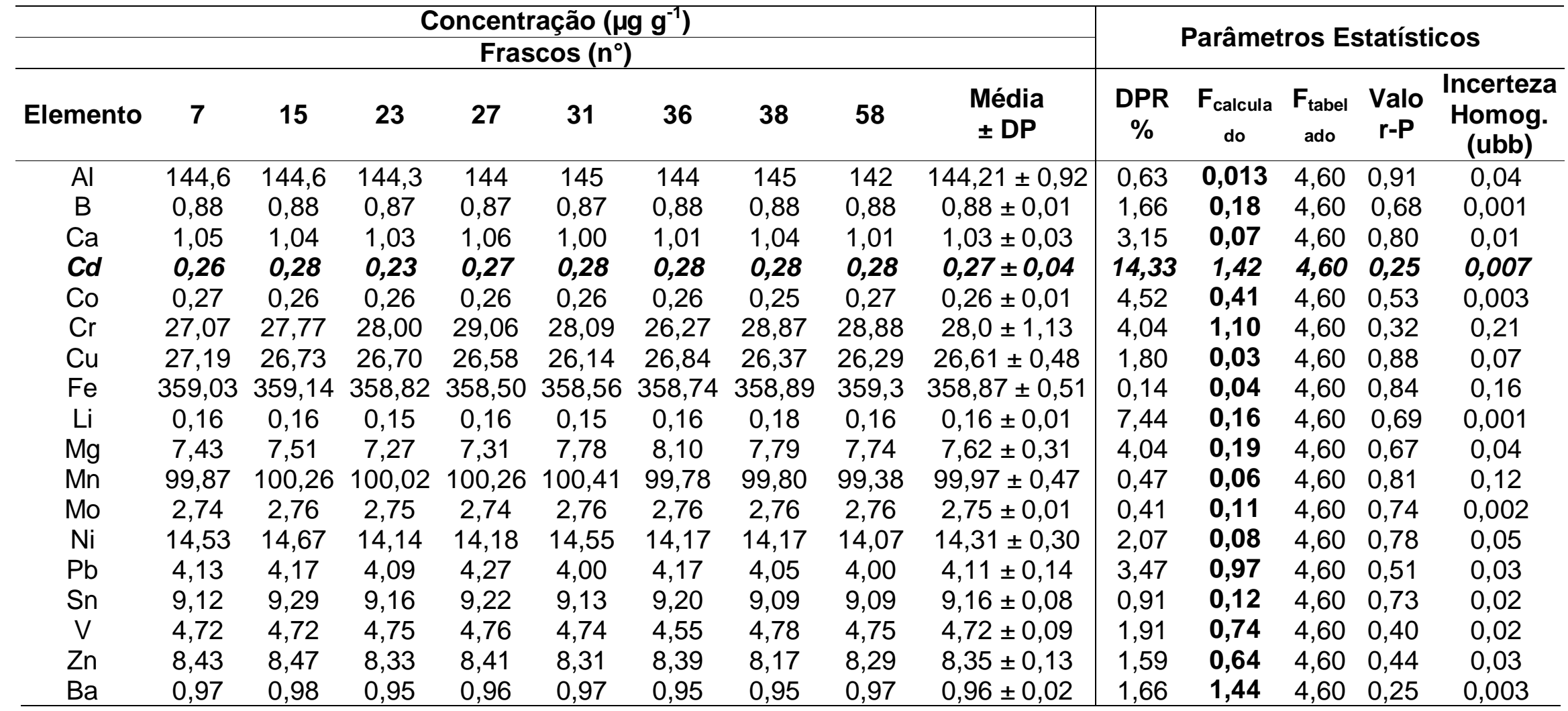

$\mathrm{n}=12$, DPR \%-desvio padrão relativo percentual, F-valor obtido para teste de Fisher, valor-P para $95 \%$ de confiança, gl-grau de liberdade.

Fonte: autora da tese 
Tabela 23 - Concentração média, desvio padrão, DPR e resultados da regressão linear, calculados na determinação de impurezas, em $\mu \mathrm{g} \mathrm{g}^{-1}$ em massa de $\mathrm{U}_{3} \mathrm{Si}_{2}$, nas amostras, nas temperaturas de 5 a $50{ }^{\circ} \mathrm{C}$.

\begin{tabular}{|c|c|c|c|c|c|c|c|c|c|c|c|}
\hline \multicolumn{5}{|c|}{$\frac{\text { Concentração }\left(\mu \mathrm{g} \mathrm{g}^{-1}\right)}{\text { Temperatura }}$} & \multicolumn{7}{|c|}{ Parâmetros Estatísticos } \\
\hline Elemento & $5 \pm 2^{\circ} \mathrm{C}$ & $23 \pm 1^{\circ} \mathrm{C}$ & $50 \pm 2^{\circ} \mathrm{C}$ & Média \pm DP & $\begin{array}{c}\text { DPR } \\
\%\end{array}$ & $\begin{array}{l}\text { Valor-P } \\
(95 \%)\end{array}$ & $\begin{array}{c}\text { Inclinaçã } \\
0 \\
\left(b_{1}\right)\end{array}$ & $\begin{array}{c}\text { Erro } \\
\text { padrão } \\
\text { inclinaç } \\
\text { ão } \\
\left(\mathbf{s}\left(\mathbf{b}_{1}\right)\right)\end{array}$ & $\begin{array}{c}\left|b_{1}\right|< \\
t(0,95, n-2)^{\star} s(b 1)\end{array}$ & $\begin{array}{c}\text { Incerteza } \\
\text { estabilidade } \\
\text { Its }\end{array}$ & $\begin{array}{c}\text { Incerteza } \\
\text { estabilidade } \\
\text { sts }\end{array}$ \\
\hline $\mathrm{Al}$ & 143,44 & 143,53 & 143,36 & $143,44 \pm 0,22$ & 0,2 & 0,88 & 0,014 & 0,012 & $2,84 E-10<0,06$ & 0,17 & 0,04 \\
\hline $\mathrm{B}$ & 0,89 & 0,89 & 0,90 & $0,89 \pm 0,02$ & 1,8 & 0,08 & $2,2 \mathrm{E}-16$ & $-0,0002$ & $2,2 E-16<0,007$ & 0,02 & 0,005 \\
\hline $\mathrm{Ca}$ & 1,05 & 1,04 & 1,04 & $1,04 \pm 0,01$ & 1,4 & 0,88 & $-4,4 \mathrm{E}-16$ & 0,012 & $4,4 E-16<0,003$ & 0,01 & 0,002 \\
\hline $\mathrm{Cd}$ & 0,29 & 0,27 & 0,28 & $0,28 \pm 0,02$ & 7,3 & 0,64 & $-5,6 \mathrm{E}-17$ & 0,0002 & $5,6 \mathrm{E}-17<0,002$ & 0,05 & 0,001 \\
\hline Co & 0,28 & 0,27 & 0,26 & $0,27 \pm 0,01$ & 4,9 & 0,74 & 0 & 0,0011 & $0<0,002$ & 0,01 & 0,002 \\
\hline $\mathrm{Cr}$ & 28,72 & 28,49 & 29,04 & $28,75 \pm 0,62$ & 2,2 & 0,37 & $7,1 \mathrm{E}-15$ & 0,034 & $7,1 \mathrm{E}-15<0,14$ & 0,40 & 0,10 \\
\hline $\mathrm{Cu}$ & 27,60 & 28,84 & 26,96 & $27,80 \pm 2,92$ & 10,5 & 0,37 & $7,1 \mathrm{E}-16$ & 0,034 & $7,1 \mathrm{E}-16<0,14$ & 0,40 & 0,10 \\
\hline $\mathrm{Fe}$ & 355,00 & 359,82 & 364,99 & $359,94 \pm 28,40$ & 7,9 & 0,31 & $-5,7 E-14$ & 1,61 & $5,7 \mathrm{E}-14<11$ & 30,72 & 7,68 \\
\hline $\mathrm{Li}$ & 0,16 & 0,15 & 0,16 & $0,16 \pm 0,011$ & 7,03 & 0,37 & $-2,8 \mathrm{E}-17$ & 0,00029 & $2,8 \mathrm{E}-18<0,0012$ & 0,0034 & 0,0009 \\
\hline $\mathrm{Mg}$ & 6,86 & 6,82 & 6,80 & $6,83 \pm 0,18$ & 2,7 & 0,86 & 0 & 0,012 & $0<0,03$ & 0,07 & 0,02 \\
\hline $\mathrm{Mn}$ & 98,96 & 98,49 & 98,92 & $98,79 \pm 0,60$ & 0,6 & 0,12 & $-1,4 \mathrm{E}-14$ & 0,007 & $-1,4 E-14<0,1$ & 0,38 & 0,09 \\
\hline Mo & 2,50 & 2,68 & 2,90 & $2,69 \pm 0,75$ & 27,8 & 0,39 & 0 & 0,027 & $0<0,2$ & 0,57 & 0,14 \\
\hline $\mathrm{Ni}$ & 15,20 & 14,18 & 14,32 & $14,56 \pm 1,23$ & 8,4 & 0,86 & 0 & 0,089 & $0<0,2$ & 0,58 & 0,14 \\
\hline $\mathrm{Pb}$ & 4,13 & 4,12 & 4,12 & $4,12 \pm 0,03$ & 0,7 & 0,37 & $8,9 E-16$ & 0,0007 & $8,9 E-16<0,003$ & 0,01 & 0,002 \\
\hline Sn & 9,17 & 9,17 & 9,15 & $9,16 \pm 0,05$ & 0,5 & 0,76 & $-1,8 \mathrm{E}-15$ & 0,002 & $1,8 \mathrm{E}-15<0,01$ & 0,02 & 0,005 \\
\hline V & 4,75 & 4,77 & 4,71 & $4,74 \pm 0,05$ & 1,0 & 0,09 & $8,9 E-16$ & 0,0005 & $8,9 \mathrm{E}-16<0,01$ & 0,02 & 0,004 \\
\hline $\mathrm{Zn}$ & 8,24 & 8,23 & 8,27 & $8,25 \pm 0,06$ & 0,7 & 0,32 & 0 & 0,003 & $0<0,01$ & 0,03 & 0,01 \\
\hline $\mathrm{Ba}$ & 0,97 & 0,97 & 0,96 & $0,97 \pm 0,01$ & 1,1 & 0,34 & 0 & 0,0004 & $0<0,002$ & 0,01 & 0,0014 \\
\hline
\end{tabular}

$\mathrm{n}=12$; DPR \%-desvio padrão relativo percentual, valor-P para $95 \%$ de confiança.

Fonte: autora da tese 
Para corroborar o resultado obtido pelo Teste t para inclinação da reta foi utilizada o teste ANOVA para regressão linear, neste caso avalia-se o resultado do valor-p (probabilidade $P$ ( $t_{\text {calc }} \geq t_{\text {crit }}$ ) observado) o qual indica que a regressão não é estatisticamente significativa quando o valor-P for maior que 0,05 (ela se torna significativa para um nível de confiança de $95 \%$ quando for menor que 0,05).

O valor-P foi maior que 0,05, comprovando que não há tendência nos resultados para estabilidade das amostras irradiadas armazenadas a 5 a $50{ }^{\circ} \mathrm{C}$ pelo período de estudo (12 meses). A regressão foi considerada insignificante.

No estudo de estabilidade foi observado o mesmo comportamento atípico para o elemento Molibdênio como ocorreu com o Cádmio no estudo de homogeneidade.

\subsubsection{Representação gráfica dos resultados de impurezas pelo método de ICPOES}

As figuras 13(a) a 13(f) apresentam graficamente o que foi descrito no item 7.7. 
Figura 13(a) - Gráfico dos resultados da análise de regressão para 0 estudo de estabilidade para Al, B e Ba em diferentes temperaturas e períodos de tempo
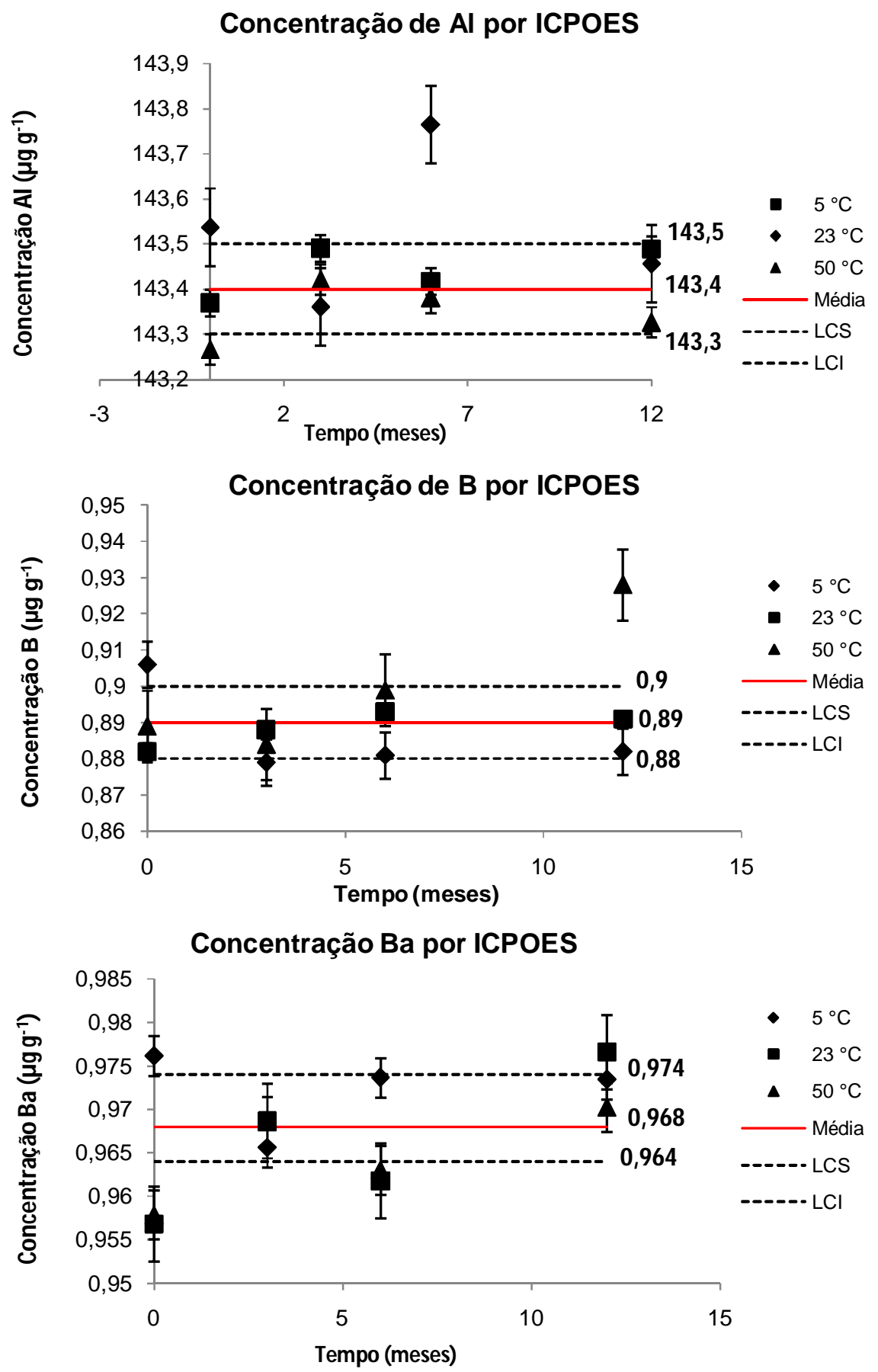

Fonte: autora da tese 
Figura 13(b) - Gráfico dos resultados da analise de regressão para 0 estudo de estabilidade para $\mathrm{V}$, $\mathrm{Ca}$ e $\mathrm{Cd}$ em diferentes temperaturas e períodos de tempo
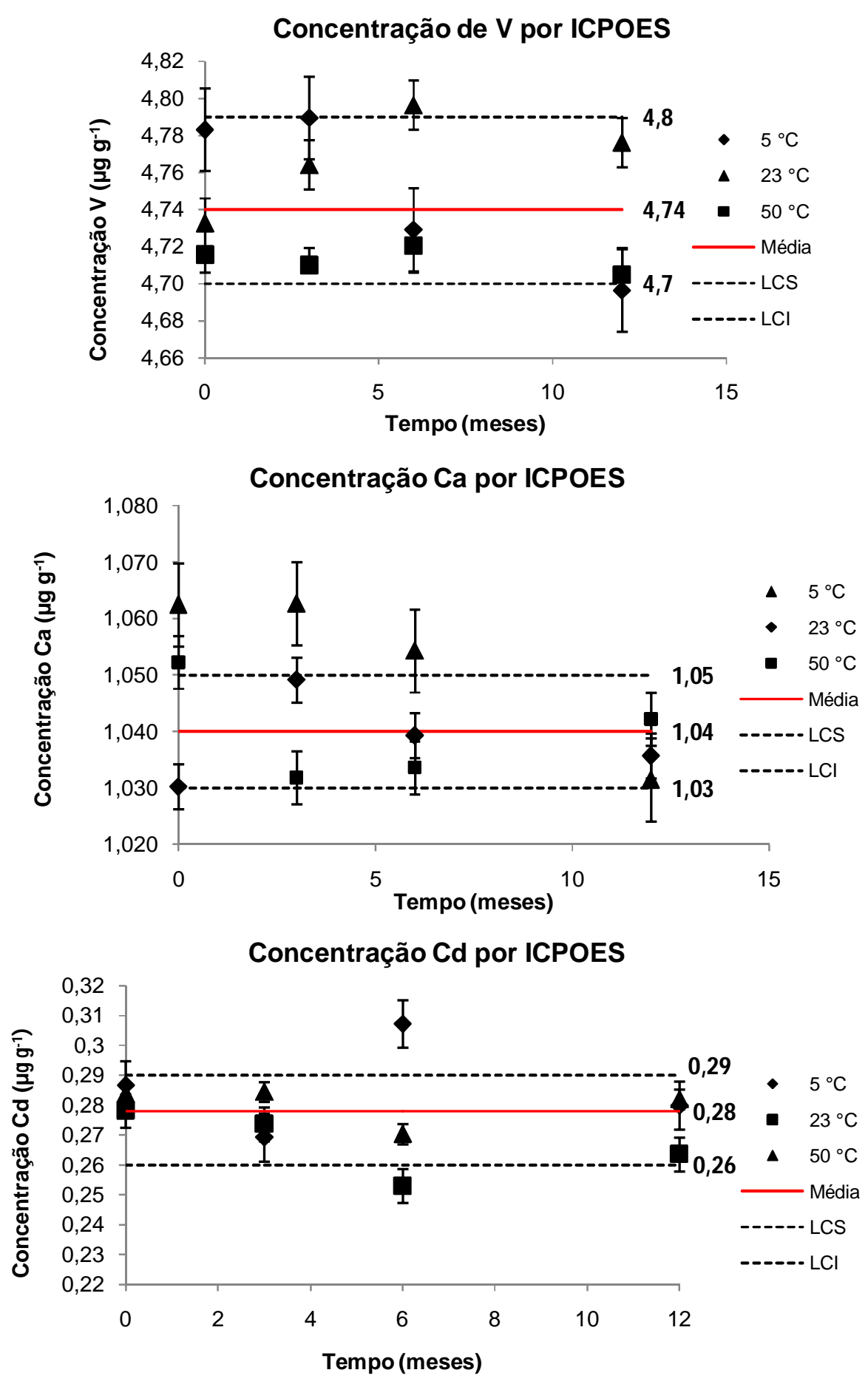

Fonte: autora da tese 
Figura 13(c) - Gráfico dos resultados da analise de regressão para 0 estudo de estabilidade para $\mathrm{Cu}$, Fe e $\mathrm{Li}$ em diferentes temperaturas e períodos de tempo
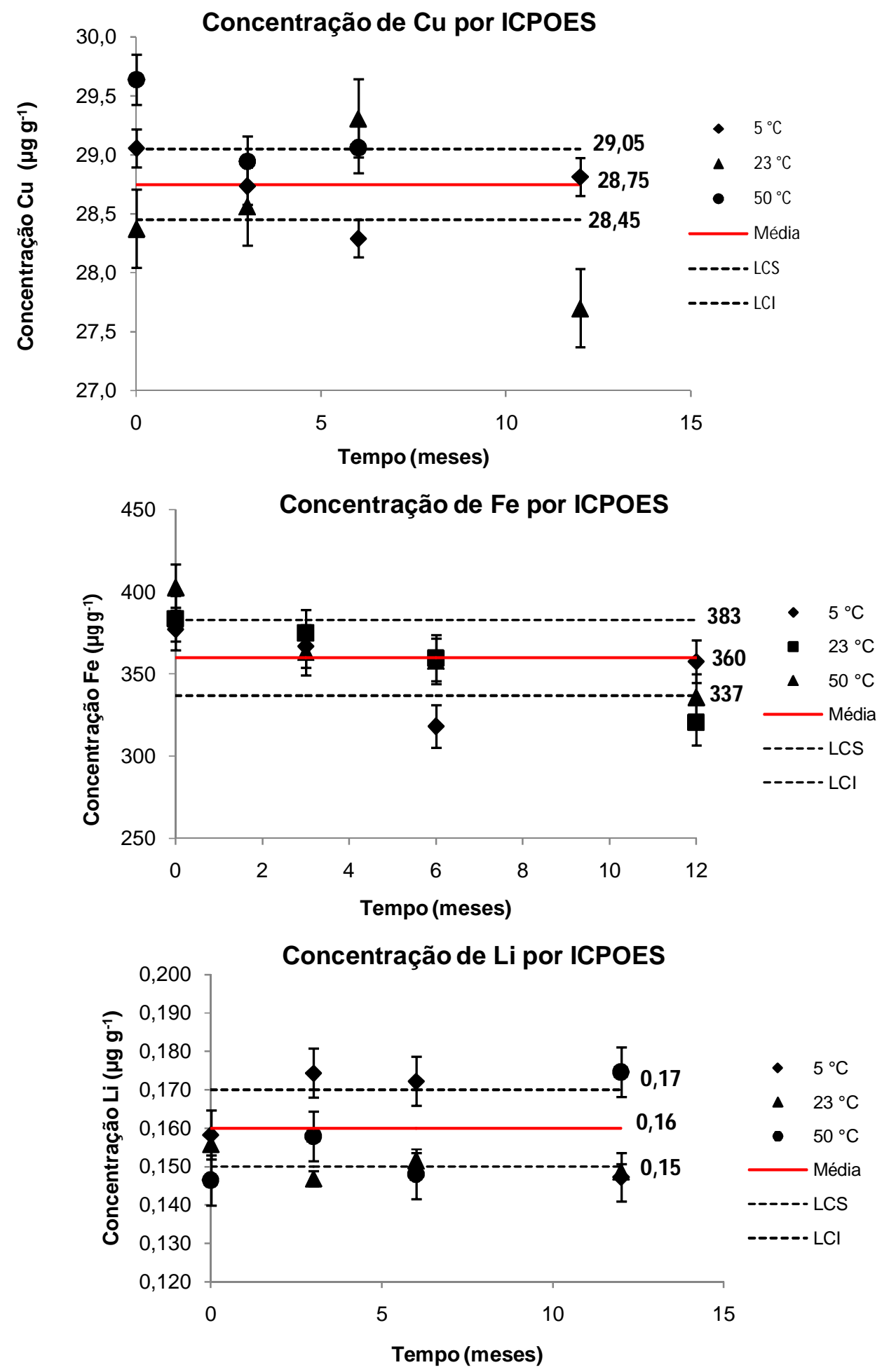

Fonte: autora da tese 
Figura 13(d) - Gráfico dos resultados da analise de regressão para 0 estudo de estabilidade para $\mathrm{Zn}$, Co e $\mathrm{Cr}$ em diferentes temperaturas e períodos de tempo
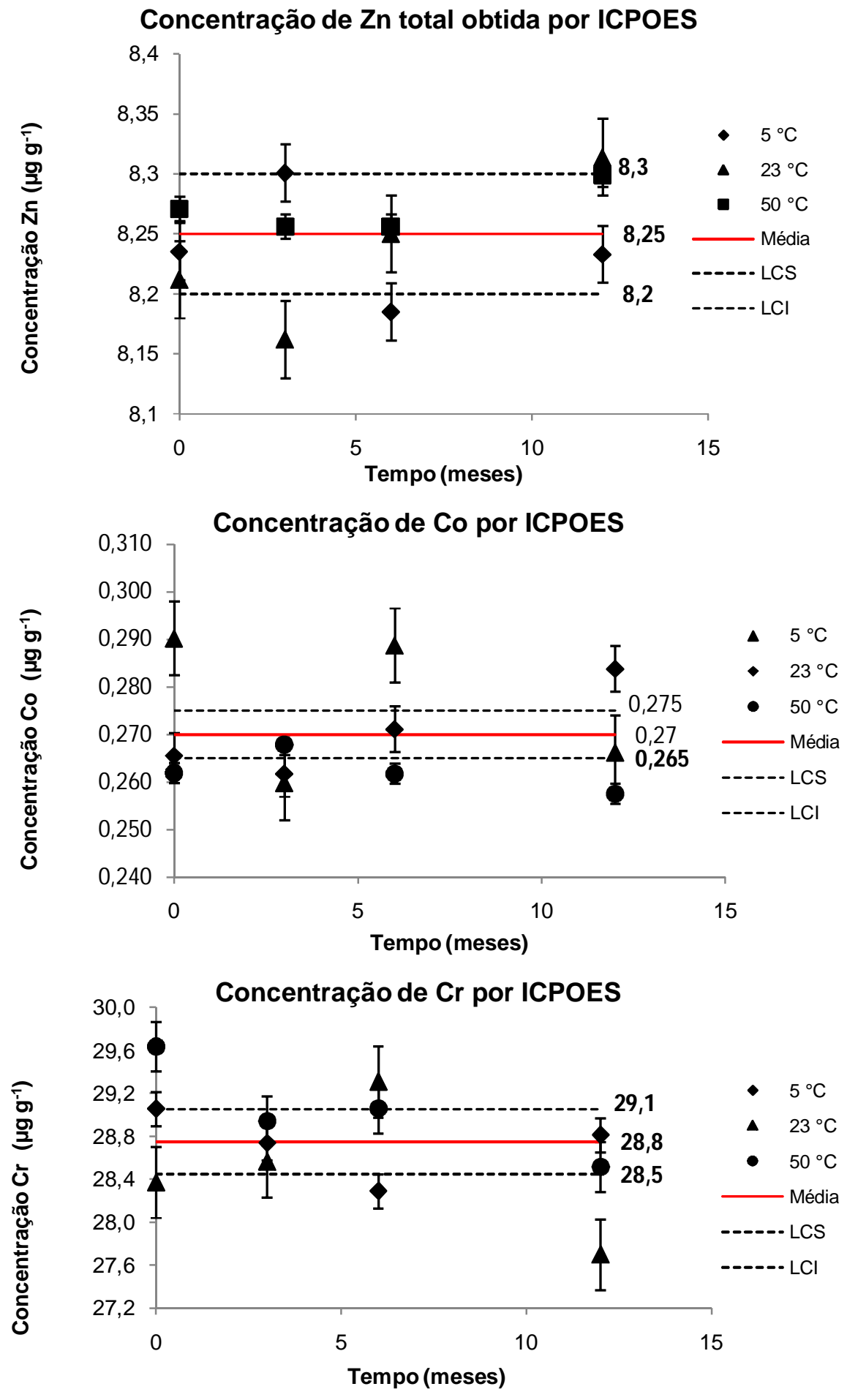

Fonte: autora da tese 
Figura 13(e) - Gráfico dos resultados da análise de regressão para o estudo de estabilidade para $\mathrm{Sn}, \mathrm{Mg}$ e $\mathrm{Mn}$ em diferentes temperaturas e períodos de tempo
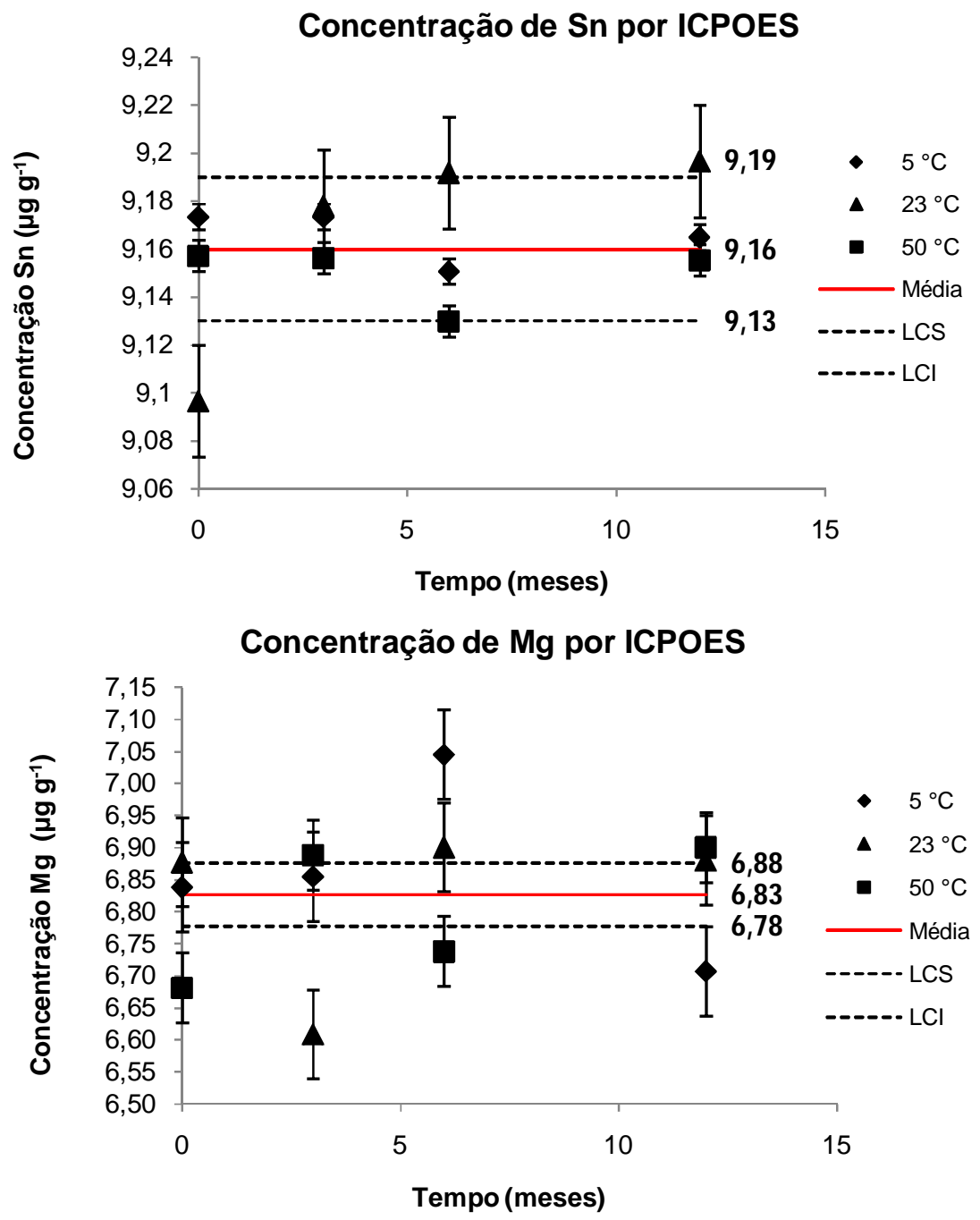

Concentração de Mn por ICPOES

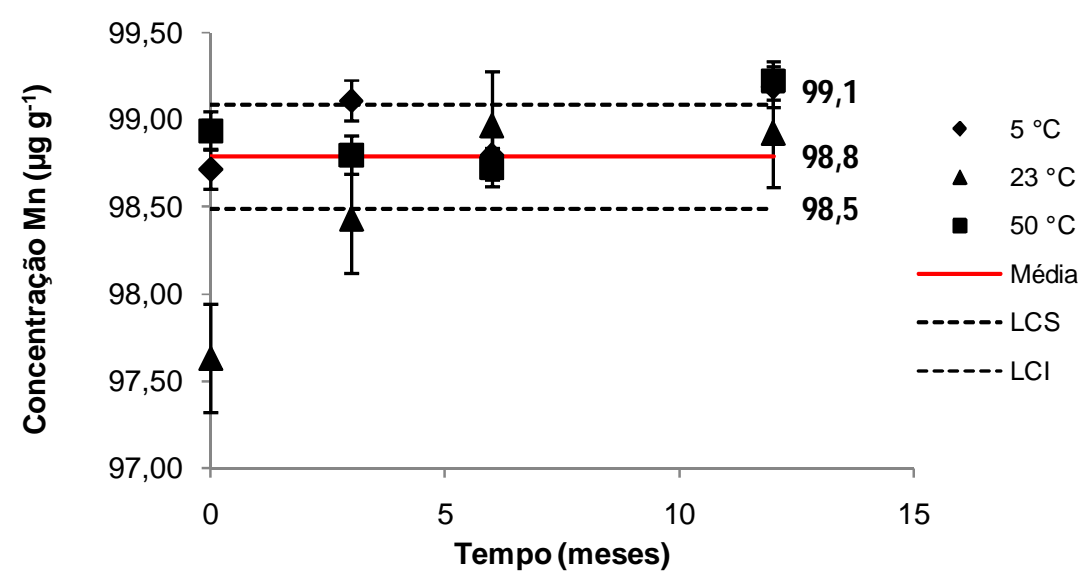

Fonte: autora da tese 
Figura 13(f) - Gráfico dos resultados da analise de regressão para o estudo de estabilidade para $\mathrm{Mo}, \mathrm{Ni}$ e $\mathrm{Pb}$ em diferentes temperaturas e períodos de tempo
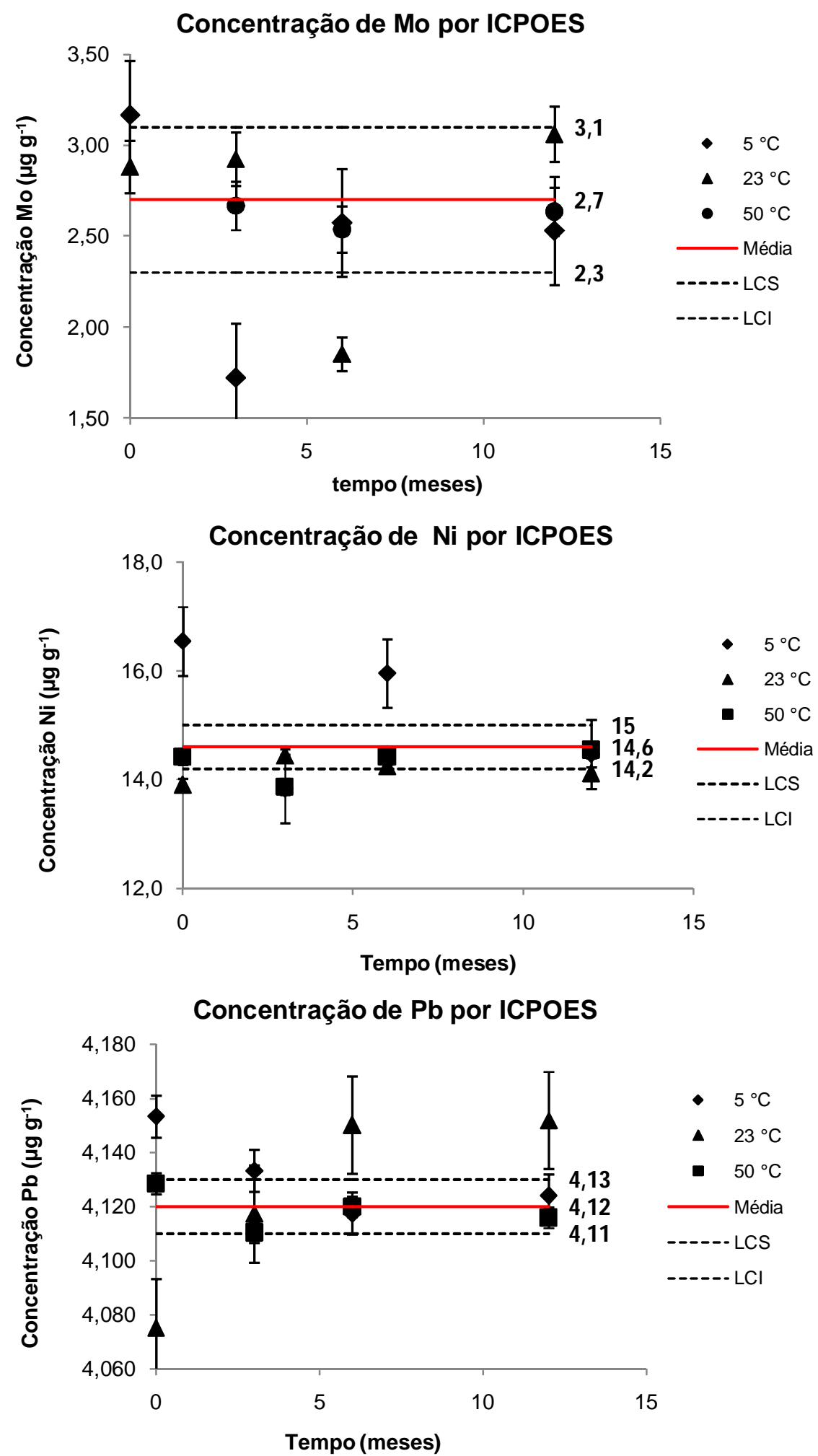

Fonte: autora da tese 
O resultado obtido pela aplicação do método de ICPOES ao estudo de estabilidade em longo prazo para as impurezas mostrou que não houve mudanças significativas na concentração dos quinze elementos estudados durante o período do teste, apesar do desvio padrão relativo apresentar valor ligeiramente alto para os elementos $\mathrm{Cd}$ e Mo. Conseqüentemente essa variação não impediu que o candidato a material de referência de $\mathrm{U}_{3} \mathrm{Si}_{2}$ seja suficientemente estável para ser armazenado à temperatura ambiente, sem alterações significativas na composição dos demais elementos estudados.

\subsection{Atribuição dos valores de propriedade para as impurezas}

Para a atribuição dos valores de propriedade para os elementos considerados como impurezas, optou-se pela avaliação da incerteza associada para fazer a seguinte distinção entre os valores:

- valores informativos são valores para os quais há pouca confiabilidade metrológica nos resultados;

- valores de referência são valores para os quais há maior confiabilidade nos dados, mas para os quais essa confiabilidade não é suficiente para que se recomende a certificação;

- valores certificados são valores com maior confiabilidade metrológica, para os quais a certificação é considerada possível.

Para a definição de quais elementos se encaixam nas definições acima, utilizaram-se as informações apresentadas na Tabela 24.

Tabela 24 - Informações para a decisão sobre a atribuição de valores certificados ao candidato a material de referência de siliceto de urânio

\begin{tabular}{|c|c|c|c|c|c|}
\hline \multirow[b]{2}{*}{ Elemento } & \multirow[b]{2}{*}{ Técnica } & \multirow[b]{2}{*}{ U (\%) } & \multicolumn{3}{|c|}{ Decisão } \\
\hline & & & $\begin{array}{c}\text { Valor } \\
\text { informativo }\end{array}$ & $\begin{array}{c}\text { Valor de } \\
\text { referência }\end{array}$ & $\begin{array}{c}\text { Valor } \\
\text { certificado }\end{array}$ \\
\hline Al & ICPOES, & Adequada & & & $X$ \\
\hline B & ICPOES & Adequada & & & $X$ \\
\hline $\mathrm{Ca}$ & ICPOES & Alta & & $X$ & \\
\hline Cd & ICPOES & Muito alta & $X$ & & \\
\hline Co & ICPOES & Muito alta & $X$ & & \\
\hline
\end{tabular}




\begin{tabular}{c|c|r|l|l|l}
\hline $\mathbf{C r}$ & ICPOES & Adequada & & & $\mathrm{X}$ \\
\hline $\mathbf{C u}$ & ICPOES & Adequada & & & $\mathrm{X}$ \\
\hline $\mathbf{F e}$ & ICPOES, & Adequada & & & $\mathrm{X}$ \\
\hline $\mathbf{L i}$ & ICPOES & Muito alta & $\mathrm{X}$ & & \\
\hline $\mathbf{M g}$ & ICPOES & Adequada & & & $\mathrm{X}$ \\
\hline $\mathbf{M n}$ & ICPOES, & Adequada & & & $\mathrm{X}$ \\
\hline $\mathbf{M o}$ & ICPOES & Adequada & & & $\mathrm{X}$ \\
\hline $\mathbf{N i}$ & ICPOES & Adequada & & & $\mathrm{X}$ \\
\hline $\mathbf{P b}$ & ICPOES & Adequada & & & $\mathrm{X}$ \\
\hline $\mathbf{S n}$ & ICPOES & Adequada & & & $\mathrm{X}$ \\
\hline $\mathbf{V}$ & ICPOES & Adequada & & & $\mathrm{X}$ \\
\hline $\mathbf{Z n}$ & ICPOES & Adequada & & & $\mathrm{X}$ \\
\hline $\mathbf{B a}$ & ICPOES & Alta & & $\mathrm{X}$ & \\
\hline $\mathbf{F O n t e}$ & & & & \\
\hline
\end{tabular}

Fonte: autora da tese, adaptada de Moreira, 2010.

\subsection{Estimativa das incertezas para impurezas por ICPOES}

A incerteza para caracterização foi estimada usando-se o cálculo da incerteza expandida para determinação de Alumínio (Al), Boro (B), Cálcio (Ca), Cádmio (Cd), Cobalto (Co), Cromo (Cr), Cobre (Cu), Ferro (Fe), Lítio (Li), Magnésio (Mg), Manganês (Mn), Molibdênio (Mo), Níquel (Ni), Chumbo (Pb), Estanho (Sn), Vanádio (V), Zinco (Zn), Bário (Ba), desenvolvido em planilha do programa Excel ® pelo laboratório.

Os resultados da incerteza de medição obtidos podem ser observados na Tabela 25 para o método analítico utilizado nas medições dos elementos de interesse.

A incerteza padrão de homogeneidade foi calculada de acordo com a equação (2) como descrito no item 4.9. Sua escolha foi determinada porque o $\mathrm{s}_{\mathrm{r}}$ - desvio padrão de repetibilidade foi maior do que o desvio padrão de homogeneidade $\mathrm{s}_{\mathrm{bb}}$, para as amostras.

A incerteza padrão de estabilidade foi calculada considerando as incertezas de estabilidade em curto prazo e em longo prazo (equação 3). 
Tabela 25 - Estimativa das incertezas padrão combinadas para as impurezas

\begin{tabular}{|c|c|c|c|c|}
\hline Elemento & $\begin{array}{c}\mathrm{u}_{\mathrm{car}} \\
\mu \mathrm{g} \mathrm{g}^{-1}\end{array}$ & $\begin{array}{c}u_{b b} \\
\mu g g^{-1}\end{array}$ & $\begin{array}{c}\mathrm{u}_{\mathrm{sts}} \\
\mu \mathrm{g} \mathrm{g}^{-1}\end{array}$ & $\begin{array}{c}u_{\mathrm{Its}} \\
\mu \mathrm{g} \mathrm{g}^{-1}\end{array}$ \\
\hline $\mathrm{Al}$ & 0,01 & 0,04 & 0,04 & 0,17 \\
\hline B & 0,06 & 0,001 & 0,005 & 0,02 \\
\hline $\mathrm{Ba}$ & 0,23 & 0,003 & 0,0014 & 0,01 \\
\hline $\mathrm{Ca}$ & 0,23 & 0,01 & 0,002 & 0,01 \\
\hline $\mathrm{Cd}$ & 0,17 & 0,007 & 0,001 & 0,05 \\
\hline Co & 0,15 & 0,003 & 0,002 & 0,01 \\
\hline $\mathrm{Cr}$ & 0,03 & 0,21 & 0,10 & 0,40 \\
\hline $\mathrm{Cu}$ & 0,08 & 0,07 & 0,10 & 0,40 \\
\hline $\mathrm{Fe}$ & 0,07 & 0,16 & 7,68 & 30,72 \\
\hline $\mathrm{Li}$ & 0,2 & 0,003 & 0,0001 & 0,0003 \\
\hline$M g$ & 0,06 & 0,04 & 0,02 & 0,07 \\
\hline $\mathrm{Mn}$ & 0,03 & 0,12 & 0,09 & 0,38 \\
\hline Mo & 0,05 & 0,002 & 0,14 & 0,57 \\
\hline $\mathrm{Ni}$ & 0,09 & 0,05 & 0,14 & 0,58 \\
\hline $\mathrm{Pb}$ & 0,03 & 0,03 & 0,002 & 0,01 \\
\hline V & 0,03 & 0,02 & 0,004 & 0,02 \\
\hline Sn & 0,05 & 0,02 & 0,005 & 0,02 \\
\hline $\mathrm{Zn}$ & 0,04 & 0,03 & 0,01 & 0,03 \\
\hline
\end{tabular}

Ucar = incerteza de caracterização; ubb = incerteza de homogeneidade; usts = incerteza de estabilidade em curto prazo e ults = incerteza de estabilidade em longo prazo.

Fonte: autora da tese

\subsection{Incerteza associada ao valor de referência para impurezas}

A equação 8 expressa como foi calculada a incerteza associada $U(\%)$ ao valor referência do material ( $\mu \mathrm{g} \mathrm{g}^{-1}$ massa $\mathrm{U}_{3} \mathrm{Si}_{2}$ ) produzido neste trabalho. Para este cálculo $k$ é o fator de abrangência, o qual foi arredondado para 2, assim, na Tabela 26 são apresentados os valores referentes à concentração média e incerteza expandida associada ao valor de referência do material produzido analisado respectivamente pelo método de ICPOES: 


$$
U_{M R}=k \sqrt{u_{c a r}^{2}+u_{b b}^{2}+u_{s t s}^{2}+u_{t s}^{2}}
$$

Tabela 26 - Estimativa da incerteza expandida associada $U$ (\%) para o valor de referência das amostras de impurezas para um nível de confiança de 95 \% $(\mathrm{k}=2)$, em $\mu \mathrm{g} \mathrm{g}{ }^{-1}$ massa de $\mathrm{U}_{3} \mathrm{Si}_{2}$

\begin{tabular}{|c|c|}
\hline Elemento & Valor de referência + Incerteza expandida associada U (\%) \\
\hline $\mathrm{Al}$ & $144 \pm 0,1$ \\
\hline$B$ & $1 \pm 6$ \\
\hline $\mathrm{Ba}$ & $1 \pm 23$ \\
\hline $\mathrm{Ca}$ & $1 \pm 22$ \\
\hline $\mathrm{Cd}$ & $0,3 \pm 64$ \\
\hline Co & $0,3 \pm 59$ \\
\hline $\mathrm{Cr}$ & $28 \pm 4$ \\
\hline $\mathrm{Cu}$ & $27 \pm 0,3$ \\
\hline $\mathrm{Fe}$ & $359 \pm 0,1$ \\
\hline $\mathrm{Li}$ & $0,1 \pm 72$ \\
\hline $\mathrm{Mg}$ & $7 \pm 1$ \\
\hline $\mathrm{Mn}$ & $99 \pm 0,1$ \\
\hline Mo & $3 \pm 2$ \\
\hline $\mathrm{Ni}$ & $14 \pm 1$ \\
\hline $\mathrm{Pb}$ & $4 \pm 1$ \\
\hline $\mathrm{V}$ & $5 \pm 1$ \\
\hline $\mathrm{Sn}$ & $9 \pm 1$ \\
\hline $\mathrm{Zn}$ & $8 \pm 1$ \\
\hline
\end{tabular}

Fonte: autora da tese

\subsection{Certificação do material}

O material de referência para siliceto de urânio foi desenvolvido dentro de um programa de qualidade implantado no Laboratório de Análises Química e Ambiental (LAQA) teve início em 2009, por ocasião do projeto SIBRATEC. 
Atuando como apoio ao ciclo do combustível nuclear, do IPEN, desenvolvendo metodologias analíticas para a caracterização química e isotópica visando à qualificação do elemento combustível para o reator IEA R1 do IPEN.

A implantação do Sistema de Gestão da Qualidade (SGQ) baseado na Norma ABNT NBR ISO/IEC 17025 garante a conformidade aos seus requisitos, além de assegurar a qualidade dos resultados analíticos e possibilidade de acreditação de ensaios por organismos que tenham acordos de reconhecimento mútuo equivalentes em outros países que utilizem a Norma (ABNT NBR ISO/IEC 17025:2017).

O SGQ-CQMA (Sistema de Gestão da Qualidade do CQMA) segue as diretrizes da norma CNEN NN 1.16 em relação aos requisitos para a segurança de suas instalações radiativas. Além disso, o laboratório participa constantemente de intercomparações para ensaios ambientais e de compostos de urânio.

Deste modo a certificação do material foi realizada para os elementos urânio e silício por meio das técnicas analíticas de Davies \& Gray e gravimetria utilizadas pelo NBL e pela ABAAC (Agência Brasileiro-Argentina de Contabilidade e Controle de Materiais Nucleares).

Para as impurezas a técnica de espectrometria de emissão óptica com plasma indutivamente acoplado (ICPOES) foi adotada para os 18 elementos estudados.

Foram considerados como valores certificados aqueles obtidos com incertezas expandidas inferiores a $20 \%$.

O limite inferior a $20 \%$ foi escolhido como o adequado para o uso pretendido para o material de referência e para a determinação dos elementos na matriz nas condições desse estudo. Os valores certificados são apresentados na Tabela 26.

Os valores de incerteza expandida no intervalo de $20 \%$ a $30 \%$ foram considerados altos e, assim, os elementos com incerteza expandida nesse intervalo foram incluídos e considerados apenas como valores de referência (Tabela 26). 
Os elementos cujos valores de incerteza expandida ficaram acima de 30 $\%$ foram considerados muito altos e incluídos como valores informativos (Tabela 26).

Os elementos $\mathrm{Cd}$, Co, e $\mathrm{Li}$ foram incluídos na Tabela 26 , como valor informativo, pois não foi possível contornar de forma satisfatória os altos valores de incerteza obtidos.

A metodologia usada para atribuir valores de propriedade foi baseada na ABNT ISO GUIA 34 (2012) e em análises realizadas anteriormente pelo laboratório para o CCN e estudos de intercomparação conduzidos visando a certificação do laboratório pela ISO 17025 e validação de metodologia realizada com o material da NBL CRM 124.

\section{CONCLUSÃO}

Os dados obtidos com as análises realizadas até 0 momento comprovam que o material é homogêneo e estável para os elementos urânio, silício e impurezas. Verificou-se que apenas os elementos Fe e Mn apresentam discordância dos valores estipulados.

Observou-se que o estudo de estabilidade em longo prazo, não apresentou mudanças significativas na concentração de $\mathrm{U}$ e $\mathrm{Si}$, durante o período de ensaio, obtendo-se a mesma resposta positiva para os elementos considerados impurezas analisados pelo método de ICPOES.

Conclui-se, então, que o candidato a material de referência de $\mathrm{U}_{3} \mathrm{Si}_{2}$ é suficientemente estável para ser armazenado à temperatura ambiente, sem alterações significativas na composição dos elementos estudados no prazo de um ano.

O candidato a material de referência possui tempo de vida ilimitado, contudo é necessário que após o prazo de 1 ano sejam realizados novos ensaios de estabilidade para confirmar os resultados obtidos.

O material atende perfeitamente as especificações técnicas aceitas como material de referência, tornando o material adequado ao uso pretendido.

O estudo de massa mínima para impurezas definiu como 2,0 g a menor massa adequada para análise por ICPOES (técnicas analíticas empregada). 
Os estudos realizados sugeriram que as incertezas dos valores certificados do material para estabelecer rastreabilidade metrológica adequada deveriam encontrar-se com incerteza expandida associada inferior a $20 \%$.

O número reduzido de artigos disponíveis na literatura, foi usado para estabelecer esse limite (NBL, 2018; VENCHIARUTTI et.al., 2016; BÜRGER et al., 2009).

No estudo realizado, o limite de $20 \%$ para a incerteza expandida é colocado para elementos com concentrações superiores a $100 \mu \mathrm{g} \mathrm{g}^{-1}$. O limite é de $30 \%$ para elementos com concentração na faixa de 10 a $100 \mu \mathrm{g} \mathrm{g}^{-1}$ e de 50 a $60 \%$ para elementos com concentração na faixa de 0,1 a $10 \mu \mathrm{g} \mathrm{g}^{-1}$.

A partir destes dados o laboratório tem capacidade técnica de garantir maior segurança na utilização das informações para elaboração do certificado, dando continuidade ao trabalho.

A análise de impurezas pela técnica de ICPOES foi validada como pode ser observado no apêndice 8. Os resultados obtidos com os testes de validação demonstraram que o método é adequado à finalidade proposta e que seus resultados podem ser amplamente empregados a fim de atender as necessidades do laboratório para o problema analítico proposto.

Avaliando a literatura disponível observou-se que não existe um acordo unânime sobre todas as características a serem estudadas em uma validação de método. Contudo a maioria dos documentos existentes indica as características que contribuem para confirmar a adequação do método analítico.

Assim no processo de validação adotado neste trabalho, as características seletividade, recuperação/tendência, repetibilidade/precisão, precisão intermediária, linearidade/faixa de trabalho, limite de detecção, limite de quantificação e incerteza de medição, foram utilizados para demonstrar a aplicabilidade da metodologia.

Comparando-se as características estudadas e os resultados obtidos e documentados, conforme Tabela 28, concluiu-se que o método desenvolvido preenche inteiramente as necessidades necessidade do LAQA para a análise de impurezas em $\mathrm{U}_{3} \mathrm{Si}_{2}$ pela técnica de ICPOES. 


\section{APÊNDICE}

\subsection{Ensaios para validação da análise de Impurezas em $\mathrm{U}_{3} \mathrm{Si}_{2}$}

Dentro deste anexo encontram os passos realizados para demonstrar que o método de determinação de impurezas por meio da técnica de Espectrometria de Emissão Óptica com Plasma Indutivamente Acoplado ICPOES apresenta as características necessárias para a obtenção de resultados com a qualidade exigida.

Todo o procedimento aqui realizado teve como base o documento do INMETRO "DOC-CGCRE-008", 2016. Contudo, este não foi abordado na integra, mas buscaram-se as técnicas que mais se aplicam ao estudo em questão.

Neste contexto, foram definidos os seguintes parâmetros: seletividade, recuperação/tendência, repetibilidade/precisão, precisão intermediária, linearidade/faixa de trabalho, limite de detecção, limite de quantificação e incerteza de medição.

\subsubsection{Seletividade}

Seletividade é o grau em que o método pode quantificar o analito na presença de outros analitos, matrizes ou de elementos considerados potencialmente como interferentes (BRITO et. al., 2003; AOAC, 2011; BRAMARDI, 2015; INMETRO, 2016). Deste modo, quando um método consegue produzir respostas para vários analitos, podendo distinguir as respostas de um analito das de outros, é chamado seletivo.

A matriz da amostra pode conter componentes que interferem no desempenho da medição. Esses interferentes podem aumentar ou reduzir o sinal, comprometendo o resultado. Adicionalmente a magnitude desse efeito também pode depender da concentração. Logo, no estudo de seletividade é necessário verificar também a existência de efeito de matriz.

Neste trabalho, a seletividade foi avaliada com testes de presença e ausência da matriz da amostra. 


\subsubsection{Recuperação/Tendência}

Os processos normalmente utilizados para avaliar a tendência de um método são, entre outros: uso de materiais de referência certificados (MRC), participação em comparações interlaboratoriais, comparação com método de referência (ou método validado) e realização de ensaios de recuperação (BRITO et. al., 2003; AOAC, 2011;BRAMARDI, 2015;INMETRO, 2016).

A tendência, quando aplicada a uma série de resultados de ensaio, implica numa combinação de componentes de erros aleatórios e sistemáticos (AOAC, 2011). A determinação da tendência com relação aos valores de referência apropriados é importante no estabelecimento da rastreabilidade aos padrões reconhecidos. A tendência pode ser expressa (equação 12) como recuperação analítica, definida como:

$$
\operatorname{Re} \text { cuperação }(\%)=\left(\frac{C_{1}-C_{2}}{C_{3}}\right) \times 100
$$

Onde:

C1: concentração do analito na amostra fortificada

C2: concentração do analito na amostra não fortificada

C3: concentração do analito adicionado à amostra fortificada

A exatidão é avaliada numericamente por meio da tendência.Foram realizados ensaios de recuperação e tendência com material de referência certificado e com amostras adicionadas com os elementos de interesse, os critérios de aceitação adotados para a recuperação, foram os sugeridos pela Association of Official Analytical Chemists (AOAC, 2011). Tabela 27. 
Tabela 27 - Critério adotado para aceitação da recuperação

\begin{tabular}{cccc}
\hline Analito, \% & Razão do analito & Unidade & $\begin{array}{c}\text { Recuperação } \\
\text { média, \% }\end{array}$ \\
\hline 100 & 1 & $100 \%$ & $98-102$ \\
10 & $10^{-1}$ & $10 \%$ & $98-102$ \\
1 & $10^{-2}$ & $1 \%$ & $97-103$ \\
0,01 & $10^{-3}$ & $0,1 \%$ & $95-105$ \\
0,001 & $10^{-4}$ & $100 \mathrm{ppm}$ & $90-107$ \\
0,0001 & $10^{-5}$ & $10 \mathrm{ppm}$ & $80-110$ \\
0,00001 & $10^{-6}$ & $1 \mathrm{ppm}$ & $80-110$ \\
0,000001 & $10^{-7}$ & $100 \mathrm{ppb}$ & $80-110$ \\
0,0000001 & $10^{-8}$ & $10 \mathrm{ppb}$ & $60-115$ \\
0,00000001 & $10^{-9}$ & $1 \mathrm{ppb}$ & $40-120$ \\
\hline
\end{tabular}

Fonte: Tabela extraída de: AOAC Peer-Verified Methods Program, Manual on policies and procedures, Arlington, Va., USA (1998). AOAC, 2011.

$\mathrm{Na}$ Tabela 28, podem ser observados os resultados obtidos para a recuperação de amostras fortificadas e do material de referência certificado analisado.

\subsubsection{Repetibilidade/precisão}

A condição de repetibilidade de medição, de acordo com o VIM (2012), faz parte de um conjunto de condições, nas quais incluem o mesmo procedimento de medição, os mesmos operadores, o mesmo sistema de medição, as mesmas condições de operação e o mesmo local, assim como medições repetidas no mesmo objeto ou em objetos similares durante um curto período de tempo.

A repetibilidade pode ser expressa quantitativamente em termos da característica da dispersão dos resultados e pode ser determinado por meio da análise de padrões, material de referência ou adição do analito ao branco da amostra, em várias concentrações na faixa de trabalho (BRITO et. al., 2003; AOAC, 2011; BRAMARDI, 2015; INMETRO, 2016). 
As repetições devem ser independentes, ou seja, incluir todas as etapas de preparo do processo de medição.

De acordo com o INMETRO "DOC-CGCRE-008", 2016 para avaliar a repetibilidade do método, o número mínimo de repetições para cada nível de concentração variam de acordo com diferentes documentos de validação, mas tipicamente são entre 6 e 15 por material usado no estudo.

Considerando-se a dificuldade de estimar um desvio padrão confiável a partir de poucas repetições, optamos pela utilização de vários pequenos grupos de repetições para que pudessem ser agrupados a fim de se obter estimativas com números suficientes de graus de liberdade (AOAC, 2011; EURACHEM, 2014).

Os ensaios foram feitos testando as concentrações baixam média e alta da faixa de trabalho. Na Tabela 28 , observam-se os resultados reportados para o teste de repetibilidade/precisão.

\subsubsection{Precisão intermediária}

A precisão intermediária, refere-se à precisão avaliada sob condições que compreendem o mesmo procedimento de medição, o mesmo local e medições repetidas no mesmo objeto ou em objetos similares, ao longo de um período extenso de tempo, mas pode incluir outras condições submetidas às mudanças. Nesse estudo, foram definidas as seguintes condições, (VIM, 2012):

- diferentes analistas;

- diferentes equipamentos;

- diferentes tempos.

Esta medida de precisão representa a variabilidade dos resultados em um laboratório. Na maioria dos casos, o valor de precisão intermediária é função do nível de concentração do ensaio e o seu cálculo é efetuado, preferencialmente, a partir dos resultados obtidos, após eliminação dos resultados discrepantes (BRITO et. al., 2003; AOAC, 2011; BRAMARDI, 2015; INMETRO, 2016).

A visualização gráfica dos valores também pode ser útil para identificálos. Dependendo do ensaio e do tipo de aplicação do estudo da precisão intermediária, existem vários métodos para determinação e controle desse 
parâmetro, tais como (BRITO et. al., 2003; AOAC, 2011; VIM, 2012; BRAMARDI, 2015; INMETRO, 2016):

- por meio de gráfico de controle do desvio padrão, que poderá ser aplicado para replicatas de amostras e para padrões estáveis ao longo do tempo;

- por meio da equação (13):

$$
\operatorname{Spi}\left({ }_{j, k}\right)=\sqrt{\frac{1}{t(n-1)} \sum_{j=1}^{t} \sum_{k=1}^{n}\left(y_{j, k}-\bar{y}_{j}^{2}\right)}
$$

Onde:

$\operatorname{Spi}\left({ }_{j, k}\right)=$ desvio padrão de precisão intermediária;

$\mathrm{t}=$ total de amostras ensaiadas (não confundir com o $\mathrm{t}$ de Student);

$\mathrm{n}=$ total de ensaios efetuados por amostra;

$\mathrm{j}=\mathrm{n}^{\circ}$ da amostra, $\mathrm{j}=1, \mathrm{t} \mathrm{k}=\mathrm{n}^{\circ}$ do ensaio da amostra

$\mathrm{j}, \mathrm{k}=1, \mathrm{n}$ yjk $=$ valor do resultado $\mathrm{k}$ para a amostra

j j y = representa a média aritmética dos resultados da amostra j.

No caso deste trabalho, a determinação da precisão intermediária foi feita por meio de $t$ valores de $n$ ensaios de amostras.

A precisão intermediária baseou-se na dispersão entre os ensaios. Sendo utilizado o valor "t (n-1)", correspondendo a 15 (BRITO et. al., 2003; AOAC, 2011; BRAMARDI, 2015; INMETRO, 2016).

Deste modo, pode-se avaliar se alguma condição influenciou significativamente o valor do desvio padrão da precisão intermediária.

$\mathrm{Na}$ Tabela 28 pode-se observar os resultados obtidos, nos grupos de resultados que foram comparados pelos testes $\mathrm{F}$ e t para verificar se eram considerados estatisticamente semelhantes.

\subsubsection{Linearidade/ faixa de trabalho}

A linearidade pode ser entendida como a capacidade de um método analítico obter resultados que sejam diretamente proporcionais à concentração do analito em amostras, em uma dada faixa de concentração (BRITO et. al., 2003; AOAC, 2011; BRAMARDI, 2015; INMETRO, 2016).

A linearidade é obtida por padronização interna ou externa e formulada como expressão matemática usada para o cálculo da concentração do analito a ser determinado na amostra real. 
A equação da reta (14) que relaciona as duas variáveis é:

$$
y=a x+b
$$

Onde:

$\mathrm{y}=$ Resposta medida (absorbância, altura ou área do pico, etc); $\mathrm{x}=$ Concentração; a = Inclinação da curva de calibração = sensibilidade $\mathrm{b}=$ Interseção com o eixo $\mathrm{y}$, quando $\mathrm{x}=0$.

Pode avaliar a linearidade de um método pelo gráfico dos resultados dos ensaios em função da concentração do analito ou então os calculando a partir da equação de regressão linear, determinada pelo método dos mínimos quadrados (BRITO et. al., 2003; AOAC, 2011; BRAMARDI, 2015; INMETRO, 2016).

O coeficiente de correlação linear $(r)$ é freqüentemente usado para indicar o quanto pode ser considerada adequada à reta como modelo matemático. Um valor acima de 0,90 é usualmente requerido.

O método pode ser considerado como livre de tendências se o intervalo de confiança da reta de regressão linear contiver a origem. Para tal, deve ser verificada a ausência de valores discrepantes para cada nível de concentração e a homocedasticidade dos dados, antes de fazer a regressão linear (BRITO et. al., 2003; AOAC, 2011; BRAMARDI, 2015; INMETRO, 2016).

A verificação da ausência de valores discrepantes pode ser feita pelo teste de Grubbs ou de resíduo (BRITO et. al., 2003; AOAC, 2011; BRAMARDI, 2015;INMETRO, 2016)e a homocedasticidade, isto é, homogeneidade da variância dos resíduos pelo teste de Cochranbem como pelos testes de Levene, teste de Brown-Forsythe (BRITO et. al., 2003; AOAC, 2011; BRAMARDI, 2015; INMETRO, 2016).

Todo experimento de determinação da faixa de trabalho foi iniciado pela escolha de uma faixa preliminar. A faixa de trabalho cobriu a faixa de aplicação para a qual o ensaio é aplicado no laboratório e a concentração mais esperada ficou situada no centro da faixa de trabalho.

No limite inferior da faixa de concentração, o fator considerado limitante foi o valor do limite de quantificação (Tabela 28). 


\subsubsection{Limite de detecção}

O limite de detecção é definido como sendo o menor valor de concentração do analito ou da propriedade que pode ser detectado pelo método. Para a validação de um método analítico, é normalmente suficiente fornecer uma indicação do nível em que a detecção do analito começa a ficar problemática, ou seja, "branco $+3 \mathrm{~s}$ " e " $0+3 \mathrm{~s}$ ", considerando a análise de sete ou mais amostras de branco e, se necessário, de brancos com adição, respectivamente. O símbolo "s" significa desvio padrão (BRITO et. al., 2003; AOAC, 2011; BRAMARDI, 2015; INMETRO, 2016).

De acordo com as recomendações do documento DOQ-CGCRE-008, para se obter o limite de detecção (LD) (equação 20) podem ser analisados sete (7) ou mais soluções de branco da amostra, obtendo média e desvio padrão. Os resultados do limite de detecção estão expressos na Tabela 28.

$$
L D=\bar{X}+t_{(n-1,1-\alpha)} \times S
$$

\subsubsection{Limite de quantificação}

O LQ foi determinado a partir do LD, apesar de ser mais apropriado determinar o LD a partir do LQ por meio da equação (16):

$$
L D=L Q \div 3,3
$$

O método analítico deve ser especificado e o LQ para cada analito deve ser expresso nas unidades apropriadas, de acordo com o preconizado no método analítico (BRITO et. al., 2003; AOAC, 2011; BRAMARDI, 2015; INMETRO, 2016).

Adotamos 7 replicatas do branco da amostra (BRITO et. al., 2003; AOAC, 2011; BRAMARDI, 2015; INMETRO, 2016) para o teste e foi calculada a recuperação (\%) e o coeficiente de variação (\%), Tabela 28. 


$$
L Q=\bar{X}+5 s ; L Q=\bar{X}+6 s ; \text { ou } L Q=\bar{X}+10 s
$$

\subsubsection{Incerteza de medição}

A incerteza de medição foi calculada através de planilhas desenvolvidas no LAQA baseadas no ISO GUM, 2008 após análise nas porções do MRC e amostras.

O resultado de uma medição é apenas uma aproximação ou estimativa do valor do mensurando. Sendo assim, a representação completa desse mensurando deve incluir a incerteza de medição.

Em sentido amplo, "incerteza" significa uma dúvida a cerca de algo, no contexto da química analítica, a "incerteza de medição" significa uma dúvida sobre a qualidade do resultado de uma medição.

Segundo o VIM, 2012, a definição formal do termo incerteza de medição significa o "parâmetro associado ao resultado de uma medição, que caracteriza a dispersão dos valores que podem ser razoavelmente atribuídos ao mensurando".

A incerteza de medição da concentração de um analito em uma determinadamatriz, por exemplo, é expressa na forma de desvio padrão, chamada de incerteza padrão.Entretanto, a incerteza total do método proposto é a soma de todas as incertezas geradasem cada passo do método pelos diversos componentes do processo de medição. Um experimento bem planejado pode, em muito, facilitar as avaliações confiáveis da incertezae é um requisito importante na organização das atividades de medição (BRITO et. al., 2003; ISO GUM, 2008, AOAC, 2011; BRAMARDI, 2015; INMETRO, 2016).

Com o objetivo de identificar e analisar as possíveis fontes de incerteza na metodologia proposta, os procedimentos adotados, para cada etapa, foram detalhados e estruturados de forma a garantir a abrangência necessária para o entendimento e conhecimento do processo de medição e evitar a duplicidade de fontes de incerteza, os resultados são apresentados na Tabela 28. 
Tabela 28 - Resultados obtidos com os testes estatísticos para validação da análise de impurezas em $\bigcup_{3} \mathrm{Si}_{2}$ por ICPOES

\begin{tabular}{|c|c|c|c|c|c|c|c|c|c|}
\hline Elemento & $\begin{array}{c}\text { Seletividade } \\
\mathbf{t}_{\text {calc }}<t_{\text {tab }}\end{array}$ & $\begin{array}{c}\text { Recuperação } \\
\text { Adição } \\
\%\end{array}$ & $\begin{array}{c}\text { Recuperação } \\
\text { MRC 124-1 } \\
\%\end{array}$ & $\begin{array}{c}\text { Repetibilidade } \\
\text { RSD }<10 \%\end{array}$ & $\begin{array}{c}\text { Precisão } \\
\text { intermediaria } \\
F_{\text {calc }}<F_{\text {tab }}\end{array}$ & Linearidade & LDM ug g $^{-1}$ & LQM ug g ${ }^{-1}$ & $\begin{array}{c}\text { Incerteza } \\
\text { Expandida } \\
\text { (U) \% }\end{array}$ \\
\hline Al & 31,8 & 99 & 133 & 2,30 & 5,17 & 0,9996 & 0,001 & 0,003 & 0,1 \\
\hline B & $-28,5$ & 98 & 55 & 52,00 & 1,75 & 1 & 0,11 & 0,32 & 6,4 \\
\hline $\mathrm{Ca}$ & 14,5 & 95 & 60 & 4,00 & 3,7 & 1,03 & 0,003 & 0,008 & 22,2 \\
\hline Cd & $-5,1$ & 91 & 66 & 5,40 & 2,25 & 0,9998 & 0,00004 & 0,0001 & 63,7 \\
\hline Co & $-43,8$ & 91 & 57 & 9,50 & 9 & 0,9998 & 0,02 & 0,06 & 59,1 \\
\hline $\mathrm{Cr}$ & $-34,4$ & 89 & 52 & 4,60 & 3,6 & 0,9999 & 0,24 & 0,73 & 3,7 \\
\hline $\mathrm{Cu}$ & -9 & 94 & 51 & 1,50 & 3,9 & 0,9996 & 0,07 & 0,22 & 0,3 \\
\hline $\mathrm{Fe}$ & $-23,3$ & 89 & 54 & 4,40 & 0,33 & 0,9998 & 0,01 & 0,03 & 0,1 \\
\hline $\mathrm{Li}$ & $-32,9$ & 99 & $X$ & 4,90 & 1,12 & 0,9998 & 0,04 & 0,13 & 72 \\
\hline Mg & $-0,9$ & 88 & 53 & 4,00 & 62,4 & 0,9999 & 0,0002 & 0,001 & 0,80 \\
\hline Mn & 16,7 & 102 & 156 & 4,20 & 10,49 & 0,9999 & 0,0003 & 0,001 & 0,03 \\
\hline Mo & $-35,1$ & 86 & 44 & 5,00 & 0,02 & 0,9998 & 0,0005 & 0,001 & 1,70 \\
\hline $\mathrm{Ni}$ & 15 & 88 & 58 & 5,20 & 1,36 & 0,9999 & 0,006 & 0,02 & 0,60 \\
\hline $\mathbf{P b}$ & $-34,1$ & 95 & $X$ & 4,90 & 0,49 & 0,9999 & 0,03 & 0,08 & 0,80 \\
\hline Sn & $-47,4$ & 109 & $X$ & 2,30 & 0,02 & 0,9998 & 0,11 & 0,34 & 0,60 \\
\hline $\mathbf{V}$ & $-3,8$ & 90 & 118 & 4,10 & 0,65 & 0,9998 & 0,01 & 0,04 & 0,60 \\
\hline $\mathrm{Zn}$ & 9 & 88 & 125 & 3,60 & 3,11 & 0,998 & 0,04 & 0,11 & 0,50 \\
\hline $\mathrm{Ba}$ & -17 & 99 & $X$ & 3,30 & 0,39 & 0,995 & 0,03 & 0,10 & 23,40 \\
\hline
\end{tabular}

LDM = Limite de deteç̧ão; $L Q M=$ Limite de quantificação; $t_{\text {tab }}=2,04 ; F_{\text {tab }}=18,5 ; R S D \%<10 \%$; $X$ elementos que não estão presentes no material de referência certificado (MRC).

Fonte: autora da tese 


\section{ANEXO}

\subsection{Qualificações obtidas pelo LAQA}

O Laboratório de Análises Química e Ambiental (LAQA), procura constantemente seguir padrões de qualidade, para tanto implantou o Sistema de Gestão da Qualidade (SGQ) baseado na Norma ABNT NBR ISO/IEC 17025, além de seguir as diretrizes da norma CNEN NN 1.16. O laboratório participa constantemente de comparações e ensaios interlaboratoriais no Brasil e América Latina para analises de metais em amostras ambientais como pode ser verificado nas cópias dos relatórios de análise crítica de participação anexa.

\subsection{Relatórios de análise das amostras}

São apresentados no anexo 9, os relatórios analíticos de caracterização química do lote de pó de $\mathrm{U}_{3} \mathrm{Si}_{2} \mathrm{EULAB}$, Identificação: UNSI05, utilizado como matéria prima para o preparo do material de referência e um modelo para elaboração do certificado de análise do material.

De modo a complementar os estudos deste material são apresentados os relatórios de caracterização isotópica de duas amostras, representando este lote preparado. Podendo ser verificado nas cópias dos relatórios de análise de amostras anexos. 


\subsection{Qualificações obtidas pelo LAQA}


ANÁLISE CRÍTICA DO PROGRAMA DE ENSAIO DE PROFICIÊNCIA - PEP

EM ANÁLISES AMBIENTAIS - REDE METROLÓGICA DO RIO GRANDE DO SUL -

$4^{0}$ RELATÓRIO DE 2018 (BLOCO A)

Em setembro de 2018 o LAQA participou do Programa de Ensaio de Proficiência - PEP promovido pela Rede Metrológica do Rio Grande do Sul, intitulado como "PEP em Análises Ambientais - ensaios físico-químicos e íons".

Foram recebidas duas (02) amostras de água identificadas como Efluente Industrial e Água Tratada. Sendo solicitadas as determinações de $\mathrm{Cu}, \mathrm{Li}, \mathrm{Sr}, \mathrm{B}, \mathrm{Be}$, V, U, Co, Mo em Efluente Industrial e as determinações de Al, As, $\mathrm{Fe}, \mathrm{Ni}, \mathrm{Ca}, \mathrm{Cd}$, $\mathrm{Pb}, \mathrm{Cr}, \mathrm{Na}, \mathrm{Ba}, \mathrm{Mn}, \mathrm{Zn}, \mathrm{K}, \mathrm{Mg}$ em Água Tratada.

Os relatórios do provedor identificados como " $4^{0}$ Relatório de 2018 (Bloco A)" e "ANEXO $4^{0}$ Relatório de 2018 (Bloco A)" foram recebidos no formato eletrônico e depois arquivados.

\section{RESULTADOS PARA EFLUENTE INDUSTRIAL:}

Conforme tabela anexa, os resultados foram satisfatórios, com exceção apenas para o elemento Cu (cobre) que apresentou resultado "Questionável".

Quando analisados os resultados obtidos nos testes de adicionado (adicionado sobre a amostra real), verificou-se que para o elemento $\mathrm{Cu}$, obteve-se um valor de recuperação igual a 145

$\%$, sendo esse valor o maior valor obtido nos testes de recuperação e o mesmo não foi utilizado nos cálculos finais para emissão e envio para o provedor. Assim, sugere-se que em uma próxima participação a recuperação seja considerada.

\section{RESULTADOS PARA ÁGUA TRATADA:}

Conforme tabela anexa, os resultados foram satisfatórios, com exceção apenas para o elemento As (arsênio) que apresentou resultado "Questionável".

Quando analisados os resultados obtidos nos testes com amostra controle e análise do MRC 1643f, verificou-se que para o elemento As, obteve-se valores de recuperação iguais a $128 \%$ e 107

$\%$, respectivamente, sendo esses valores os maiores valores obtidos e os mesmos não foram utilizados nos cálculos finais para emissão e envio para o provedor. Assim, sugere-se que em uma próxima participação a recuperação seja considerada.

João Cristiano Ulrich

$30 / 01 / 2019$ 


\section{ipen}

\section{ANÁLISE CRÍTICA DO PROGRAMA DE ENSAIO DE PROFICIÊNCIA - PEP EM ANÁLISES AMBIENTAIS - REDE} METROLÓGICA DO RIO GRANDE DO SUL - 4 ${ }^{0}$ RELATÓRIO DE 2018 (BLOCO A)

Anexo: Tabela com avaliação dos resultados.

\begin{tabular}{|c|c|c|c|c|c|c|c|c|c|c|c|c|}
\hline & $\begin{array}{l}\text { Código } \\
\text { Lab }\end{array}$ & $\begin{array}{r}\text { Método } \\
\text { Analítico }\end{array}$ & $1^{\mathrm{a}}$ via & $2^{\mathrm{a}} \mathrm{via}$ & $3^{\mathrm{a}}$ via & $\begin{array}{c}\text { Média das } \\
\text { vias }\end{array}$ & $\begin{array}{l}\text { Desvio } \\
\text { Padrão }\end{array}$ & $\begin{array}{c}\mathrm{CV} \\
\text { Interno(\%) }\end{array}$ & $\begin{array}{l}\text { z score da } \\
\text { média - } \\
\text { Exatidão }\end{array}$ & $\begin{array}{c}\text { Valor } \\
\text { Designado } \\
\text { como } \\
\text { Referência } \\
\text { (XPT) mg de } \\
\text { elem/L }\end{array}$ & $\begin{array}{l}\text { Desvio } \\
\text { Designado } \\
\text { ( } \sigma \mathrm{PT}) \mathrm{mg} \\
\text { de elem } / \mathrm{L}\end{array}$ & $\begin{array}{r}|Z| \leq 2 \text { Resultado Sati } \\
2<|Z|<3 \text { Resultado Q } \\
|Z| \geq 3 \text { Resultado Insa }\end{array}$ \\
\hline COBRE: EFLUENTE INDUSTRIAL & MA 30 & ICP OES & 4,431 & 4,435 & 4,411 & 4,426 & 0,01 & 0,29 & 2,83 & 3,263 & 0,387 & Questionável \\
\hline LITIO: EFLUENTE INDUSTRIAL & & & 2,876 & 2,864 & 2,857 & 2,866 & 0,01 & 0,34 & 0,88 & 2,394 & 0,534 & Satisfatório \\
\hline ESTRONCIO: EFLUENTE INDUSTRIAL & & & 1,807 & 1,798 & 1,778 & 1,794 & 0,01 & 0,83 & 0,70 & 1,676 & 0,168 & Satisfatório \\
\hline BORO: EFLUENTE INDUSTRIAL & & & 1,889 & 1,874 & 1,873 & 1,879 & 0,01 & 0,49 & 1,38 & 1,607 & 0,196 & Satisfatório \\
\hline BERILIO: EFLUENTE INDUSTRIAL & & & 2,487 & 2,46 & 2,453 & 2,467 & 0,02 & 0,73 & 0,93 & 2,256 & 0,227 & Satisfatório \\
\hline VANÁDIO: EFLUENTE INDUSTRIAL & & & 2,032 & 2,025 & 2,027 & 2,028 & 0,00 & 0,18 & 1,38 & 1,754 & 0,198 & Satisfatório \\
\hline URÁNIO : EFLUENTE INDUSTRIAL & & & 0,644 & 0,646 & 0,648 & 0,646 & 0,00 & 0,31 & 1,36 & 0,5338 & 0,0827 & Satisfatório \\
\hline COBALTO : EFLUENTE INDUSTRIAL & & & 2,4946 & 2,4792 & 2,4758 & 2,483 & 0,01 & 0,40 & 1,16 & 2,178 & 0,263 & Satisfatório \\
\hline MOLIBDENIO : EFLUENTE INDUSTRIAL & & & 2,4637 & 2,4552 & 2,4472 & 2,455 & 0,01 & 0,34 & 1,34 & 2,118 & 0,253 & Satisfatório \\
\hline ALUMINIO: AGUA TRATADA & & & 0,319 & 0,305 & 0,301 & 0,308 & 0,01 & 3,07 & 0,97 & 0,266 & 0,043 & Satisfatório \\
\hline ARSËNIO: ÁGUA TRATADA & & & 0,088 & 0,087 & 0,088 & 0,0877 & 0,00 & 0,66 & 2,05 & 0,0626 & 0,0123 & Satisfatório/Questic \\
\hline FERRO TOTAL: AGUA TRATADA & & & 0,27 & 0,27 & 0,27 & 0,27 & 0,00 & 0,00 & 0,08 & 0,267 & 0,037 & Satisfatório \\
\hline NIQUEL: ÁGUA TRATADA & & & 0,312 & 0,305 & 0,311 & 0,309 & 0,00 & 1,22 & 0,49 & 0,293 & 0,033 & Satisfatório \\
\hline CALCIO: AGUA TRATADA & & & 108 & 110 & 109 & 109 & 1,00 & 0,92 & 0,02 & 108,8 & 9,2 & Satisfatório \\
\hline CÁDMIO: ÁGUA TRATADA & & & 0,812 & 0,809 & 0,822 & 0,814 & 0,01 & 0,84 & 0,20 & 0,804 & 0,053 & Satisfatório \\
\hline CHUMBO:AGUA TRATADA & & & 0,0474 & 0,0468 & 0,048 & 0,0474 & 0,00 & 1,27 & 0,83 & 0,042 & 0,0065 & Satisfatório \\
\hline CROMO:AGUA TRATADA & & & 0,093 & 0,091 & 0,093 & 0,092 & 0,00 & 1,25 & 0,21 & 0,091 & 0,008 & Satisfatório \\
\hline SODIO:AGUA TRATADA & & & 82,8 & 81,1 & 81,8 & 81,9 & 0,85 & 1,04 & $-0,15$ & 83,4 & 10,0 & Satisfatório \\
\hline BÁRIO:ÁGUA TRATADA & & & 1,224 & 1,235 & 1,257 & 1,239 & 0,02 & 1,36 & 0,22 & 1,215 & 0,107 & Satisfatório \\
\hline MANGANES:AGUA TRATADA & & & 0,157 & 0,157 & 0,159 & 0,158 & 0,00 & 0,73 & 0,22 & 0,153 & 0,020 & Satisfatório \\
\hline ZINCO:ÁGUA TRATADA & & & 0,153 & 0,153 & 0,154 & 0,153 & 0,00 & 0,38 & 0,17 & 0,150 & 0,019 & Satisfatório \\
\hline POTASSIO:AGUA TRATADA & & & 3,67 & 3,63 & 3,63 & 3,64 & 0,02 & 0,63 & 1,21 & 2,94 & 0,58 & Satisfatório \\
\hline MAGNESIO:AGUA TRATADA & & & 4,99 & 4,91 & 5,02 & 4,97 & 0,06 & 1,14 & 0,78 & 4,54 & 0,56 & Satisfatório \\
\hline
\end{tabular}




\section{ANÁLISE CRÍTICA DO PROGRAMA NACIONAL DE INTERCOMPARAÇÃO - PNI/IRD - RODADA DE AGOSTO DE 2018}

Entre agosto e outubro/2018 o LAQA participou do Programa Nacional de Intercomparação promovido pelo Instituto de Radioproteção e Dosimetria IRD, intitulado como "Rodada de agosto de 2018".

Foram recebidas duas (02) amostras de água identificadas como 456 6328-ZU21/0818 - Tório em água e 457 - 6329-ZU26/0818 - Rádio e Urânio em água. Sendo solicitadas as determinações dos radionuclídeos tório natural (Th - 232), urânio natural $(\mathrm{U})$ e rádio $(\mathrm{Ra})$. As determinações realizadas foram de Th-232 e U natural.

O relatório do provedor identificado como "Avaliação de resultados Rodada de agosto de 2018" foi recebido no formato eletrônico e depois arquivado.

\section{RESULTADOS DE Th - 232:}

- Os valores obtidos a partir do relatório do provedor são (unidade: $\mathrm{Bq} / \mathrm{L})$ :

\begin{tabular}{|c|c|c|c|c|c|c|c|}
\hline $\begin{array}{c}\mathrm{X}_{\mathrm{i}}= \\
\text { Valores } \\
\text { obtidos no } \\
\text { laboratório }\end{array}$ & $\begin{array}{c}X=\text { Valor } \\
\text { médio } \\
\text { obtido no } \\
\text { laboratório }\end{array}$ & $\begin{array}{c}S= \\
\text { Desvio } \\
\text { padrão } \\
\text { em } \\
\text { relação } \\
\text { a X }\end{array}$ & $\begin{array}{l}\mathrm{U}=\text { Valor de } \\
\text { referência, } \\
\text { considerado } \\
\text { como o valor } \\
\text { "verdadeiro" }\end{array}$ & $\begin{array}{c}\text { su }= \\
\text { Desvio } \\
\text { padrão do } \\
\text { valor de } \\
\text { referência }\end{array}$ & $\begin{array}{l}\mathrm{D}=\text { Desvio } \\
\text { normalizado, } \\
\text { utilizado } \\
\text { como } \\
\text { parâmetro de } \\
\text { avaliação }\end{array}$ & $\begin{array}{c}\mathrm{NA}=\text { critério } \\
\text { de avaliação, } \\
\text { significando } \\
\text { intervalo de } \\
\text { valores bons } \\
\text { entre níveis } \\
\text { de } \\
\text { advertência } \\
\text { (valores U } \\
\leq \pm 2 \mathrm{sm} \text { ) }\end{array}$ & $\begin{array}{c}\mathrm{LC}=\text { critério de } \\
\text { avaliação, significand } \\
\text { intervalo de valores } \\
\text { aceitáveis, entre os } \\
\text { limites de controle } \\
(\text { valores } U< \pm 3 \mathrm{sm})\end{array}$ \\
\hline $\begin{array}{l}0,267 \\
0,252 \\
0,250\end{array}$ & 0,256 & 0,009 & 0,300 & 0,045 & $-1,67$ & Dentro & Dentro \\
\hline
\end{tabular}

- Resumindo: Resultado aceitável.

\section{RESULTADOS DE U - natural:}

- Os valores obtidos a partir do relatório do provedor são (unidade: $\mathrm{mg} / \mathrm{L})$ : 


\begin{tabular}{|c|c|c|c|c|c|c|c|}
\hline $\begin{array}{l}X_{i}= \\
\text { Valores } \\
\text { obtidos no } \\
\text { laboratório }\end{array}$ & $\begin{array}{l}\mathrm{X}=\text { Valor } \\
\text { médio } \\
\text { obtido no } \\
\text { laboratório }\end{array}$ & $\begin{array}{l}\mathrm{S}= \\
\text { Desvio } \\
\text { padrão } \\
\text { em } \\
\text { relação } \\
\text { a X }\end{array}$ & $\begin{array}{l}U=\text { Valor de } \\
\text { referência, } \\
\text { considerado } \\
\text { como o valor } \\
\text { "verdadeiro" }\end{array}$ & $\begin{array}{l}\text { su }= \\
\text { Desvio } \\
\text { padrão do } \\
\text { valor de } \\
\text { referência }\end{array}$ & $\begin{array}{l}\text { D = Desvio } \\
\text { normalizado, } \\
\text { utilizado } \\
\text { como } \\
\text { parâmetro de } \\
\text { avaliação }\end{array}$ & $\begin{array}{l}\text { NA = critério } \\
\text { de avaliação, } \\
\text { significando } \\
\text { intervalo de } \\
\text { valores bons } \\
\text { entre niveis } \\
\text { de } \\
\text { advertência } \\
\text { (valores U } \\
\leq \pm 2 \mathrm{sm} \text { ) }\end{array}$ & $\begin{array}{l}\mathrm{LC}=\text { critério de } \\
\text { avaliação, significando } \\
\text { intervalo de valores } \\
\text { aceitáveis, entre os } \\
\text { limites de controle } \\
\text { (valores } U< \pm 3 \mathrm{sm} \text { ) }\end{array}$ \\
\hline $\begin{array}{l}0,124 \\
0,112 \\
0,123\end{array}$ & 0,120 & 0,007 & 0,121 & 0,018 & $-0,13$ & Dentro & Dentro \\
\hline
\end{tabular}

- Resumindo: Resultado aceitável.

Comentários analíticos:

- As determinações foram realizadas em 17/10/2018, sendo a terceira participação do LAQA.

- Os pontos da curva foram preparados em 15/10/2018 nas seguintes concentrações reais: $U$

$=0,104 ; 0,207 ; 0,260 ; 0,516 ; 1,032$ e $2,579 \mu \mathrm{g} \mathrm{g}{ }^{-1}(\mathrm{ppm}) / \mathrm{Th}=0,109 ; 0,217$;

0,$273 ; 0,541 ;$ 1,083 e $2,706 \mu \mathrm{g} \mathrm{g}^{-1}$ (ppm).

- As amostras foram analisadas sem nenhuma diluição, ou seja, amostra como recebida (já estava em $\mathrm{HNO}_{3} 1 \%$ ).

- Os resultados obtidos para Th, na amostra original, estavam dentro da curva de calibração, (resultado médio obtido $=0,667 \mu \mathrm{g}$ $\mathrm{g}^{-1}$ ). $\mathrm{O}$ mesmo para $U$, pois resultado médio obtido $=1,85 \mu \mathrm{g} \mathrm{g}^{-1}$.

- Nesta rodada foi analisada uma alíquota da amostra anterior de Th e de U para controle das análises. 
9.2 Relatórios de análise das amostras 


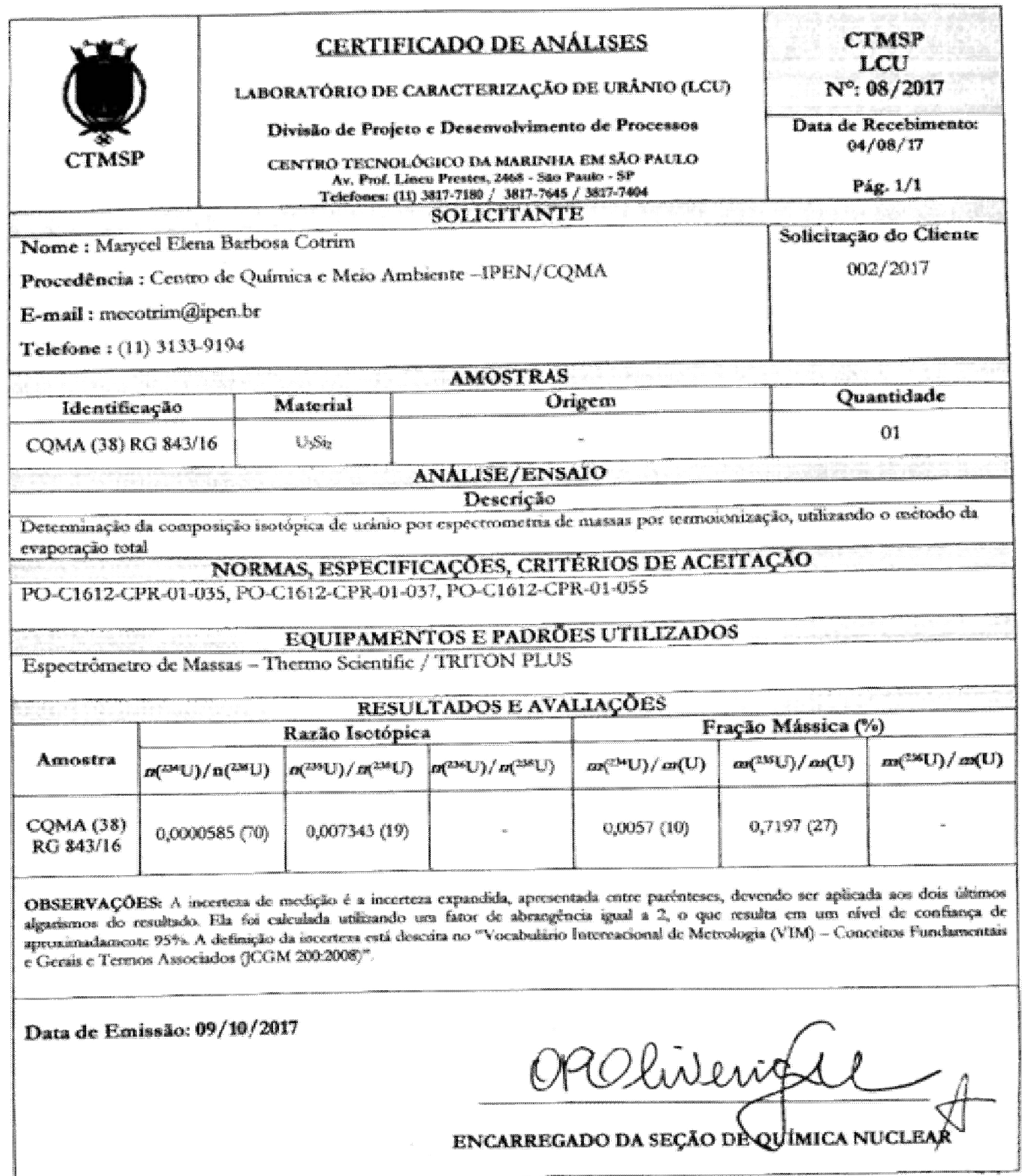


comiss a naclonal de energla nuclear instituto de pesquisas energoticas e nucleares

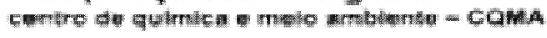

01 Relatóno $n^{2}, 057 / 17$

o2. RC da(s) Amostra(s) 1264/17 a 1271/1?

os. Salo Paulo 22 de Malo de 201 ?

\section{RELATÓRIO DE ANÁLISE}

\section{Solicitante \\ OS. Enoarvo: \\ 06. Amostra}

07. Analise Solicitada

Q8. intompotes fomplementares

9. Data de Recebirvento para Andisa:

*0. Data da Realracto da Analime

\section{Luchana Vietra de Santana \\ IPEN-CQMA, Setor E4-Prédlo 30}

Sticeto de uranto natural em po

B. Mg. Al, S, Ca, V, Cr. Mn, Fa, Co, Ni, Cu, Zn, Mo, Cd, Ba, Pb, Sn, U.

\section{7}

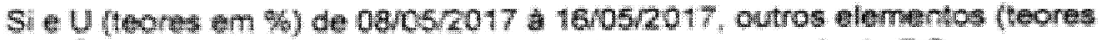

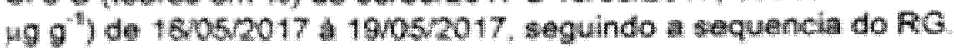

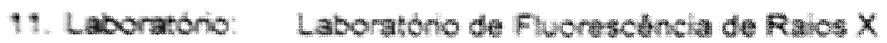

Responsavel: Vera Luela $\mathrm{F}$. Salvador walvado

Analista: Marcos Antonto Scapin

Tecnica analitica. Espoctrometrit de fuoreschncia de rasos $X$ por dispersäo de comprimento de onda

12. Resultados:

\begin{tabular}{|c|c|c|c|}
\hline \multirow{2}{*}{ ChementorTer } & \multicolumn{3}{|c|}{ RG 1.264/17 - ML-07 - Silketo de uranio natural } \\
\hline & Replica 14 & Replicil 10 & Reglica 1c \\
\hline$B\left(1+8 \mathrm{~B}^{-1}\right)$ & $<2,6$ & 62.6 & -26 \\
\hline $\operatorname{Mr}\left(\mu g^{4}\right)$ & C43 & 543 & 643 \\
\hline Al $\left(14 C^{-1}\right)$ & $156+16$ & $156 \pm 16$ & $156 \pm 16$ \\
\hline Si ( $\mathbf{3})$ & $7,804 \pm 0,004$ & $7,803+0,004$ & $7,80310,004$ \\
\hline$C a\left(u s e^{3}\right)$ & 587 & 687 & $<3$ \\
\hline$\left.v(\mu s)^{4}\right)$ & 222 & $<22$ & $<22$ \\
\hline $\operatorname{cr}\left(1 \mathrm{se} \mathrm{e}^{2}\right)$ & 43 & $<3$ & $<3$ \\
\hline $\operatorname{Mn}\left(H \mathrm{~g}^{\circ}\right)$ & $191+19$ & $191+19$ & 19139 \\
\hline Fe $\left(\mu \mathrm{s} \mathrm{E}^{\mathrm{A}}\right)$ & $206 \pm 20$ & $206 \pm 20$ & 20620 \\
\hline $\operatorname{col}(\mu \mathrm{se})$ & $<7$ & 47 & 477 \\
\hline Ni (hes है) & 67 & 67 & 67 \\
\hline $\mathrm{Cu}\left(\mathrm{He} \mathrm{B}^{*}\right)$ & $<22$ & 22 & 622 \\
\hline $\ln \left(\mu s E^{-3}\right)$ & $\mathrm{cBg}$ & 488 & $<88$ \\
\hline Mo $\left.(\mu)^{2}\right)^{2}$ & $<40$ & $<40$ & $<40$ \\
\hline cd $\left(j+8 \mathrm{r}^{1}\right)$ & 2 & $<2$ & $<2$ \\
\hline $04(H g)$ & 22 & 2 & 52 \\
\hline $\mathrm{Pb}(1 \mathrm{se})$ & $<18$ & $<18$ & $<18$ \\
\hline $\sin \left(48 g^{-1}\right)$ & $<20$ & 520 & 220 \\
\hline$u(\mathbf{6})$ & $91,14 \pm 0,05$ & $91,16 * 0,05$ & $91,15 \pm 0,05$ \\
\hline
\end{tabular}

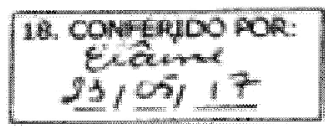


comissâo nacional de energla nuclear

instituto de pesquis as energeticas nucleares.

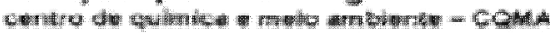

01. Retatorio n* $119 / 16$

02. RC da(s) Amostra(s) 48516 a $486 / 16$

03. Sac Pauto 01 de juho de 2016.

\section{RELATORIO DE ANALLISE}

04. Solicitante

05. Enderewa

06. Amostra

07. Analise Sollcitada

ob. Informacoses Complementares

09. Data de Resebimento para Andlise:

10. Data da Fealizacao da Andise:

1. Laboratorio:
Luciana veira do Santana

COMA

Silicete de Uranto

Hidrogeno, Nitrogeno Oxigeno, Gabono Enxotre

$-$

10052016

23060216

Laboratoro de Analises Qumbate Anbiental - LAOA

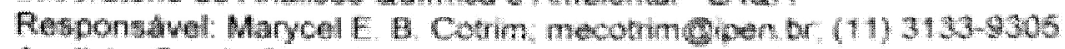

Analista: Sergio Carvalho Moura

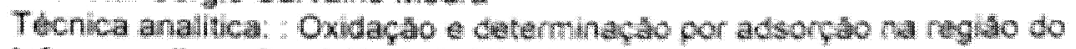

Infravermetho condutwidadie Termisa

12. Resultados:

\begin{tabular}{|c|c|c|c|c|c|c|}
\hline RG & $\begin{array}{c}\text { Identificaçăo da } \\
\text { Amostra }\end{array}$ & $\begin{array}{c}\text { Elemento } \\
\mathrm{H}_{2}(\mathrm{ppm})\end{array}$ & $\begin{array}{c}\text { Elemento } \\
\mathrm{N}_{2}(\mathrm{ppm})\end{array}$ & $\begin{array}{c}\text { Elemento } \\
O_{2}(\mathrm{ppm})\end{array}$ & $\begin{array}{c}\text { Elemento } \\
\text { Carbono }(\%)\end{array}$ & $\begin{array}{c}\text { Elemento } \\
\text { Enxofre }(\%)\end{array}$ \\
\hline $485 / 16$ & $11 \mathrm{MR} \mathrm{Si} \mathrm{O}_{3}$ & $44 \pm 11$ & $122 \pm 15$ & $1250 \pm 25$ & $0,05 \pm 0,02$ & $0,04 \pm 0,01$ \\
\hline $486 / 16$ & $11 \mathrm{MR} \mathrm{SirO}$ & $44 \pm 11$ & $122 \pm 15$ & $1250 \pm 25$ & $0,05 \pm 0,02$ & $0,04 \pm 0,01$ \\
\hline
\end{tabular}

13. Comenarios:

a) 0 resultado representa a media 6 desvio padra de tres (3) deteminacos.

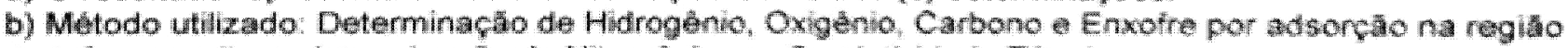
do Infravermelto e deteminaça de Nitrogenio por condutividade Temica.

Clausulas de Responsabilidade:

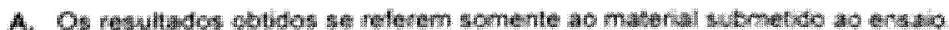

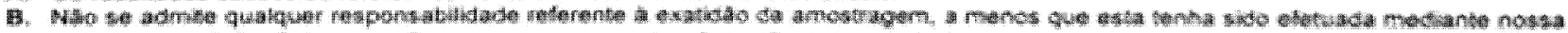

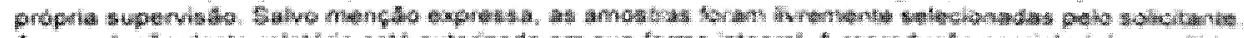

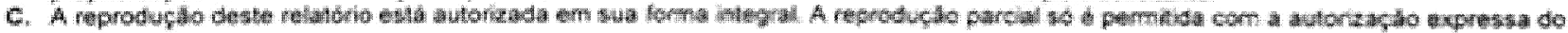
Coma.<smiles>CCCc1ccc(Cl)cc1</smiles>

15. Marycel E. B. Cotrm CRQ: 04121797 Laboratório<smiles>CCCC1(CC)CCCCC1</smiles>

16. Serow Cand Mo Mra CRQ: $04127: 14$

Sungnatarto Autorizado

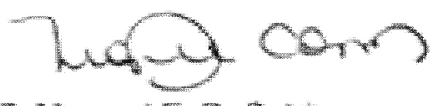

17. MaryeelE E Cotrim Contro de Quimic Malo Amblente Gerente Adjunto

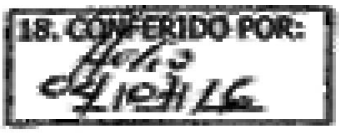




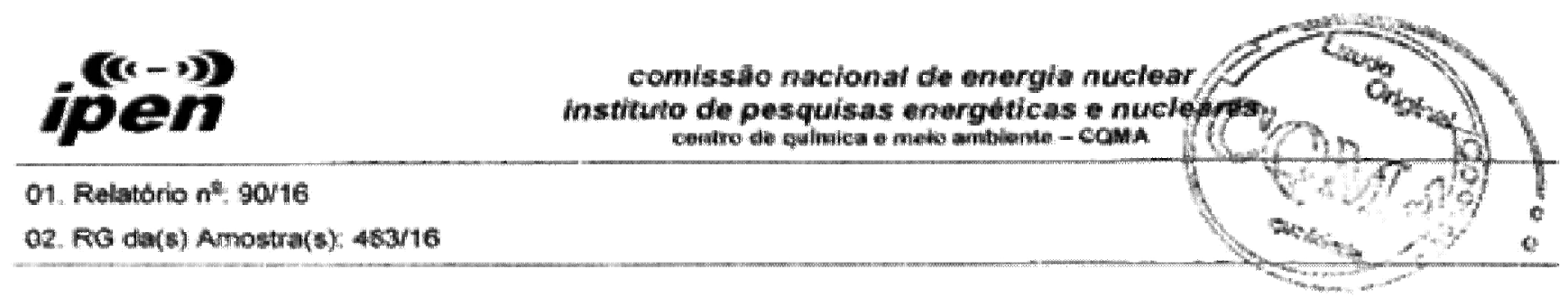

03. Sogo Paulo, 8 de Junho de 2016

\section{RELATÓRIO DE ANÁLISE}
04. Solicitarte:
Luclana Vheira de Santana
05. Endiereco:
COMA
06. Amotira:
Po de Uysis
07. Aralise Sodcitada:
Uranio : silicis
08. Hintomagoes Complementares:
U nafural
09. Duta de Recobimento para Anallse:
10052016
10. Data da Realizacto da Anthse: 03/06/2016
11. Laboratorio: Laborabrio de Andisas Oulmica e Ambiental

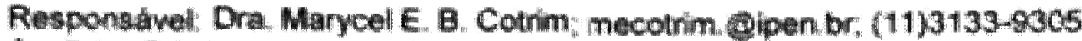
Analista: Cristina Sintil e Cleide Moreira da Siva
Tecnies anamica. Titulackbo Polunciombtica e Gravimetria

12. Resultados:

\begin{tabular}{|c|c|c|}
\hline $\begin{array}{c}\text { Identincagho do } \\
\text { Amostra }\end{array}$ & $\mathbf{U}$ & sI \\
\hline$U_{3} S_{2}-P_{1}$ & $(\%)$ & $(\%)$ \\
\hline
\end{tabular}

13. Comentarios:

O resultado corresponde a media e deswo padräo de 3 repilicatas.

Quantidade utilizada: $\mathrm{m}_{\mathrm{kempowh}}=4,81 \mathrm{~g}$

Oeterminaçio de uranio pelo método de Cavies Gray e Silioo por Gravimetria

14. Clausulas de Responsabilidade:

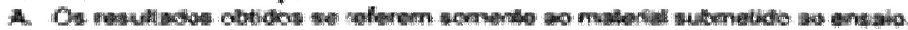

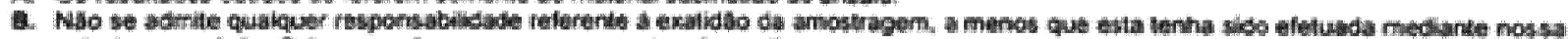

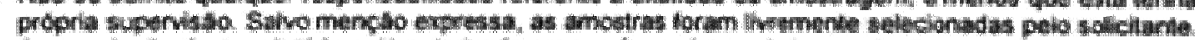

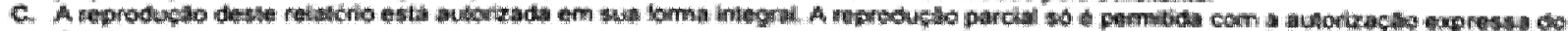
oOMa,

16.

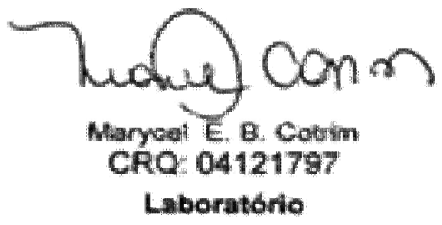

16

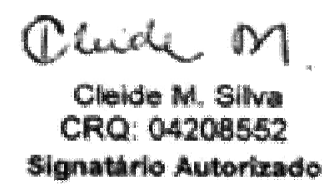

17.<smiles>CCCC1CCCCC1</smiles>

Maryced E. B. Coum

Centro de Quimics Allo Ambiente Gerente Acpunto 
comlssto nacional de energia nuclear instivio do posquisas energetlcas nueleares

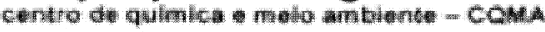

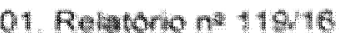

o2. RG da(s) Amostra(s) $485 / 16$. $486 / 16$

03. São Paulo, 01 de julho de 2016.

\title{
RELATÓRIO DE ANÁLISE
}

\author{
04. Sollotitante \\ Luclana Vhatra de Bantane \\ as. Enderepo \\ COMA \\ 06. Amostra \\ Silcete de Urano \\ 07. Andisid Solictad. \\ 08. Informacoes corroumentares \\ Hidrogénio Nitrogenio. Oxgenio Carbono enxotw \\ 09. Data de Recobinento para Andise: 10052016 \\ 10. Data da Realizacalo da Andise: 2306roto \\ 1. Laboratorio Laboratono de Analises Oumica Ambiantal - LAOA \\ Responsave: Marycel E B Cotrm mecotrimodinen br: (11) $3133-9305$ \\ Analista: Sergio Carvatho Moura \\ Tecnica analifica: : Oxidaço determinacto por adsoncto na regiso do \\ infavermelho condubivade Tarmict.
}

12. Resultados:

\begin{tabular}{|c|c|c|c|c|c|c|}
\hline RG & $\begin{array}{l}\text { Identificaça da } \\
\text { Amostra }\end{array}$ & $\begin{array}{l}\text { Elemento } \\
\mathrm{H}_{z} \text { (ppm) }\end{array}$ & $\begin{array}{l}\text { Elemento } \\
\mathrm{N}_{2} \text { (ppm) }\end{array}$ & $\begin{array}{l}\text { Elemento } \\
\text { O. }_{2} \text { (ppm) }\end{array}$ & $\begin{array}{c}\text { Elemento } \\
\text { Carbono }(\%)\end{array}$ & $\begin{array}{l}\text { Elemento } \\
\text { Enxofre }(\%)\end{array}$ \\
\hline $485 / 16$ & $11 \mathrm{MP}_{\mathrm{Si}} \mathrm{O}_{3}$ & $44 \pm 11$ & $722 \pm 15$ & $1250 \pm 25$ & $0,05 \pm 0,02$ & $0.04 \pm 0.01$ \\
\hline $486 / 16$ & $11 \mathrm{MR}$ S: ${ }_{2} \mathrm{O}$ & $44 \pm 11$ & $122 \pm 15$ & $1250 \pm 25$ & $0,05 \pm 0,02$ & $0,04 \pm 0,01$ \\
\hline
\end{tabular}

\section{Comentarios}

a) O resultado reprasenta a média e deswo padrâo de tress (3) determinaçées.

b) Metodo utilizado: Determinaçẳo de Hidrogennio, Oxigênio, Carbono e Enxofre por adsorçäo na regiăo do frffravermetho e determinaçăo de Nitrogünio por condutividade Têmica.

Cláusulas de Responsabilidade:

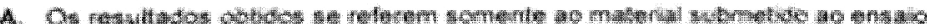

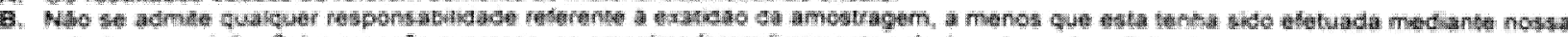

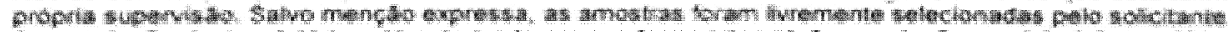

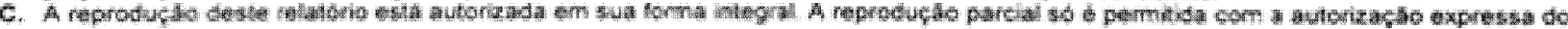
comats

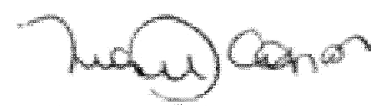

15 Marved E. Cotim CRO OA 12179 Laboratorio

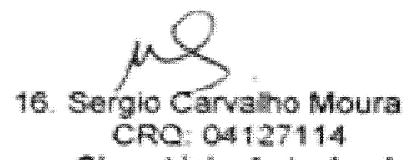

Signatario Autorizado

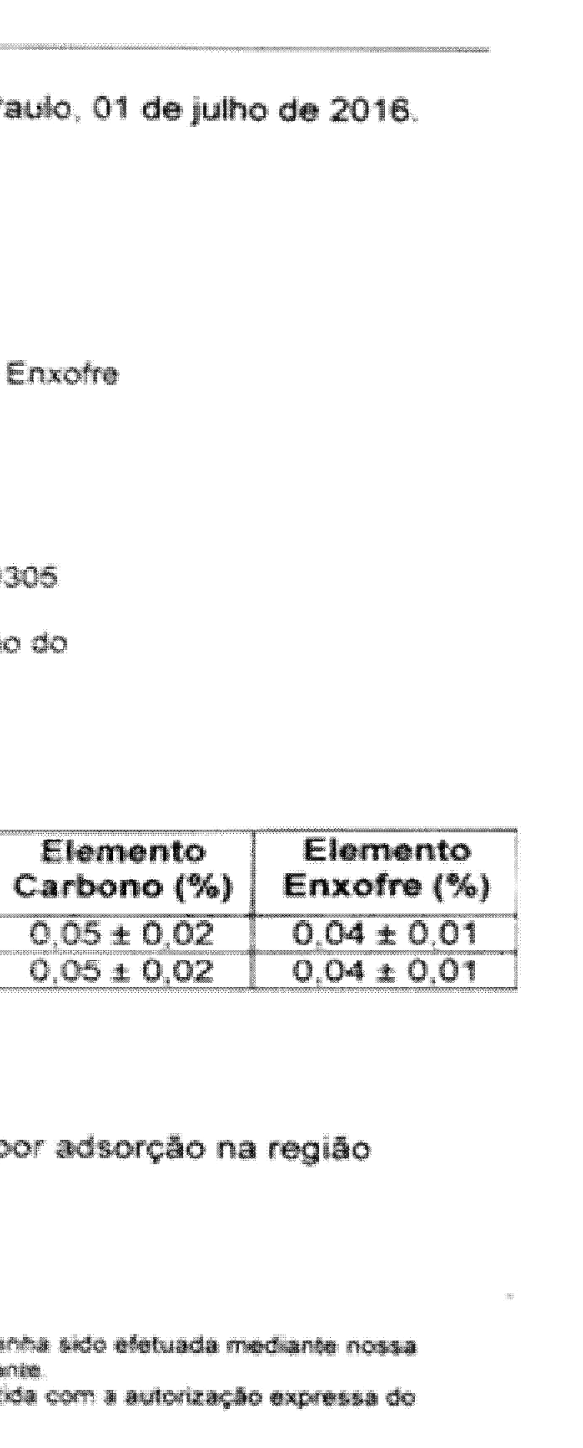

17. warycel E B. Cotrim Contro de Quimica a Mulo Ambianto Gerante Adjunto 


\title{
ipen
}

INSTITUTO DE PESQUISAS ENERGÉTICAS E NUCLEARES

Programa de Tecnologia Nuclear da Universidade de São Paulo

Modelo Certificado de Análise

MRC UNSi-15

\author{
Siliceto de Urânio $\left(\mathrm{U}_{3} \mathrm{Si}_{2}\right)$ Padrão para urânio, silício e 18 Elementos Impurezas \\ Standard
}

Este Material de Referência Certificado (Certified Reference Material - CRM) é um padrão de urânio total e silício total e 18 impurezas, destinado a ser usado na determinação do teor de desses elementos em materiais de urânio. Cada unidade do material consiste em um (1) frasco contendo siliceto de urânio- $\mathrm{U}_{3} \mathrm{Si}_{2}$ (composição isotópica natural) como material de matriz, aproximadamente 26 gramas por frasco, dezoito elementos (18) presentes na matriz do material são considerados como impurezas.

0 material da matriz de $U_{3} \mathrm{Si}_{2}$ foi preparado a partir de uma liga de urânio silício, a qual foi moída, peneirado e homogeneizada (em homogeneizador mecânico) e engarrafado. Uma discussão completa da preparação é encontrada no Banco de Teses e Dissertações da Universidade de São Paulo (USP) e do Instituto de Pesquisas Energéticas e Nucleares (IPEN).

Os valores certificados para os elementos urânio, silício e impureza são baseados nos valores "preparados". As incertezas expandidas (fator de abrangência k equivalente a 95\% de confiança) são baseadas em uma avaliação de dados analíticos que confirmaram o conteúdo de urânio, silício e impurezas. Uma avaliação do grau de homogeneidade e estabilidade é incluída no cálculo de incerteza. As incertezas expandidas para os valores certificados são consideradas conservadoras. Não houve indicação de alterações significativas nas concentrações de impurezas em função do tempo (vida de prateleira). O material de referência é rastreável para as unidades do $\mathrm{Sl}$.

NOTA:. O IPEN recomenda uma amostra mínima de $1,2 \mathrm{~g}$ do material para garantir a homogeneidade do urânio e silício, e 2,0 g do material para análise de impurezas. Não é necessário a queima do material em forno mufla para garantir a estabilidade do peso.

Uma amostra aleatória das unidades foi tomada para análise de urânio (concentração elementar) . 0 ensaio de urânio foi determinado pelo Método de Titulação Potenciométrica Davies \& Gray/NBL usando o Padrão de Referência Padrão Oxidimétrico de Dicromato de Potássio $\left(\mathrm{K}_{2} \mathrm{Cr}_{2} \mathrm{O}_{7}\right)$, como titulante e o padrão NBL CRM 129, Padrão de Ensaio de Óxido de Urânio $\left(\mathrm{U}_{3} \mathrm{O}_{8}\right)$ foram usados como controles para verificar o desempenho adequado dos sistemas de medição. As medições do ensaio de urânio foram realizadas por dois analistas, cada um utilizando sistemas de titulação independentes. Antes da preparação da titulação, amostras de análise CRM 129-A foram inflamadas a $800^{\circ} \mathrm{C}$ até peso constante como determina o procedimento recomendado para o uso do CRM 129-A.

Marycel H. B. Cotrim, Gerente CQMA, 04, Fevereiro, 2019 SP

Laboratorio de Analises Químicas e Ambientais (LAQA)

Instituto de Pesquisas Energéticas e Nucleares

Av. Prof. Lineu Prestes, no 2242 - Cidade Universitária - CEP 05508-900

Telefone: (11) 3133-8918 - Fax: (11) 3133-8908 


\section{ipen}

INSTITUTO DE PESQUISAS ENERGÉTICAS E NUCLEARES

Programa de Tecnologia Nuclear da Universidade de São Paulo

Certificado de analise

Micrograma de impureza por grama de U

\begin{tabular}{cc}
\hline Elemento & Média \pm Incerteza associada U (\%) \\
\hline $\mathrm{Al}$ & $144 \pm 0,1$ \\
\hline $\mathrm{B}$ & $1 \pm 6$ \\
\hline$\# \mathrm{Ba}$ & $1 \pm 23$ \\
\hline$\# \mathrm{Ca}$ & $1 \pm 22$ \\
\hline$\# \mathrm{Cd}$ & $0,3 \pm 64$ \\
\hline$\# \mathrm{Co}$ & $0,3 \pm 59$ \\
\hline $\mathrm{Cr}$ & $28 \pm 4$ \\
\hline $\mathrm{Cu}$ & $27 \pm 0,3$ \\
\hline $\mathrm{Fe}$ & $359 \pm 0,1$ \\
\hline$\# \mathrm{Li}$ & $0,1 \pm 72$ \\
\hline $\mathrm{Mg}$ & $7 \pm 1$ \\
\hline $\mathrm{Mn}$ & $99 \pm 0,1$ \\
\hline $\mathrm{Mo}$ & $3 \pm 2$ \\
\hline $\mathrm{Ni}$ & $14 \pm 1$ \\
\hline $\mathrm{Pb}$ & $4 \pm 1$ \\
\hline $\mathrm{Zn}$ & $5 \pm 1$ \\
\hline $\mathrm{V}$ & $9 \pm 1$ \\
\hline $\mathrm{Sn}$ & $8 \pm 1$ \\
\hline
\end{tabular}

\#Valores não certificados (valor informativo)

Certificado de analise

Urânio e silício totais (\%)

Elemento

U

$\mathrm{Si}$
Média \pm Incerteza associada

$$
\mathrm{U}(\%)
$$

$91,8 \pm 0,5$

$7,6 \pm 0,1$

Instituto de Pesquisas Energéticas e Nucleares

Av. Prof. Lineu Prestes, no 2242 - Cidade Universitária - CEP 05508-900

Telefone: (11) 3133-8918 - Fax: (11) 3133-8908 


\section{REFERÊNCIAS BIBLIOGRÁFICAS}

AIGNER, R. BINNER, E. KUHN, U. BLOHM-HIEBER, K. MAYER, S. GUARDINE, C. PIETRI, T. ADACHI, B. RAPPINGER, B. MITTERRAND, J. REED, O. MAFRA-GUIDICINI, S. DERON, International Target Values 2000 for Measurement Uncertainties in Safeguarding Nuclear Materials, IAEA/STR-327, pp.24 (2001).

AMERICAN STANDARD FOR TESTING MATERIALS, ASTM C1334-96 (2000), Standard Specification for Uranium Oxides with a ${ }^{235} \mathrm{U}$ Content of Less Than $5 \%$ for Dissolution Prior to Conversion to Nuclear-Grade Uranium Dioxide, ASTM, 2000.

AMERICAN STANDARD FOR TESTING MATERIALS, C 1334-94 Standard Specification for Nuclear-grade Uranium Oxide $\left(\mathbf{U}_{3} \mathrm{O}_{8}\right)$, ASTM, 1993.

AMERICAN STANDARD FOR TESTING MATERIALS, C 1334-93 Standard Specification for Nuclear-Grade Uranium Oxide (U3O8), ASTM, 1993.

AMERICAN STANDARD FOR TESTING MATERIALS, B 214-16 Standard Test Method for Sieve Analysis of Metal Powders, ASTM, 2016.

ANALYTICAL METHODS COMMITTEE. Robust statistics- how not to reject outliers. Part 1. Basic concepts. The Analyst114, 1693-1697, (1989a)

ANALYTICAL METHODS COMMITTEE. Robust statistics- how not to reject outliers. Part 2. Inter-laboratory trials. The Analyst114, 1699-1702, (1989b) 
ASSOCIATION OF OFFICIAL ANALYTICAL CHEMISTS. AOAC.Standard Method Performance Requirement (SMPR) Documents (Version12.1; 31Jan-11).

Disponível em:<http://www.aoac.org/aoac_prod_imis/AOAC_Docs/ISPAM/3.5SMPRGuideli SMS12.1.pdf>Acesso: 10/01/2019.

ASSAD S. AL-AMMAR*, H. A. HAMID, B. H. RASHID AND H. M. BASHEER. Preparation of uranium by reversed-phase partition chromatography: Application to the determination of trace elements in nuclear-grade uranium compounds by inductively coupled plasma atomic emission spectrometry, Journal of Chromatography, 537, 287-294, 1990.

ASSOCIAÇÃO BRASILEIRA DE NORMAS TÉCNICAS. Requisitos gerais para a competência de laboratórios de ensaio e calibração, ABNT NBR ISO/IEC 17025, 2017.

ASSOCIAÇÃO BRASILEIRA DE NORMAS TÉCNICAS. Avaliação de Conformidade-Requisitos geral para ensaios de proficiência, ABNT NBR ISO/IEC 17043, 2011.

ASSOCIAÇÃO BRASILEIRA DE NORMAS TÉCNICAS. Materiais de referência - Termos e definições selecionados, ABNT ISO GUIA 30, 2016.

ASSOCIAÇÃO BRASILEIRA DE NORMAS TÉCNICAS. Materiais de referência - Princípios gerais e estatísticos para certificação, ABNT NBR ISO 17034:2017.

ASSOCIAÇÃO BRASILEIRA DE NORMAS TÉCNICAS. Materiais de referência - Princípios gerais e estatísticos para certificação, ABNT ISO GUIA 35, 2012.

AWANI. Z., KHAN A. Q. Uranium - The Element: Its Occurrence and Uses, J.Chem.Soc.Pak., Vol. 37, No. 06, 2015. 
BAIMA C. Reator multiproposito vai garantir independência do Brasil. O GLOBO, rio de Janeiro, 07 Fev. 2012, Cad. CIENCIA. Disponível em $<$ http://www.naval.com.br/blog/2012/02/07/reator-multiproposito-vai-garantirindependencia-nuclear-do-brasil/\#axzz2EeAJy8oG>Acesso em: 15/11/17.

BAM RM GUIDELINES - Guidelines for the production of BAM reference materials.

Disponível

em:

$<$ http://www.bam.de/en/fachthemen/referenzmaterialien/referenzmaterialien_me dien/bam_rm_guidelines.pdf >Acesso em: 15/11/17.

BRAMARDI S. Method validation for pesticide residue testing. Workshop de Validação de Métodos de Ensaios Analíticos, FAO/IAEA. 6-8 May, Santiago, Chile, 2015. (Material didático apresentado no workshop de validação de métodos de ensaios analíticos).

BRITO N. M; JUNIOR O. P. A; POLESE L.; RIBEIRO M. L. Validação de métodos analíticos: estratégia e discussão. Pesticidas: R.Ecotoxicol. e Meio Ambiente, Curitiba, v.13, p 129-146, jan/dez. 2003.

BINFORD, F.T. E KNIGHT, R.W. The use of UgOg-Al cermet fuel in research reactors. Trans. Amer. Nucl. Soc., v.27,,p.34-35,1977.

BU"RGER, S.; BOULYGA, S. F.; PEN'KIN, M. V.; BOSTICK, D.; JOVANOVIC, S.; LINDVALL, R.; RASMUSSEN, G.; RICIPUTI, L. Quantifying multiple trace elements in uranium ore concentrates: An interlaboratory comparison. $J$ Radioanal Nucl Chem, 2015.

CARDOSO M. H. M. Preparação de um material de referência certificado para controle de agrotóxicos em hortifrutigranjeiros: Estudo da homogeneidade, Ciênc. Tecnol. Aliment., Campinas, 30(2): 429-438, abr-jun. 2010.

CENTRO DO COMBUSTÍVEL NUCLEAR. Disponível em $<$ https://www.ipen.br/portal_por/portal/interna.php?secao_id=544>Acesso em 12/11/2017. 
CENTRO DE ENGENHARIA NUCLEAR. Especificação do pó de U3Si2 para a placa combustível do reator IEA-R1, 2013. Informação técnica INF.CENC.CEN.046.00, IPEN-CNEN/SP, São Paulo.

COMISSÃO NACIONAL DE ENERGIA NUCLEAR. "Controle de materiais nucleares", CNEN-NN-2.02, 1999. Disponível em <http://appasp.cnen.gov.br/seguranca/normas/pdf/Nrm202.pdf> Acesso em 12/09/2018.

COMISSÃO NACIONAL DE ENERGIA NUCLEAR. Programa Política Nuclear PPA 2016 - 2019 E LOA 2016. Rio de Janeiro. 2016. Disponível em:<http://www.cnen.gov.br/images/cnen/documentos/planejamento/Programa PoliticaNuclear-PPA-2016-2019.pdf>Acesso em 07/11/2017.

COMISSÃO NACIONAL DE ENERGIA NUCLEAR, 2000. Garantia da Qualidade para a Segurança de Usinas Nucleoelétricas e outras Instalações, CNEN-NN-1.16.

Disponível em:<http://appasp.cnen.gov.br/seguranca/normas/pdf/Nrm116.pdf>, acesso em 07/11/2017.

COMISIÓN NACIONAL DE ENERGÍA ATÓMICA, 2008. Determinacion de urânio y silício em siliciuros de urânio (Instrucción de ensayo). IT-ATN NQ-24.

CUNNINGHAM, J.E.; BOYLE, E.J. MTR-Type fuel elements. In: UNITED NATIONS. Peaceful uses atomic energy: proceedings of the International Conference on..., held in Geneva, 8-20 Aug. 1955. V. 9: Reactor technology and chemical processing. New York, N.Y., 1956. p. 203-7.

CUNNINGHAM, J.E.; BEAVER, R.J.; THURBER, W.C.; WAUGH, R.C. Fuel dispersions in aluminum-base elements for research reactors. In: USAEC. FUEL ELEMENTS, Conference held in Paris, November 18-23, 1957. Oak Ridge, Tn: Oak Ridge: USAEC, 1958, p.269-297,(TID-7546). 
COTRIM M. E. B., MARTINS E. J. A., DANTAS E. S. K., PIRES M. A. F. Desenvolvimento de metodologia para avaliação de impurezas em $\mathrm{U}_{3} \mathrm{O}_{8}$, por ICPOES. In: vi Congresso Geral de Energia Nuclear, 2002, Rio de Janeiro. INAAC 2002 International Nuclear Atlantic Conference, 2002. v. 1. p. 1-3.

COTRIM M. B., SATO I. M., SALVADOR V. L., DANTAS K. E. S.,CANTAGALLO M.I., LEMES M. J. L., SCAPIN M. A., SISTI C., SILVEIRA E.S., FURUSAWA H. A., PIRES M. A. F., Participação da Divisão de Diagnóstico Ambiental do IPEN-CNEN/SP em Programas de Intercomparação Laboratoriais em Amostras Ambientais. METROLOGIA2003 - Metrologia para a Vida Sociedade Brasileira de Metrologia (SBM) Setembro 01-05, 2003, Recife, Pernambuco - BRASIL.

CRISTIANO, B.F.G., 2010. Implementação do Método de Titulação Potenciométrica Automatizado para Urânio Total no Laboratório de Salvaguardas da CNEN. Dissertação de Mestrado em Ciências, Instituto de Radio Proteção e Dosimetria/CNEN, Rio de Janeiro.

CRISTIANO B. F. G., DIAS F. C., BARROS P. D., ARAÚJO R. M. S., LOPES R. T., DELGADO J. U., E SILVA J.W. Método de titulação potenciométrica de alta precisão semi-automatizado para a caracterização de compostos de urânio. 18th International Conference on Radionuclide Metrology and its Applications, 2011.

DAVIES, W. \& GRAY, W. A rapid and specific titrimetric method for the precise determination of uranium using iron (II) sulphate as reductant. Talanta,11:1203-11, 1964.

DURAZZO M., CARVALHO. E. F. U., SILVA A. M. S., SOUZA J. A. B., RIELLA H. G. A tecnologia de fabricação do combustível nuclear a base de dispersão no instituto de pesquisas energéticas e nucleares IPEN/CNENSP. $18^{\circ}$ CBECIMAT-Congresso Brasileiro de Engenharia e Ciência dos Materiais, 24 a 28 de Novembro, Porto de galinhas, PE, Brasil, 2008. 
EBÊRLE. A. R.; LERNER, NI. W.; GOLDBEK, C. G. RODDEN. C. J. Titrimetric determination of uranium in product, fuel and scrap materials after ferrous ions reduction in phosphoric acid. Manual and automatic titration. In: INTERNATIONAL ATOMIC ENEKGY AGENCY. Safeguards techniques proceedings of the symposium on held in Karlsruhe, 6- 10 July, 1970. Vienna, 1970 , «. 2, p. 27 - 43.

EMSLEY J. Nature's Building Blocks: An A to $Z$ Guide to the Elements. Cap. Uranium. Oxford University Press ,2001. pag. 476-82. isbn=0-19850340-7.

EURACHEM/CITAC Guide. Quantifying Uncertainty in Analytical Measurement. 2. Edition, 2002.

FLOYD M. A., MORROW R.W., FARRAR R.B., Inductively Coupled PlasmaAtomic Emission-Spectroscopy - the Determination of Trace Impurities in Uranium Hexafluoride, Spectrochim. Acta B Atom. Spectrosc. 38 (1-2) (1983) 303-308.

FURMAN, N.H., Standard Methods of Chemical Analysis, Vol. 1, 6th Ed., Ed. Robert E. Krieger Publishing Co., Malabar, 1975.

GIETZEN, A.J. E WEST, G.B. Low-enrichment U-ZrH fuel for TRIGA and plate- type reactors. Trans. Amer. Nucl. Soc.,v.30, p.726-727,1978.

GINÉ ROSIAS, M. F. Espectrometria de emissão atômica com plasma acoplado indutivamente - ICP-AES. Piracicaba - SP : CENA - Centro de Energia Nuclear na Agricultura/ USP - Universidade de São Paulo, 1998.

GONÇALVES F., RUIZ H. R. Energia Nuclear. n 6, Ano 3, ISSN 2358-5277, Faculdade Getulio Vargas, Abril de2016.

HOLDEN A.N. Dispersions fuel elements.New York, Gordon \& Breach, 1967.

IAEA, INTERNATIONAL ATOMIC ENERGY AGENCY, Advanced methods of process/quality control in nuclear reactor fuel manufacture, In: IAEA, 
Proceedings of a Technical Committee meeting held in Lingen, Germany, 18-22 October 1999.

IAEA, INTERNATIONAL ATOMIC ENERGY AGENCY, Preparation of reference materials and organization of proficiency test rounds, (IAEA INT 1/054 Interregional project), 2003-2005. Disponível em: $<$ http://www.iaea.org/programmes/aqcs/int1054/index.html >. Acesso em: 02/09/2017.

IAEA, INTERNATIONAL ATOMIC ENERGY AGENCY, Programme B. Nuclear Fuel Cycle and Materials Technologies, http://www.iaea.org/About/Policy/GC/GC47/Documents/ Budget/prog1-b.pdf 2007.

IAEA, INTERNATIONAL ATOMIC ENERGY AGENCY, Management of high enriched uranium for peaceful purposes: Status and trends, IAEA, June, 2005.

IGAMI, M. P. Z. (Org) ; VIEIRA, M. M. F.(Org.) Guia para a elaboração de teses e dissertações: programa de Pós-graduação Tecnologia Nuclear IPEN/USP . 3 ed. São Paulo: Instituto de Pesquisas Energéticas e Nucleares, $2017 . \quad$ Disponível em: $<$ https://intranet.ipen.br/portal por/conteudo/biblioteca/arquivos/NOVO GUIA TESES E DISSERTACOES.pdf> Acesso em: 15/06/2018.

INMETRO, INSTITUTO NACIONAL DE METROLOGIA, NORMALIZAÇÃO E QUALIDADE INDUSTRIAL, Orientação sobre validação de métodos de ensaios químicos, revisão 07, Rio de Janeiro: INMETRO, 2018 (DOQCGCRE-008).

INSTITUTO NACIONAL DE METROLOGIA, NORMALIZAÇÃO E QUALIDADE INDUSTRIAL. Avaliação de dados de medição - Guia para a expressão de incerteza de medição. Rio de Janeiro, 2008. 
INTERNATIONAL ORGANIZATION FOR STANDARDIZATION (ISO); ISO 5725-2: Accuracy (trueness and precision) of measurement methods and results - Practical guidance for the use of ISO 5725-2:1994 in designing, implementing and statistically analyzing interlaboratory repeatability and reproducibility results. Geneva, 2005 (ISO/TR 22971).Disponível em: <http:// http://www.stat.ucl.ac.be/cours/stat3320/Doc_2004_2005/GUIDE_ISO.pdf>. Acesso em 15/06/18.

JENKIS, R., GOULD, R.W. E GEDCKE, D. Quantitative X-ray spectrometry. New York, Plenum, 1972.

JUNIOR R. B. Desenvolvimento de método de medição das espessuras de núcleos e revestimentos de placas combustíveis. 2013.Dissertação de Mestrado em Ciências - Instituto de Pesquisas Energeticas e Nucleares, São Paulo.

KAKAZU M. H., COTRIM M. E. B., MARTINS E. J. A., DOUGLAS B. S., PIRES $M$. A. F. Determination of the impurities al, $\mathrm{Mn}, \mathrm{Fe}, \mathrm{Ni}, \mathrm{Cu}$ and $\mathrm{Zn}$ in nuclear grade uranium by ICPOES. 2011 International Nuclear Atlantic Conference INAC 2011.

KAUFMAN, A. R. "Nuclear Reactor Fuel Elements, Metallurgy and Fabrication". New York, Interscience,1962.

KUHN. E.; DERON, S.; AIGNER, H.; ZOIGNER, A. Destructive anal/sis of safeguards materials 2 . The NBL-potentiometric titration of uranium experience of the safeguards analytical Laboratory. Vienna, IAEA, July 1979. (IAEA-RL-62).

KUMPULAINEN, H. - Uranium analysis by X-rays from geological samples. J. Radioanal. Chem., 59: 635, 1980

LI, B.P. LI, M.B. LUO, J.Q. LI, W. LIU, Y.Z. SUN, G.L. GUO. Determination of cadmium and lead in high purity uranium compounds by flame atomic 
absorption spectrometry with on-line micro-column preconcentration by CL-7301 resin. Journal of Radioanalytical and Nuclear Chemistry, 2008. 278(1): p. 3-8.

LISINGER T. P. J.; PAUWELS J.; VAN DER VEEN A. M. H.; SCHIMMEL H, LAMBERTY A.Homogeneity and stability of reference materials. Accred Qual Assur 6:20-25, 2001.

MALHOTRA R.K., SATYANARAYANA K. Estimation of trace impurities in reactor-grade uranium using ICP-AES, Talanta 50 (3) (1999) 601-608.

MOREIRA E. G. Preparo e caracterização de um material de referência de mexilhão Perna. 2010. Tese de Doutorado em Ciências - Instituto de Pesquisas Energéticas e Nucleares, São Paulo.

MONTASER D. W., GOLIGHTLY V.C.H . Inductively Coupled Plasmas in Analytical Atomic Spectrometry Eds.: A., Weinheim, 2nd Edition. 1992, ISBN 3-527-28339-0, 984 pp., Hardcover.

MULLER, R. Spectrochemical analysis by X-ray fluorescence. New York, Plenum, 1972.

NAGAR B.K., SAHA A., DEB S.B., SAXENA AND M.K. Determination of Trace and Ultratrace Elements in Uranium-Silicide (U3Si2) Fuel Employing Inductively Coupled Plasma Mass Spectrometry. Atomic Spectroscopy, Vol. 35(5), Sept./Oct. 2014.

NEW BRUNSWICK LABORATORY. 2006. Determination of Uranium by Ferrous Reduction in Phosphoric Acid and Titration with Dichromate (NBL TITRIMETRIC METHOD). NBL-SA-U(E)- 1.

NEW BRUNSWICK LABORATORY, 2008. Certified reference material 112-A, uranium (normal) metal assay and isotopic standard. Disponível em:< 
http://www.nbl.doe.gov/docs/pdf/CRM_112A_\%20Uranium_Metal_Sept_2010.p $\mathrm{df},>$ acesso em:15/06/18.

NEW BRUNSWICK LABORATORY, 2008. Certified reference material 124, uranium $\left(\mathrm{U}_{3} \mathrm{O}_{8}\right) 24$ Element Impurity Standard (Each unit consists of a set $\begin{array}{llll}\text { of } & 7 & \text { levels). } & \text { Disponível }\end{array}$ em:<HTTP://nbl.doe.gov/docs/pdf/CRM_124_1_7\%Uranium_Normal_Oxide_U3 O8_24ElementImpurity_July_2008.pdf> acesso em:15/06/18.

NEGRO M. L. M, DURAZZO. M, MESQUitA M. A., CARVALHO E. F. U., ANDRADE D. A. Studies on Production Planning of Dispersion Type U3Si2-Al Fuel in Plate-Type Fuel Elements for Nuclear Research Reactors. World Journal of Nuclear Science and Technology, 2016, 6, 217-231.

OLIVEIRA JUNIOR O.P., Preparação, caracterização e certificação de materiais de referência isotópicos de urânio. 2006. Tese de Doutorado em Ciências - Instituto de Pesquisas Energéticas e Nucleares, São Paulo.

OLIVEIRA JUNIOR O.P., Determinação de composição isotópica de urânio por espectrometria de massas por termoionização, utilizando evaporação total. [Fonte eletrônica - PO-C1612-CPR-01-035; PO-C1612-CPR-01-037; POC1612-CPR-01-055]. Documento Interno CTMSP. São Paulo: CTMSP, 2017.

PALMIERI, M.D. FRITZ J. S., THOMPSON J.J. AND HOUK R.S. Separation of trace rare earths and other metals from uranium by liquid-liquid extraction with quantitation by inductively-coupled plasma/mass spectrometry. Analytica Chimica Acta, 184 (1986) 187-196.

RAMANAIAH G.V., Determination of yttrium, scandium and other rare earth elements in uranium-rich geological materials by ICP-AES, Talanta 46 (4) (1998) 533-540. 
REIS E.L.T., SCAPIN M., COTRIM M.B.E., SALVADOR V.L., PIRES M.A.F., Determination on Nuclear Fuel Element Components for the IEA-R1 Research Reactor by Analytical Methods based on ED-XRF and ICP-OES, In: International Nuclear Atlantic Conference 2009 - INAC, 2009.

Report. Chemical Forms of Uranium. Argonne National Laboratory, U.S.A. Disponível em: <https://www.osti.gov/servlets/purl/4018241>. Acesso em: 05/11/18.

RICHTER S., ALONSO A., DE BOLLE W., KUHN H, VERBRUGGEN A., WELLUM R. AND TAYLOR P. D. P. Preparation and certification of synthetic uranium isotope mixtures with ${ }^{236} \mathrm{U} /{ }^{238} \mathrm{U}$ ratios of $10^{-6}, 10^{-7}, 10^{-8}$. J.Anal. AtSpectrom. , 2005, 20, $1381-1385$.

ROSA D. S. Caracterização química, física e isotópica de $\mathbf{U}_{3} \mathrm{Si}_{2}$ para fins forenses nucleares. 2011. Dissertação de Mestrado em Ciências - Instituto de Pesquisas Energéticas e Nucleares, São Paulo.

SANTANA L. V. S. Preparo, caracterização e uso de um material de referência para ensaios de proficiência para determinação de metais em tecido de peixe in natura.2013. Dissertação de Mestrado em Ciências Instituto de Pesquisas Energeticas e Nucleares, São Paulo.

SANTANA L. V. S., SARKIS J. E. S., ULRICH J. C., HORTELLANI M. A. Estimation of uncertainty of a reference material for proficiency testing for the determination of total mercury in fish in nature. Journal of Physics: Conference Series 575. 2015.

SANTOS I. Descomicionamento de uma usina de produção de hexafluoreto de urânio. 2008. Tese de Doutorado em Ciências - Instituto de Pesquisas Energéticas e Nucleares, São Paulo. 
SANTOS O. Estudos do tratamento químico da superfície de placas combustíveis nucleares. 2014. Dissertação de Mestrado em Ciências Instituto de Pesquisas Energéticas e Nucleares, São Paulo.

SATYANARAYANA K., DURANI S., Separation and inductively coupled plasma optical emission spectrometric (ICP-OES) determination of trace impurities in nuclear grade uranium oxide, J. Radioanal. Nucl. Chem. 285 (3) (2010) 659-665.

SCAPIN M. A.; SALVADOR V. L. R.; COTRIM M.E.B.; MARIA A. F. PIRES M.A.F.; SATO I. M. Uncertainty measurement evaluation of WDXRF and EDXRF techniques for the $\mathrm{Si}$ and $\mathrm{U}$ total determination in $\mathrm{U}_{3} \mathrm{Si}_{2}$ nuclear fuel. J Radioanal Nucl Chem (2011) 287:807-811.

SCAPIN M. A., Análise Quantitativa por WDXRF - Método de Parâmetros Fundamentais (FP). [Fonte eletrônica - PO-LFX-0903.004]. Documento Interno IPEN. São Paulo : IPEN, 2017.

SEABORGG. T. The Encyclopedia of the Chemical Elements.

Cap. Uranium 1968. Reinhold Book Corporation. Pag.773-86.

SILVA C. P. Aplicação da quimiometria para a caracterização química de combustíveis tipo MTR por fluorescência de raios x. 2012. Dissertação de Mestrado em Ciências - Instituto de Pesquisas Energéticas e Nucleares, São Paulo.

SILVA A. M. S.,DURAZZO M., CARVALHO U. F. E., RIELLA H. G. Fabrication of $\mathrm{U}_{3} \mathrm{Si}_{2}$ powder for fuels used in IEA-R1 nuclear research reactor. Materials Science Forum. vol. 591-593. pp 194-199. 2008.

SKOOG, Douglas A, HOLLER, F James; NIEMAN, Timothy A. Principles of Instrumental Analysis. Orlando : Harcount Brace \& Company, pp. 796-829. Vol. Fifth Edition, 1998. 
SOUZA J. A. B. Procedimento de fabricação de elementos combustíveis a base de dispersões com alta concentração de urânio. 2011. Dissertação de Mestrado em Ciências - Instituto de Pesquisas Energéticas e Nucleares, São Paulo.

SNELGROVE, J.L.; BURN, R.R.; KOMORIYA, H.; MOSS, T.A. Near term reduced-enrichment conversions of plate-type research and test reactors. Trans. Amer. Nucl. Soc.,v.30, p.727-728,1978.

SNELGROVE, J.L.; DOMAGALA, R.F.; HOFMAN, G.L.; WIENCEK, T.C.; COPELAND, G.L.; HOBBS, R.W.; SENN, R.L. The Use of $\mathrm{U}_{3} \mathrm{Si}_{2}$ Dispersed in Aluminum in Plate-Type Fuel Elements for Research and Test Reactors. Argonne National Laboratory, Argonne, Illinois, October 1987. ANL/RERTR/TM11.

SNELGROVE J.L., HOFMAN G.L., MEYER M.K., TRYBUS C.L., WIENCEK T.C., Development of very-high-density low-enriched-uranium fuels, Nucl. Eng. Des. 178 (1) (1997) 119-126.

SKOOG, D. A., HOLLER, J. F., NIEMAN, A. T. Princípios de análise instrumental. Artmed, 2002.

STAHL, D.; CUNNINGHAM, J.E.; FRANCIS, W.C. Development of advanced high-uranium-density reduced-enrichment plate-type fuels. Trans. Amer. Nucl. Soc, v.30, p.726,1978.

THOMPSON, M.; ELLISON, S. L. R.; WOOD, R. The international harmonized protocol for the proficiency testing of analytical chemistry laboratories. (IUPAC Technical Report). Pure Appl. Chem. v. 78, n. 1, p. 145196, 2006.

TRAVELLI, A. Current status of the RERTR program. In: Development Fabrication and Application of Reduced-Enriched Fuels for Research and 
Test Reactor, November 12-14, 1980, Vienna, Proceedings held in Argonne III: (CONF-801144).

ULRICH J. C. Determinação de impurezas em compostos de urânio por meio da técnica de espectrometria de massas de alta resolução com fonte de plasma indutivo. 2001. Dissertação de Mestrado em Ciências - Instituto de Pesquisas Energéticas e Nucleares, São Paulo.

ULRICH, J. C. Preparo e caracterização de um material de referência de Peixe. 2011. Tese de Doutorado em Ciências - Instituto de Pesquisas Energéticas e Nucleares, São Paulo.

UNITED STATES NUCLEAR REGULATORY COMMISSION: Safety evaluation report related to the evaluation of low-enriched uranium silicide-aluminum dispersion fuel for use in non-power reactors, Maryland: USNRC, July, 1988, NUREG-1313.

VARGA Z., NICHOLL A., WALLENIUS M., MAYER K. Development and validation of a methodology for uranium radiochronometry reference material preparation. Analytica Chimica Acta 718 (2012) 25- 31.

VAN DER VEEN A. M. H; LISINGUER T.; PAUWELS J. Uncertainty calculations in the Certification of Reference Materials. 2. Homogeneity study, Accred Qual Assur. 2001. 6:26-30.

VENCHIARUTTI C, VARGA Z, RICHTER S, NICHOLL A, KRAJKO J, JAKOPIČ R, MAYER K, AREGBE Y. IRMM-1000a and IRMM-1000b: uranium reference materials certified for the production date based on the ${ }_{230} \mathrm{Th} / 234 \mathrm{U}$ radiochronometer. Part II: certification.J Radioanal Nucl Chem. 2016; 308: 105-111.

VERMA P., RAMAKUMAR K.L., Determination of alkali and alkaline earth elements along with nitrogen in uranium based nuclear fuel materials by ion chromatography (IC), Anal. Chim. Acta 601 (1) (2007) 125-129. 
VIEIRA S. Análise de Variância (ANOVA). Editora Atlas, São Paulo, 2006.

VOCABULÁRIO INTERNACIONAL DE METROLOGIA: Conceitos fundamentais e gerais e termos associados (VIM 2012). Duque de Caxias, RJ : INMETRO, 2012.94 p. 
INSTITUTO DE PESQUISAS ENERGÉTICAS E NUCLEARES

Diretoria de Pesquisa, Desenvolvimento e Ensino

Av. Prof. Lineu Prestes, 2242 - Cidade Universitária CEP:

05508-000

Fone/Fax (0XX11) 3133-8908

SÃO PAULO - São Paulo - Brasil

HTTP://www.ipen.br

O IPEN é uma Autarquia vinculada à Secretária de Desenvolvimento, associada à Universidade de São Paulo e gerida e administrativamente pela Comissão Nacional de Energia Nuclear, órgão do Ministério da Ciência, Tecnologia e Inovação. 